\title{
Contextualizing employment outcomes in family business research: current findings and future research avenues
}

\author{
Stefano Amato $^{1}$ (]) $\cdot$ Rodrigo Basco $^{2} \cdot$ Nicola Lattanzi $^{1}$
}

Received: 12 November 2020 / Accepted: 19 May 2021 / Published online: 16 June 2021

(c) The Author(s) 2021

\begin{abstract}
The empirical evidence of family business phenomenon in terms of employment outcomes is contradictory highlighting the micro-macro gap in the existing research. To address this contradiction, our study disentangles the role of context in family firms' employment outcomes. To do so, we conduct a systematic literature review of 67 articles focusing on three employment-related outcomes - namely, growth, downsizing, and quality of labour-published in peer-reviewed journals from 1980 to 2020. Based on a two-by-two framework to classify this extant research, we unpack what we know about family firms and employment outcomes and where we can go from here. We highlight three main findings. First, current research is context-less since has mainly focused on the firm level in one context (i.e., region or country) and there is a lack of studies comparing family firms' employment outcomes in different contexts and explicitly measuring the effects of contextual dimensions on family firms' employment outcomes. This context-less approach could explain the conflicting results and lack of theoretical predictability about the family effect on employment across contexts. Second, the lack of understanding of the context in which family firms dwell highlights the need for future research to focus on context by theorizing about employment outcomes-that is, measuring context and its interactions with family- and job-related variables. Third, there is a need to further explore, analyse, and theorize on the aggregate effect of family firms on employment outcomes at different level of analysis (e.g., local, regional, and national).
\end{abstract}

Keywords Family business $\cdot$ Contextualizing family firms $\cdot$ Systematic literature review · Firm employment $\cdot$ Regional employment $\cdot$ Context

Stefano Amato

stefano.amato@imtlucca.it

Extended author information available on the last page of the article 


\section{Introduction}

Recent decades have witnessed a surge of anecdotal stories and fact-based news (e.g., Schwartz 2020) showing the special commitment of family firms to their stakeholders, and specifically toward their employees. The main assumption is that family involvement in the firm results in certain specificities such as family oriented goals (Williams et al. 2019), long term orientation, nepotism culture, and social capital which affect the way human resources are managed (Jeong et al. 2021). This factual information also has a scientific counterpart, reflected in the increasing number of research articles trying to unveil the effect of family involvement in the firm's role as employer regarding job creation, downsizing, and quality of employment. However, the empirical evidence is still contradictory. For instance, while at the firm level, most empirical research has found that family firms are able to grow in terms of employment (Becchetti and Trovato 2002) and downsize less during economic crises (Lee 2006), at the aggregate level, family firms are related to less developed regions (Chang et al. 2008) and to economic entrenchment based on political rent seeking as an impediment of economic growth (Morck and Yeung 2004). This contradiction brings to the fore the micro-macro gap in the family business phenomenon in terms of employment outcomes.

Following Bamberger's thesis (2008), we argue that the aforementioned micro-macro gap is due to the failure of research efforts to move from a simple contextualization approach to context theory approach (Krueger et al. 2021). That is, the positive or negative influence of family involvement in firms in terms of employment could depend on the context in which family firms' dwell. More specifically, we propose that context may help shed new light on why, when, and where the dark or bright sides of family firms emerge because context can boost or hinder (Johns2006) the family's influence on employment outcomes. In dealing with this gap, we follow Gomez-Mejia et al. (2020) and James et al. (2020) to argue that context has been overlooked across levels of analysis when explaining the phenomenon of employment outcomes within family business research.

To begin this debate, we conducted a systematic literature review on employment outcomes in family business research by focusing on a two-by-two framework based level of analysis and meaning of context. In so doing, we classified 67 published articles in peer-reviewed journals from 1980 to 2020 to answer the following research question: What do we know about family firms and employment outcomes and where can we can go from here?

Our article contributes to the family firm debate in several ways. First, it attempts to incorporate the dimensions of context and level of analysis in family business research to explain why and how employment outcomes vary across space and time. In this sense, we identify an alternative source for family firm heterogeneity to improve our understanding of how different contexts may shape the way family firms are owned, governed, and managed in terms of employment outcomes. While family involvement in economic activities seems to be the raison d'etre for family business scholars, they cannot ignore how contexts constrain or enable the phenomenon itself. 
Second, the contextualization of family business research offers the opportunity to challenge the current theoretical approaches (e.g., agency theory and stewardship theory, among others) to test the validity of their theoretical predictions not only in particular family business samples but also across contexts, thereby making theory more context sensitive. This step is important for family business research to gain external legitimacy by developing an inverse contribution path (Pérez Rodríguez and Basco 2011) — that is, by generating contributions in the family business field that can be spread into the main research field. Third, we conclude that applying a context theorizing approach - that is, allowing context to play a more important role in family business research at the firm and aggregate levels - may help analyse, describe, and predict employment outcomes for family firms. Further, our framework can be used as a template to analyse what we know and where to go for other family business-related topics. In this sense, the proposed approach is a tool for developing further the current theory-building process in family business by closing the micro-macro gap in current research.

Finally, beyond the aforementioned academic contributions, our article offers a new perspective to interpret family firms that could be useful for both family firm and policymakers. For business families, our research puts family businesses' connections with their employees into perspective by considering context. This perspective is important not only for local but also for international firms that operate in different institutional and geographical settings to understand their strategies and consequences related to employment. For policymakers, particularly those who develop and implement public policies to stimulate employment in certain areas or mitigate the social costs of downsizing in adversity (e.g., business cycle fluctuations), our review could contribute to their understanding of how economic actors (i.e., family firms) react to public policy stimuli (Basco and Bartkevičiūtè 2016).

In the following sections, we first describe the conceptual background. We then explain the methodology used to carry out our systematic literature review. Following that, we synthetize the literature based on our conceptual framework and present the main findings. Finally, we suggest future research directions.

\section{A framework to bridge the micro-macro gap}

While family business scholars have focused on describing the distinctive behaviour and performance between family and non-family firms and among different types of family firms, current research has been mainly disconnected from macro- (Krueger et al. 2021) and micro (De Massis and Foss 2018) foundations to explain such distinctive behaviour and performance. Following the debate about micro-macro gap in management (Aguinis et al. 2011), and specifically in family business research (Gomez-Mejia et al. 2020), we propose a two-by-two framework with the purpose of delimitating the boundaries of our study enabling us to further explore the content of current research. In this sense, with the two-by-two framework, we attempted to segment and classify extant knowledge in sub-categories of homogenous groups of research during the collection process, frame our interpretations in sub-categories 
after analysing the retrieved articles, and visualize future research lines to bridge the highlighted micro-macro gap.

Basically, the framework combines two dimensions. First, the level of analysis represents the focus of research at the firm or aggregate level. The firm level of analysis focuses on the influence of family involvement on firms' employment outcomes - that is, on firms' creation (i.e., growth) and destruction (i.e., downsizing) of jobs as well as quality of employment. Conversely, the aggregate level of analysis focuses on exploring the role of family firms from a supra-organizational perspective- that is, by assuming territories with administrative and symbolic boundaries as the unit of analysis. In particular, the aggregate level enhances our understanding of the ways family firms contribute to or hamper employment at the industrial, local, and regional levels in which they are situated. In other words, the primary aim of exploring the aggregate level of analysis is to understand family firms' collective role in terms of the growth, reduction and quality of employment.

Second, the meaning of context represents the extent to which context is implicitly or explicitly incorporated into research to understand how it affects or is affected by the family firm phenomenon (Bamberger 2008; Gomez-Mejia et al. 2020; Krueger et al. 2021). There are two different meanings of context. First, the "context as container" which does not consider explicitly the geographical, cultural, and institutional dimensions potentially affecting the phenomenon under study. For the contextas-container meaning, there are two approaches. The context-by-sampling approach is a research strategy aimed at investigating the phenomenon under study in a specific contextual setting and the context-by-comparing approach entails comparing the phenomenon under study in different contextual settings. Second, the "context as covariate" is when research accounts for some contextual dimensions that may influence the phenomenon under study. The context-as-covariate meaning is related to the context-by-theorizing approach, which embraces the interaction between context (by measuring it) and the phenomenon under study.

Table 1 summarizes the conceptual framework combining level of analysis and meaning of context to form four possible combinations (quadrants) of research. Quadrant A (firm level and context as a container) includes research that investigates family firms in a specific contextual setting shaped by institutional, social, cultural, and territorial factors (context by sampling approach) or research that includes family firms in different contextual settings with the aim of highlighting heterogeneity of family firms in different institutional, social, cultural, and territorial contexts (context by comparing approach). Quadrant B (firm level and context as a covariate) entails the recognition and measurement of contextual dimensions that shape or are shaped by the family firm (context by theorizing approach).

The last two quadrants in the second column are related to the aggregate level of analysis. Quadrant C (aggregate level and context as a container) integrates research focusing on the aggregate family firms' effect on creating or downsizing employment but in one specific contextual setting (context by sampling approach) or using more than one contextual setting to compare the aggregate family firms' effect on creating or downsizing employment (context by comparing approach). Quadrant D (aggregate level and context as covariate) considers context as situational opportunities or constraints that can be measured to determine their impact on family firm 
Table 1 Micro-Macro approach in family business research

\begin{tabular}{|c|c|c|}
\hline \multirow[t]{2}{*}{ Meaning of context } & \multicolumn{2}{|l|}{ Level of analysis } \\
\hline & Firm level & Aggregate level \\
\hline Context as container & $\begin{array}{l}\text { Quadrant A } \\
\text { Context by sampling: sampling FFs } \\
\text { and/or non-FFs in a contextual } \\
\text { setting } \\
\text { Context by comparing: Comparing } \\
\text { FFs and/or non-FFs operating in two } \\
\text { or more contextual settings }\end{array}$ & $\begin{array}{l}\text { Quadrant C } \\
\text { Context by sampling: Sampling } \\
\text { all FFs or a representative group } \\
\text { of FFs in a contextual setting } \\
\text { in order to explore or deter- } \\
\text { mine their contributions to the } \\
\text { employment outcomes } \\
\text { Context by comparing: Comparing } \\
\text { two or more contextual settings } \\
\text { by sampling all or a representa- } \\
\text { tive group of FFs in order to } \\
\text { determine their contributions to } \\
\text { employment outcomes }\end{array}$ \\
\hline Context as a covariate & $\begin{array}{l}\text { Quadrant B } \\
\text { Context by theorizing: Measuring } \\
\text { contextual dimensions in order to } \\
\text { determine their impact on FFs and/ } \\
\text { or non-FFs }\end{array}$ & $\begin{array}{l}\text { Quadrant D } \\
\text { Context by theorizing: Measuring } \\
\text { contextual dimensions in order } \\
\text { to determine their impact on } \\
\text { FFs or a representative group of } \\
\text { FFs and their contributions to } \\
\text { employment outcomes }\end{array}$ \\
\hline
\end{tabular}

employment or a representative group of family firms and their contributions to employment outcomes at the industry, local, regional, or aggregate level (context by theorizing).

\section{Methodology}

We decided to conduct a systematic review of the literature as a rigorous scientific procedure to minimize researcher bias in the process of addressing our research questions: What do we know about family firms and employment outcomes and where can we can go from here? For this purpose, we adopted the methodological approach suggested by Tranfield et al. (2003). The proposed systematic selection process (Denyer and Tranfield, 2009; Jesson et al. 2013) is advantageous because it enables relevant contributions to be identified by means of explicit and reproducible selection criteria. Following Hoon and Baluch (2020), our consolidated interrogation approach in the emerging field of family business studies looks for commonalities and confirming consensus to bridge the micro-macro gap around the topic of employment outcomes. 
First, in the planning stage, we created a preliminary $\operatorname{protocol}^{1}$ to identify material related to employment outcome in main stream research fields (such as management research field) and in family business field in particular (mainly literature reviews and articles describing the evolution of the field). Based on this first approach and on the current debate in the family business literature around the topic of context, the Soleimanof et al. (2018) article and the recently published article by Gomez-Mejia et al. (2020), we identified the preliminary research gaps around context and level of analysis to approach the systematic literature research on employment outcomes.

Second, during the initial stage, we conducted an unbiased search for published peer-reviewed journal articles solely written in English from January 1980 to the end of December 2018. We chose 1980 as the official starting point because Dailey and Reuschling's (1980) article is the first contribution dealing with family firms and employment outcomes. We searched in the following databases: Business Source Complete (EBSCO) and Scopus. It is important to highlight that we searched for an extensive range of keywords in titles and abstracts to identify the relevant contributions. The main keywords at the end of the planning stage had two categories: family business and employment. The keywords related to family business were necessary to define the boundary of our search into the family business field. The keywords related to employment are integrated into three sub-dimensions: growth, downsizing, employment quality. For the context we do not define any specific keyword because it has to be analysed within the articles investigating employment outcomes in family business research.

Specifically, we adopted the following keywords: 1) family firms OR family business OR family-owned business OR family enterprise OR family owner and 2) employment growth OR downsizing OR retention OR termination OR layoff OR turnover OR employment quality OR wages OR employee relationship OR regional employment OR national employment. Based on our definition of employment outcome, we focus on employment outcomes to capture the results or effects of family firms as economic actors in creating or destroying employment and in influencing the quality of employment at the firm and aggregate levels. While the firm level is related to success (employment growth), reputation (downsizing), and satisfaction (working preferences and employee relationships) as one specific dimension of firm performance (Richard et al. 2009), the aggregate level is related to regional/national performance and regional/national resilience.

\footnotetext{
1 The preliminary protocol contains a list of actions to approach the topic of employment in the field of family business. For instance, the first action was to look for articles which explain the evolution of the family business field and summarize the most important ideas. The second action was to look for literature review articles in the management, business, and entrepreneurship fields related to employment and summarize the main ideas. The rest of the actions were more operative to narrow down our knowledge of family business and employment. The protocol was not a rigid instrument but an adaptive instrument. For instance, when we discovered the importance of context we incorporated new actions to integrate this information to our debate.
} 
Table 2 Database search results

\begin{tabular}{|c|c|c|c|c|c|}
\hline & $\begin{array}{l}\text { Business Source } \\
\text { Complete }\end{array}$ & Scopus & Manual & Exclusion & Total \\
\hline $\begin{array}{l}\text { Automatic search-keywords } \\
\text { search in title/abstract }\end{array}$ & 82 & 144 & & & 227 \\
\hline Manual search-key journal & & & 20 & & 247 \\
\hline No. of duplicates & & & & -59 & 188 \\
\hline After reading Title/Abstract & & & & -47 & 141 \\
\hline After reading entire articles & & & & -74 & 67 \\
\hline Final sample & & & & & 67 \\
\hline
\end{tabular}

Search limiters: only peer-review academic journals in English

Additionally, to ensure adequate coverage, we also manually scanned major family business journals, international business journals, and entrepreneurship journals. $^{2}$ The aforementioned procedures yielded 227 articles. Once duplicate articles were eliminated (59 articles in total), we read the title, abstract, and introduction of each retrieved article to determine its relevance for the purpose of our research. In total 47 articles were removed at this step. Then, after reading the remaining articles in their entirety, we removed 74 articles we judged to lack substantial relevance for our study. In particular, we discarded both conceptual articles and those that do not explicitly explore the relationship between family firms and employment outcomes. ${ }^{3}$ At the end of this process, we obtained a final sample consisting of 67 articles, as shown in Table 2.

Even though the first retrieved paper was published in 1980, the area under investigation only became of interest in 2009. However, the topic did not acquire importance in the family business field until 2012; thus, more than $70 \%$ of the retrieved papers were published between 2011 and 2020. With reference to the distribution of the selected articles by journal, more than half of the contributions selected (23 of 44 articles) belong to the area "Entrepreneurship and small business management" in the Association of Business Schools (ABS) ranking. In particular, Family Business Review and Entrepreneurship Theory and Practice account for nearly $12 \%$ and 9\% of the sample, respectively, followed by Journal of Family Business Strategy and Small Business Economics, which account both for $6 \%$ of the total of contributions selected.

\footnotetext{
${ }^{2}$ The following journals were included in the manual research process: Academy of Management Journal, Academy of Management Review, Administrative Science Quarterly, Journal of Management, Strategic Management Journal, Organization Science, Journal of International Business Studies, Journal of World Business, Entrepreneurship Theory and Practice, Journal of Business Venturing, Journal of Small Business Management, Small Business Economics, International Small Business Journal, Family Business Review, Journal of Family Business Strategy, Journal of Family Business Management, Journal of Management Studies, and Asia Pacific Journal of Management.

3 Besides duplicates, the main criteria used to disregard papers from those originally retrieved was the lack of evidence along one of the three dimensions under investigation (e.g., employment growth, downsizing and quality of labor) and the absence of any explicit attempt to explore the influence on employment outcomes at both firm and aggregate level.
} 
Finally, during data analysis and data synthesis, we analysed the content of all the retrieved articles thoroughly following a two-step method. First, two co-authors of this article were independently responsible for classifying the retrieved papers using our proposed framework described in Sect. 2. In case of any divergence of opinion in the classification process, the third author was called upon to settle it. Second, we summarized each article using a predefined coding scheme consisting of the methods (i.e., type of analysis, sample composition, and country of analysis), theoretical framework (used for explaining the relationship between family firms and growth in term of employment and the definition of family firm used), level of context, employment measure, and the main findings. Finally, to analyse the articles in each quadrant, several meetings were conducted where thorough debate was carried out. These meetings served to define the structure and narrative to describe the existing evidence and, from there, future research in each quadrant.

\section{Literature review on family firms' employment outcomes}

In this section, we describe and interpret the results of our systematic literature review and classification, focusing on each of the quadrants of the conceptual framework for the micro-macro approach in family business (see Table 1).

\subsection{Firm level}

\subsubsection{Context as a container-firm level}

Most the research in family business falls in this quadrant (Quadrant A in Table 1) and to better understand its content we re-organize the retrieved article in two subgroups based on how the context was interpreted: context by sampling (those articles that use one single country) and context by comparing (those articles that use two or more countries)

\subsubsection{Context by sampling}

There are 39 articles (almost $60 \%$ of the retrieved articles-see Table 3) contextualizing the relationship between family firms and employment at the firm level by sampling the phenomenon of analysis in a specific country. While developed countries represent the prominent research context (e.g., the United States, Italy and Belgium), only two studies cover emerging economies (e.g., China, Korea). In these contributions, family dimensions, as a micro-context, are more important than the meso- and macro-contexts implicitly defined by the origin of the sample. Regarding family dimensions, most of the articles use the demographic approach when measuring family involvement (e.g., family owned, family managed, family controlled, and generation involved) (Basco 2013) to capture family effects on employment outcomes, while only two articles (Ensley et al. 2007; Khanin et al. 2012) focus on essence dimensions (e.g., culture) of family involvement. 


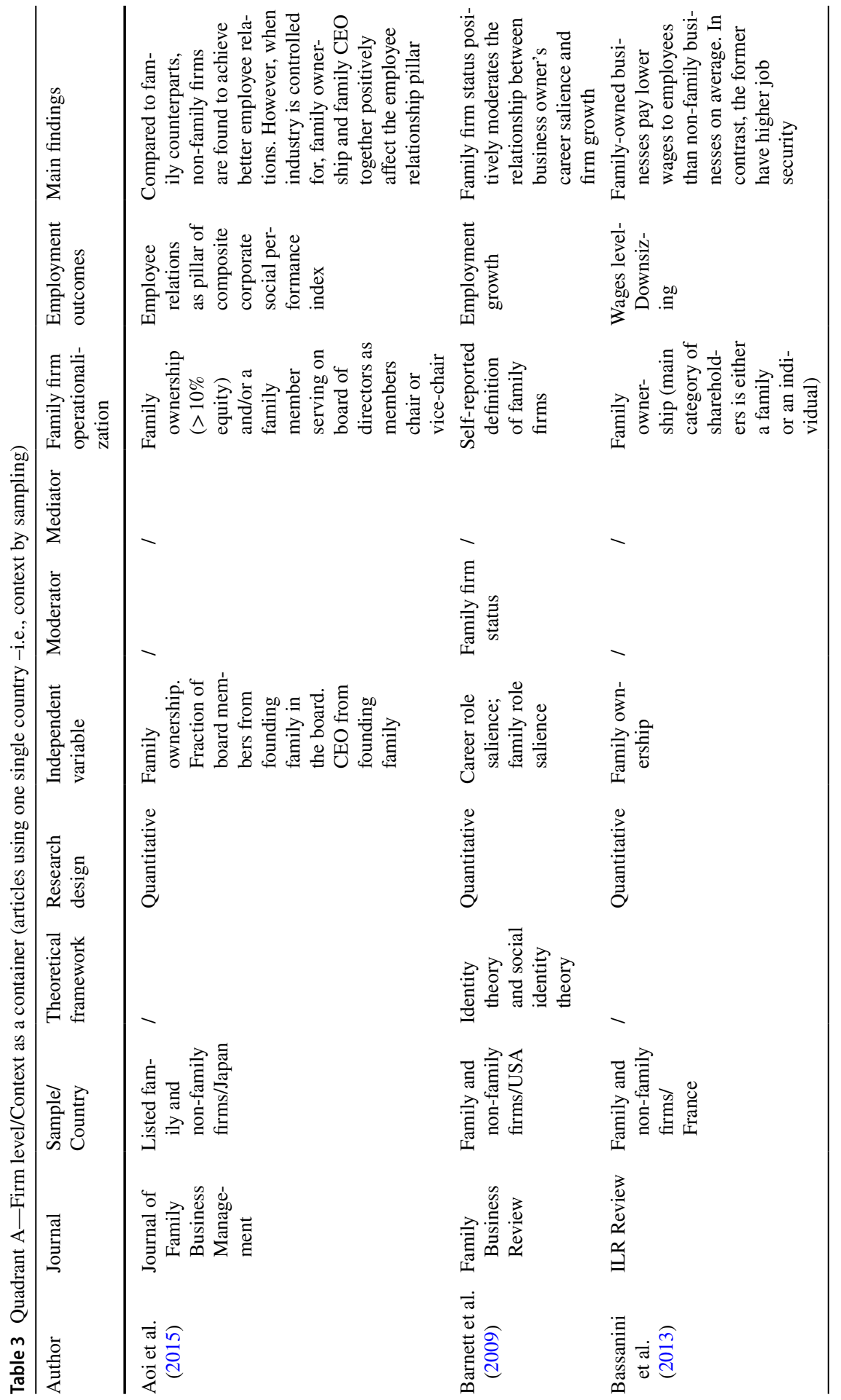




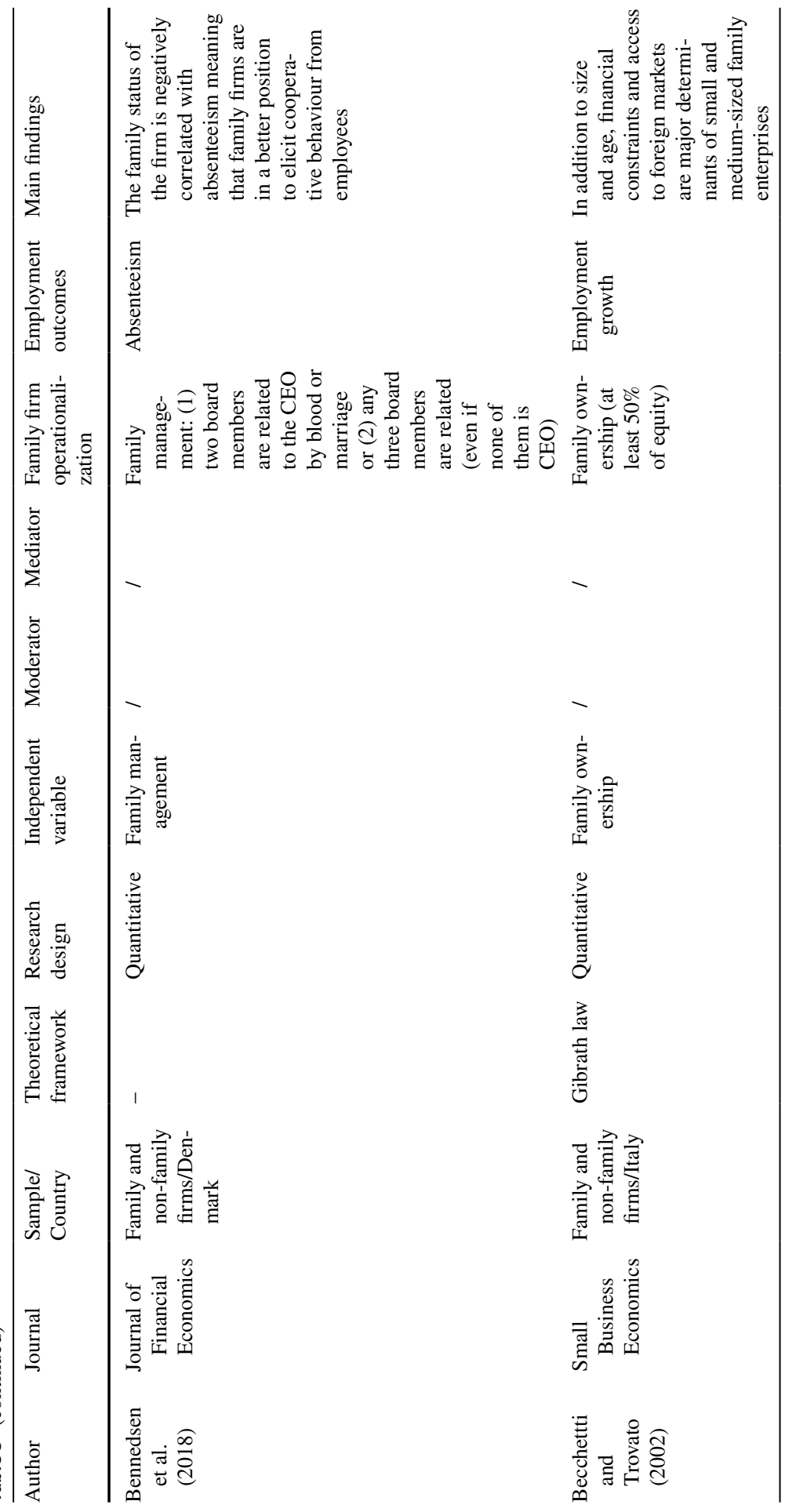




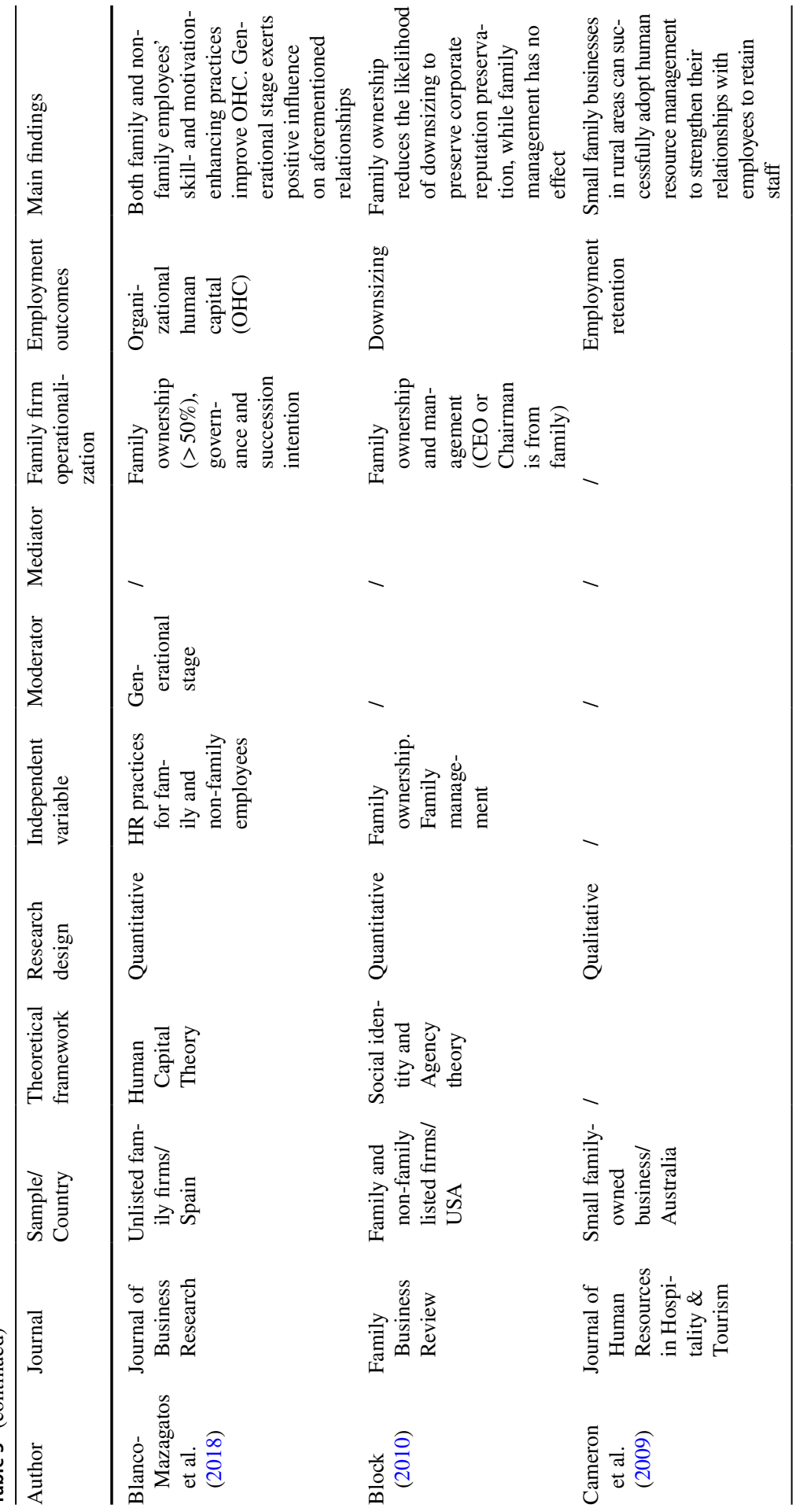




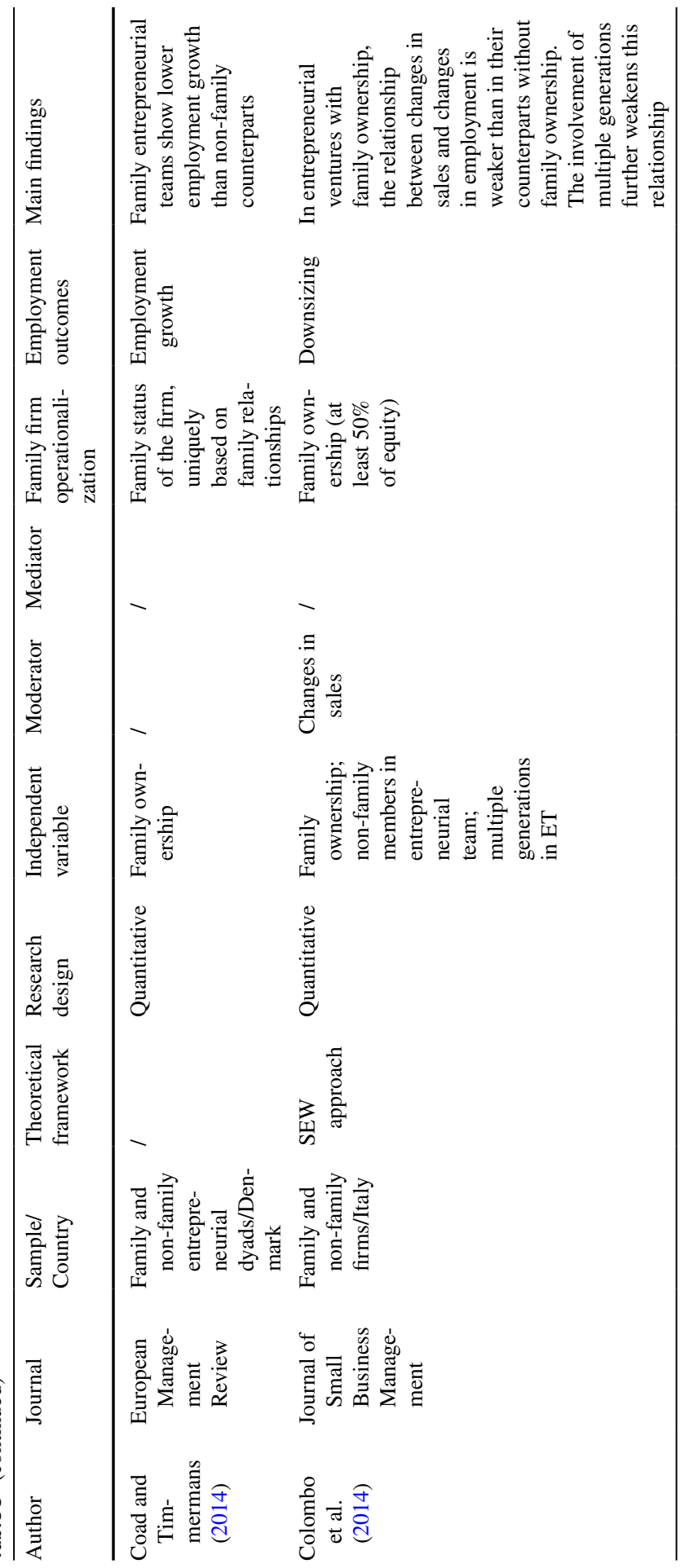




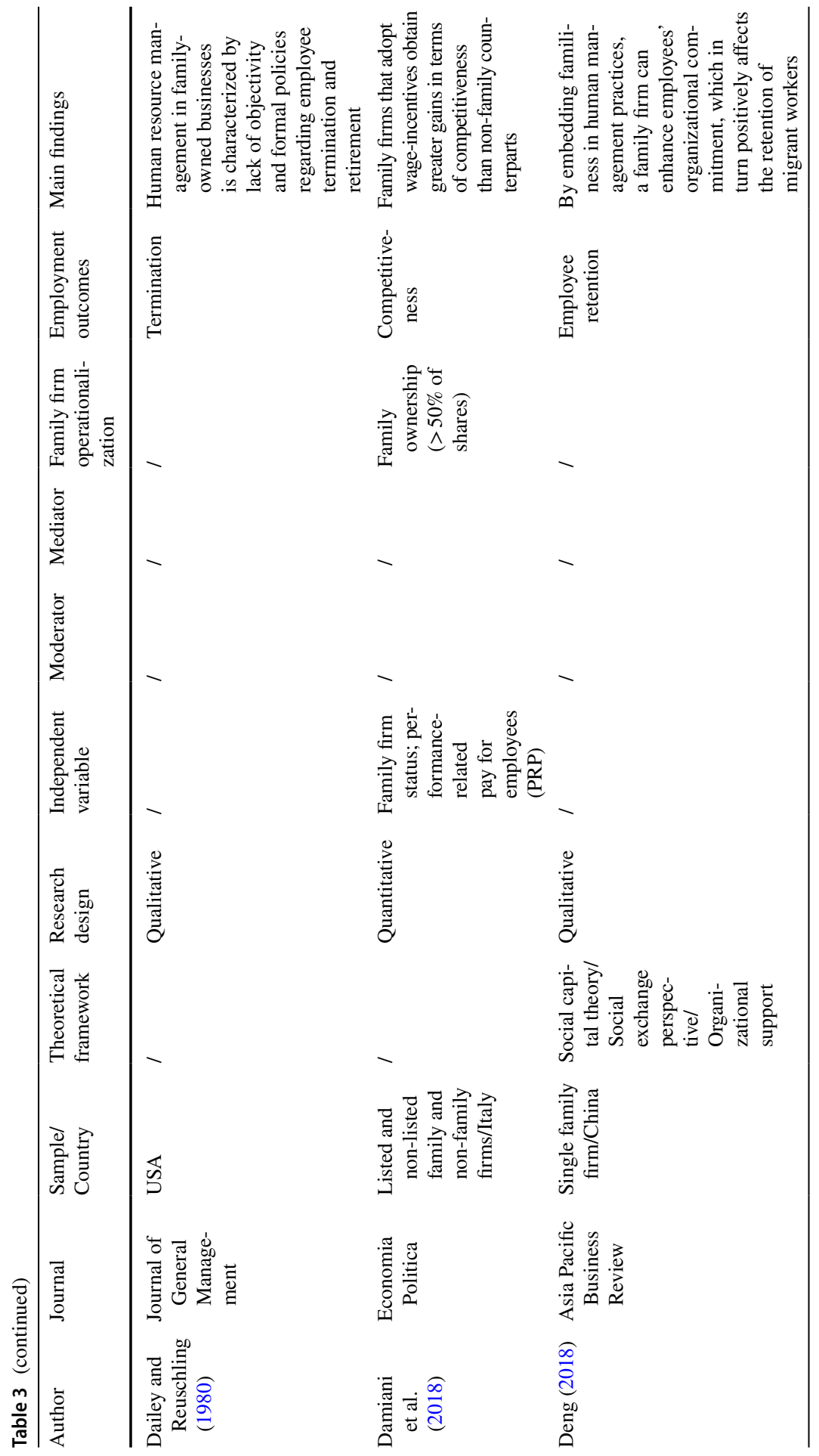




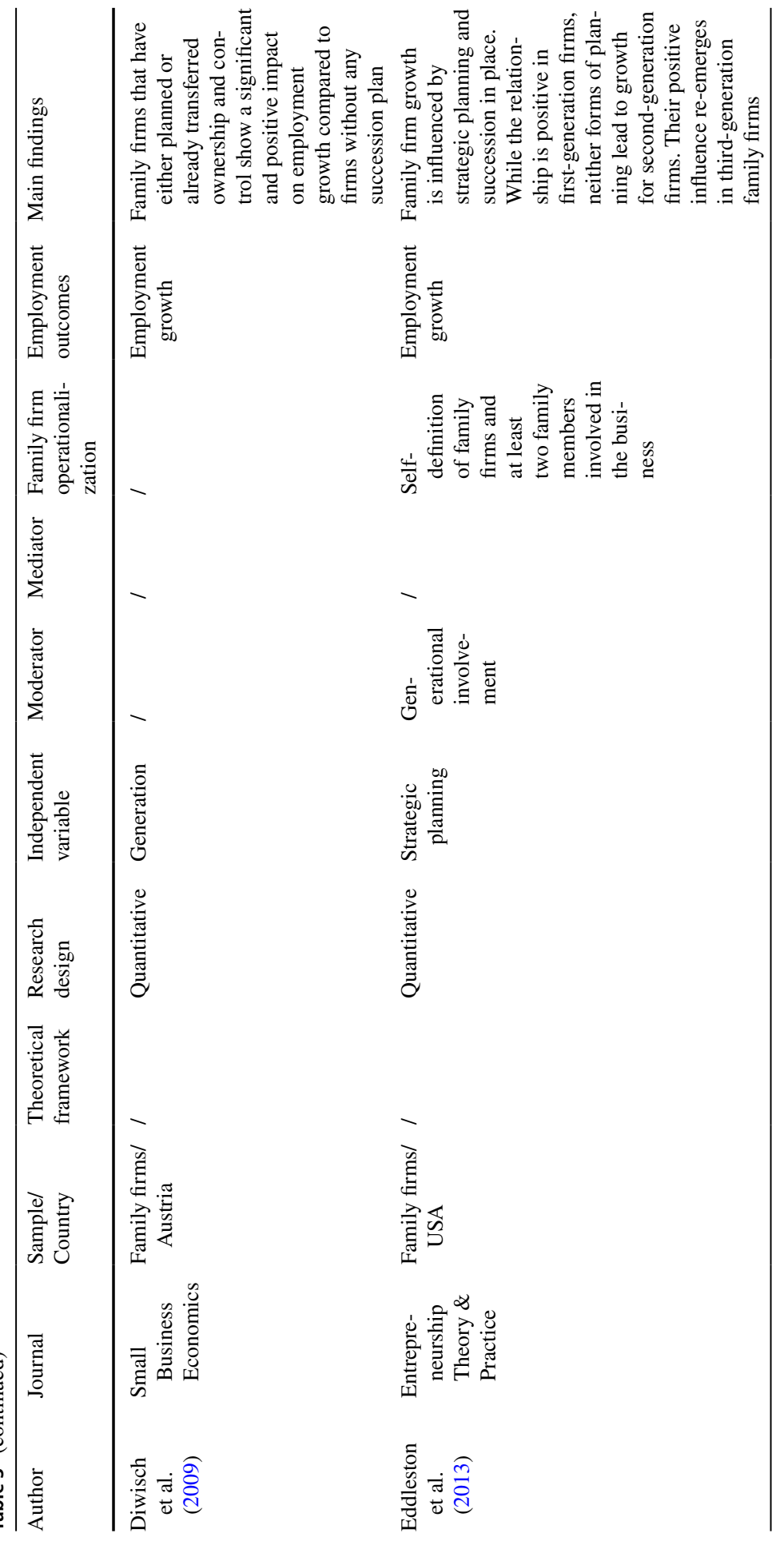




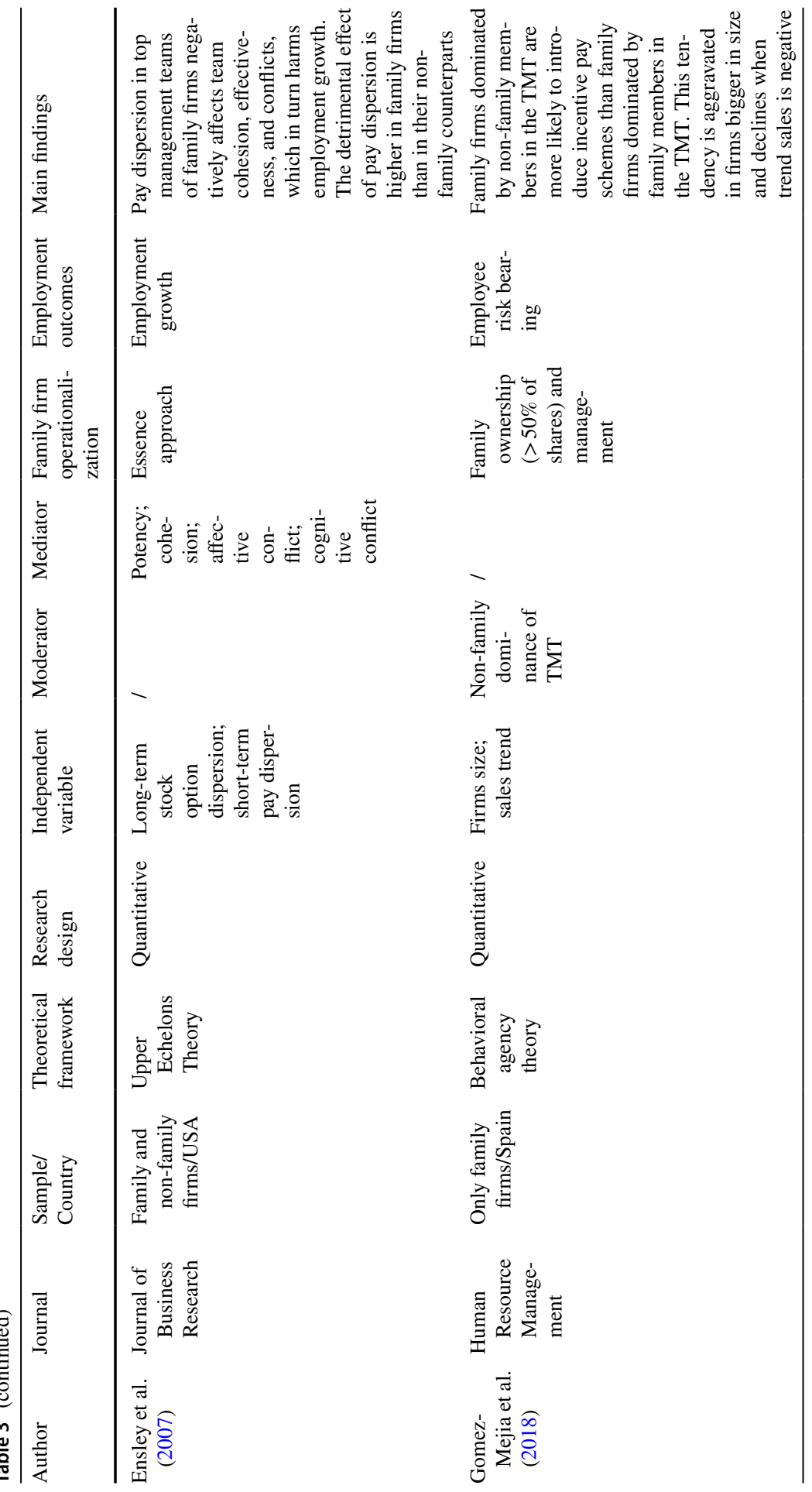




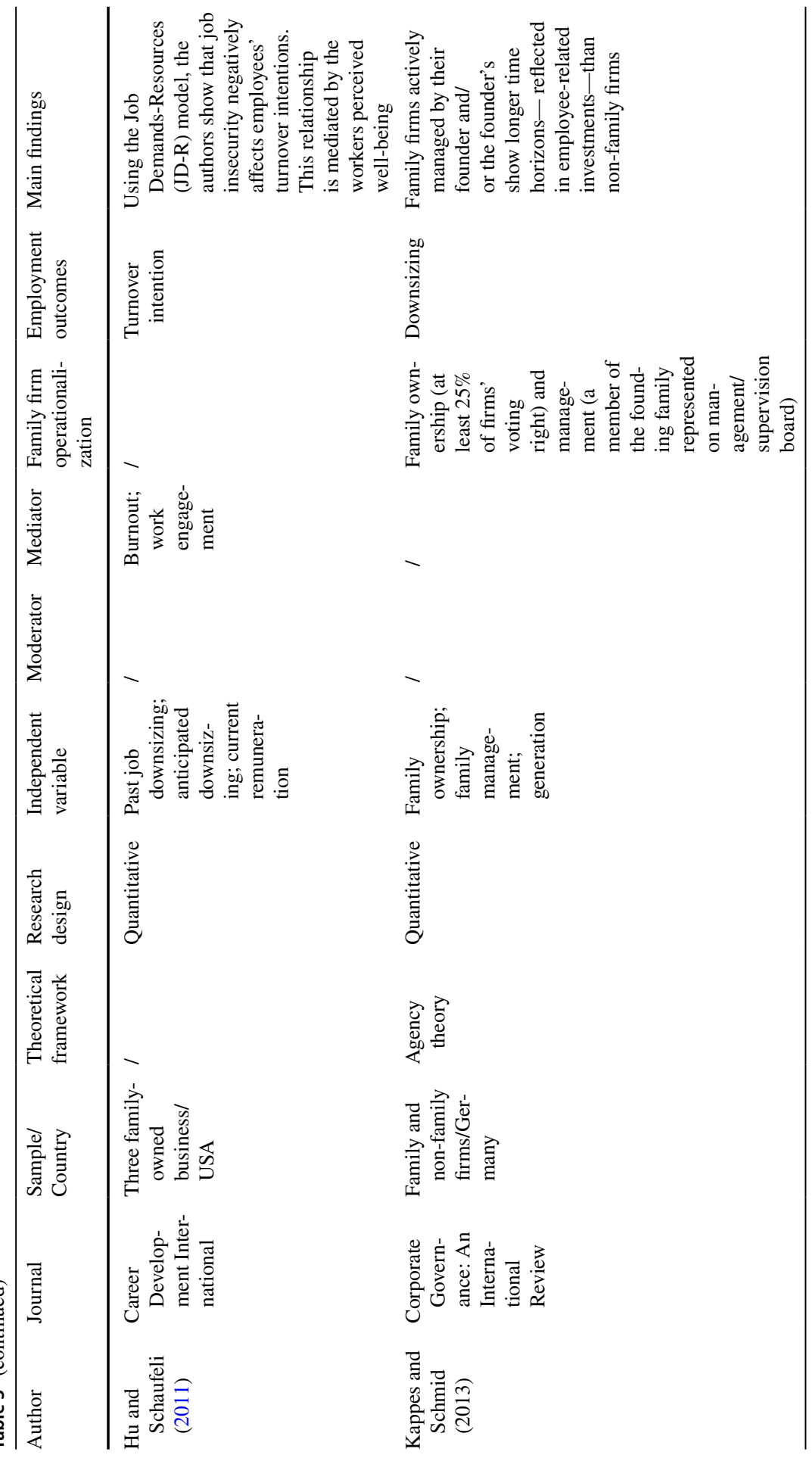




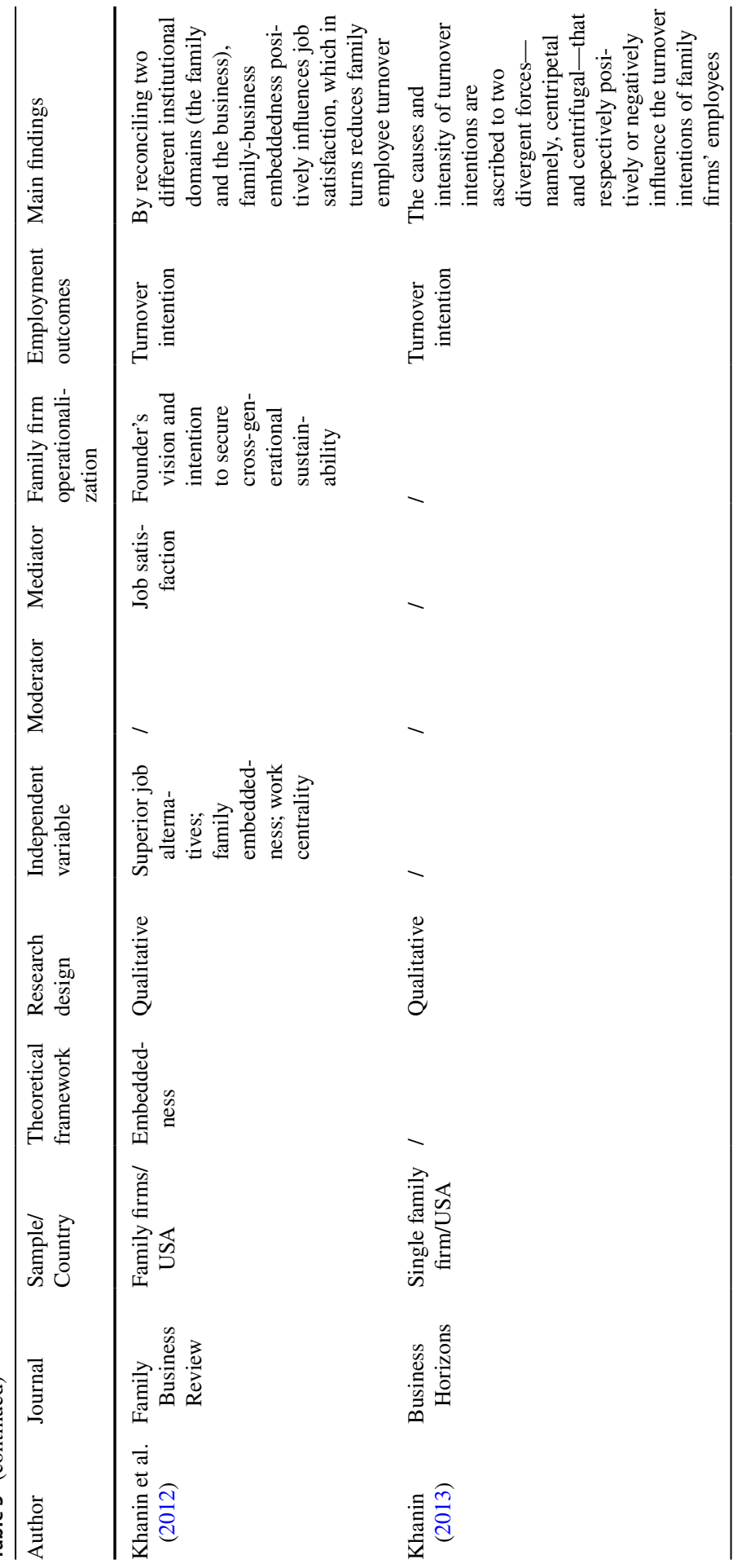




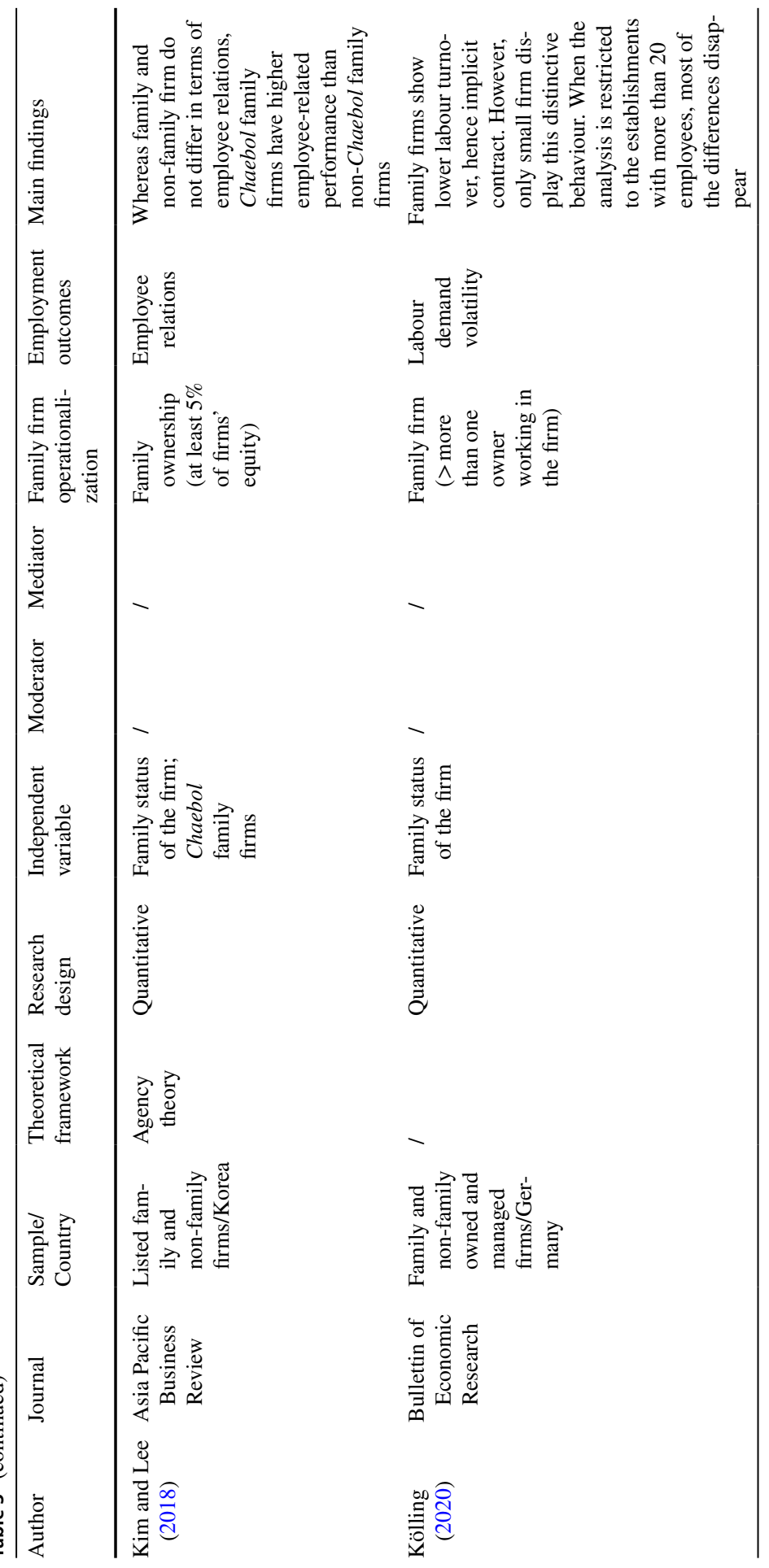




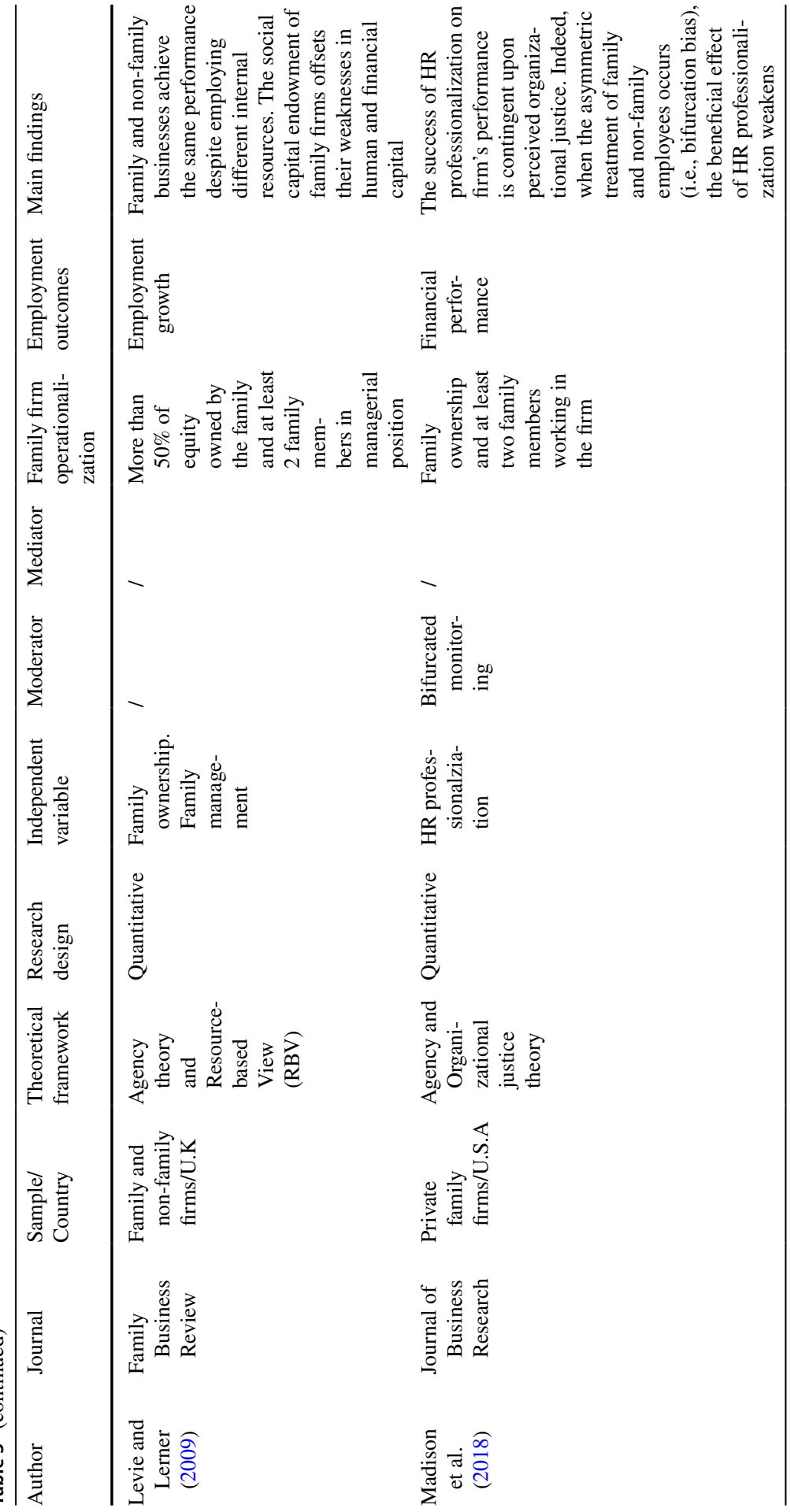




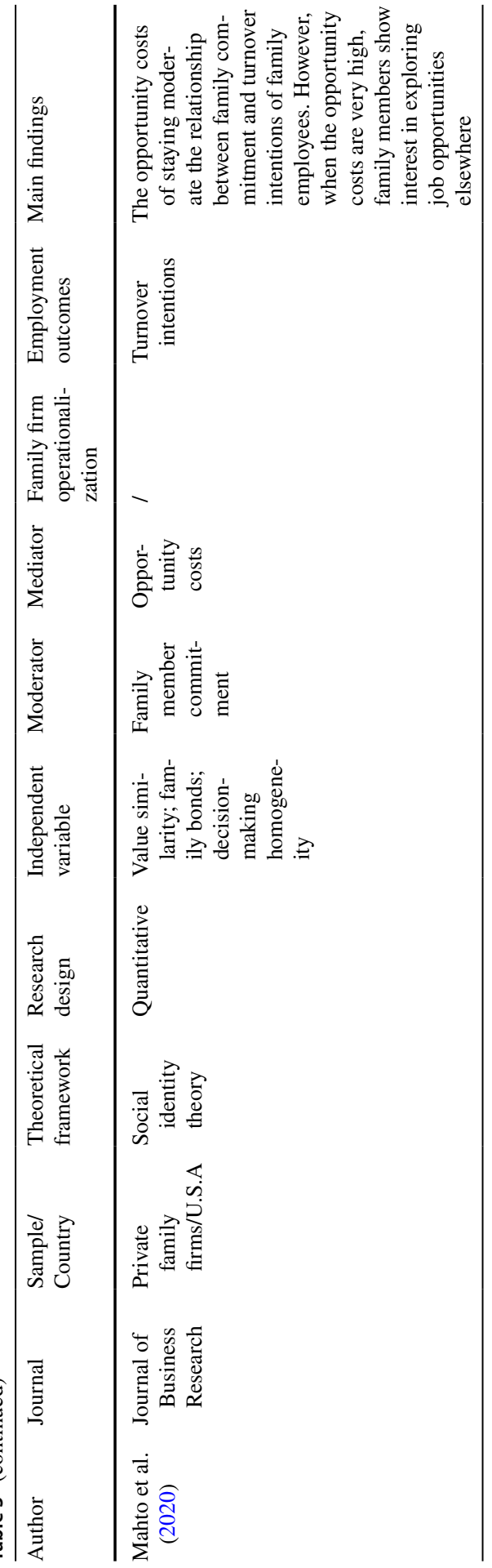




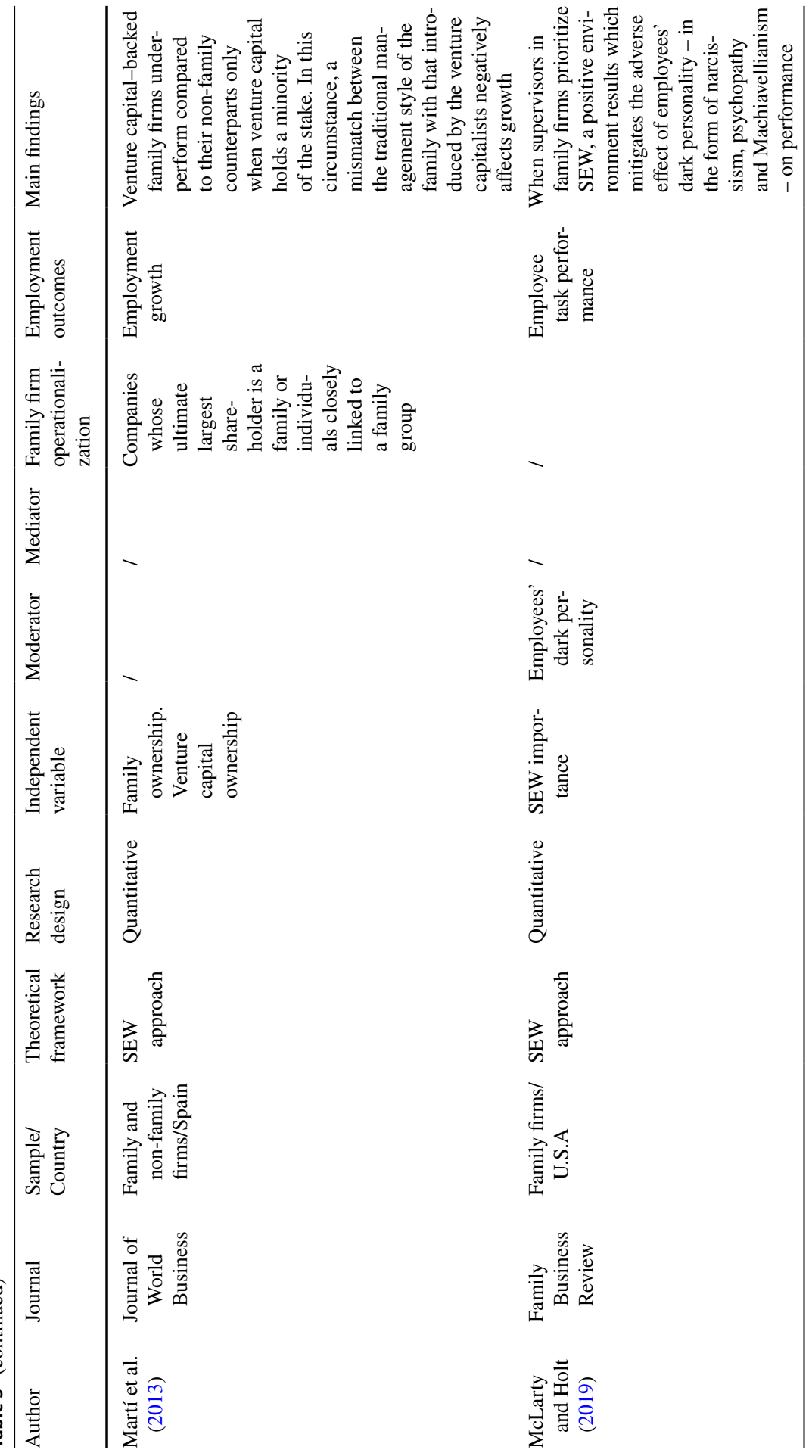




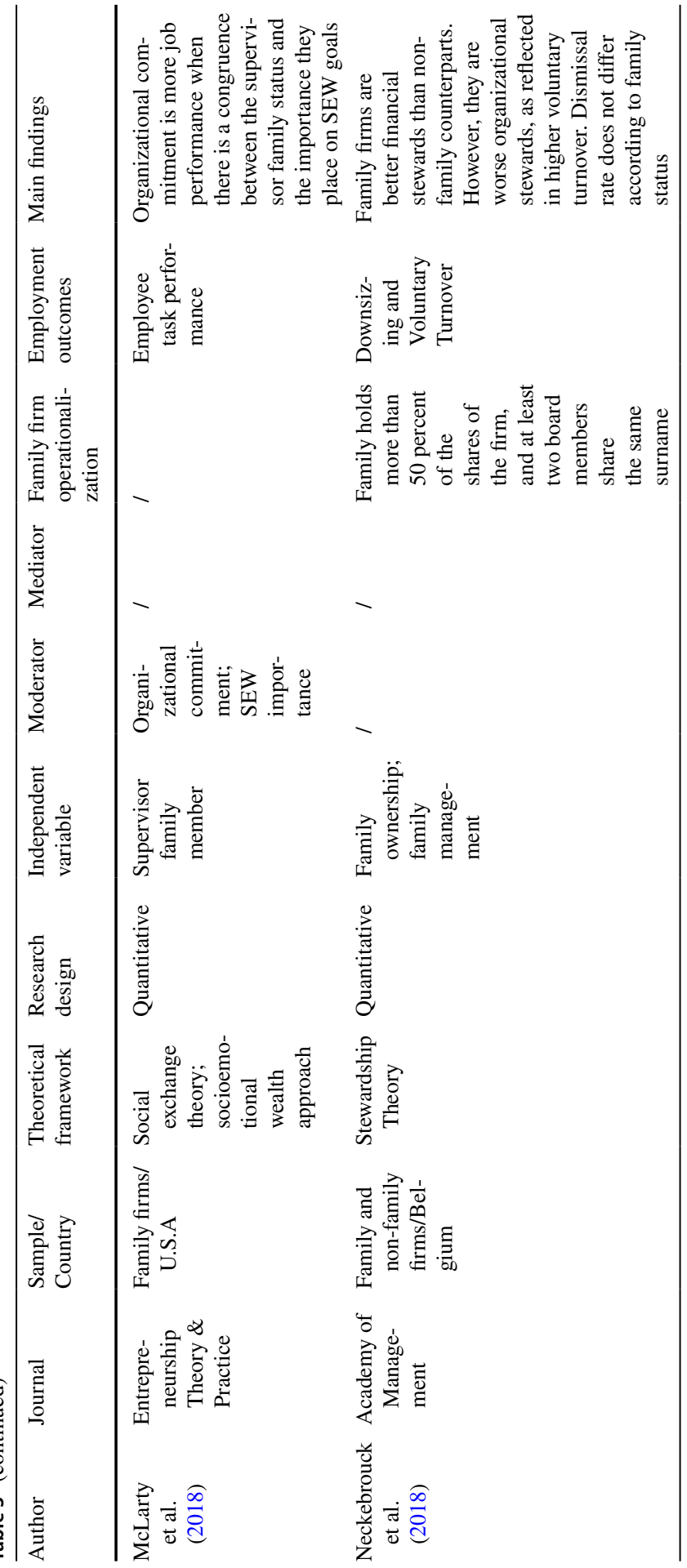




\begin{tabular}{|c|c|}
\hline 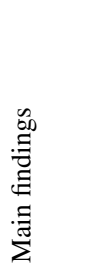 & 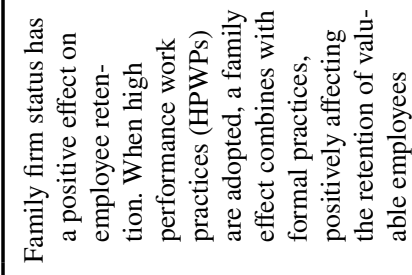 \\
\hline 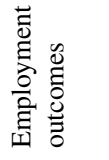 & 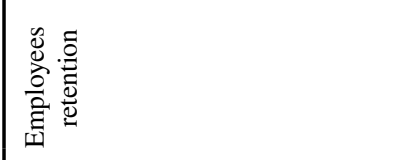 \\
\hline 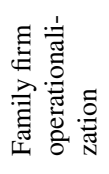 & 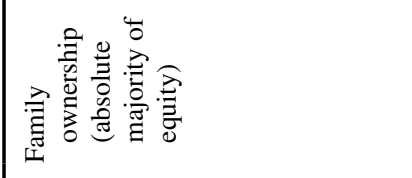 \\
\hline & - \\
\hline 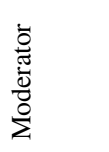 & 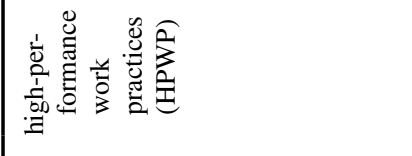 \\
\hline 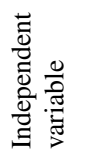 & 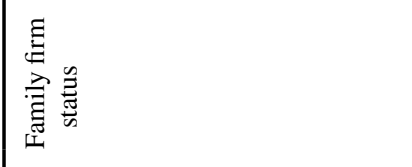 \\
\hline 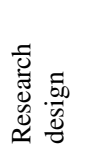 & 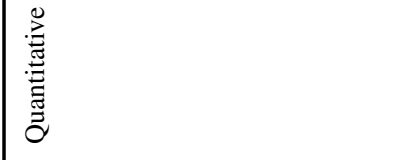 \\
\hline 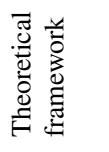 & 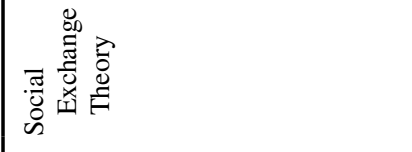 \\
\hline 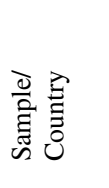 & 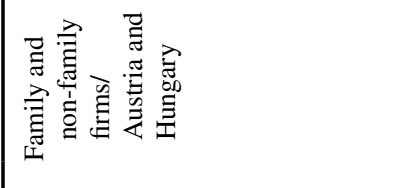 \\
\hline 馬 & 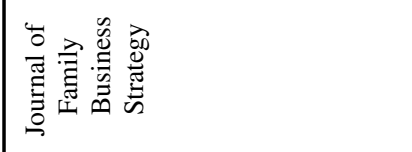 \\
\hline & 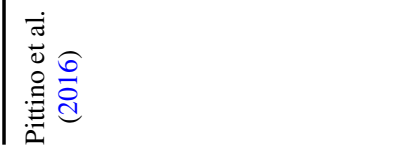 \\
\hline
\end{tabular}




\begin{tabular}{|c|c|c|}
\hline 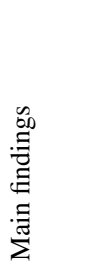 & 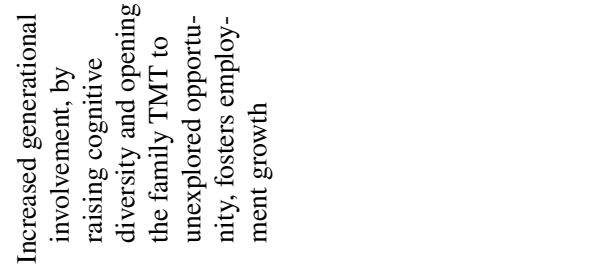 & 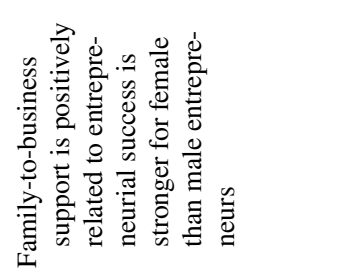 \\
\hline 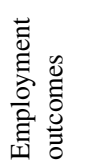 & 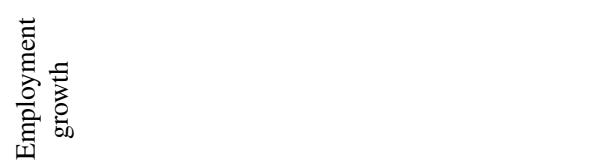 & 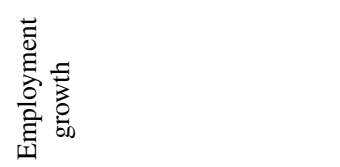 \\
\hline 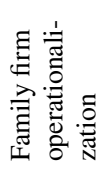 & 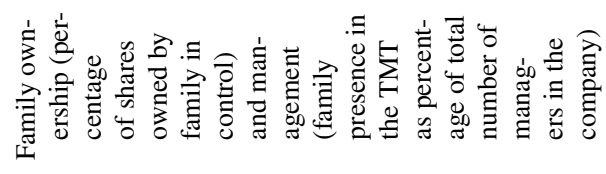 & \\
\hline & . & - \\
\hline 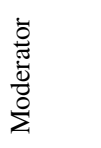 & 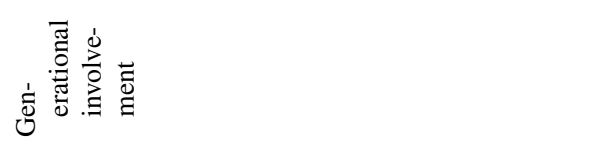 & 产 \\
\hline 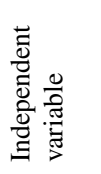 & 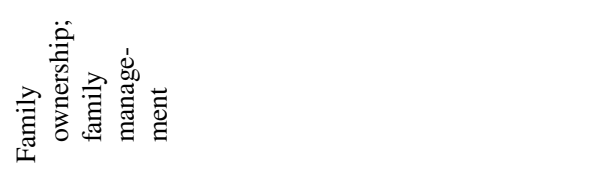 & 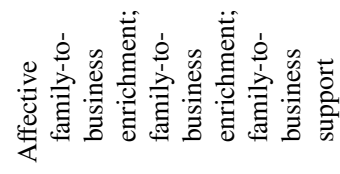 \\
\hline 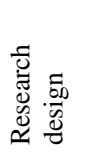 & 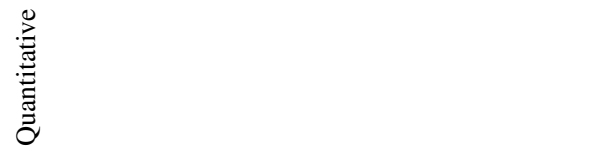 & 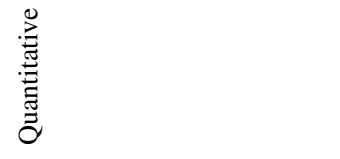 \\
\hline 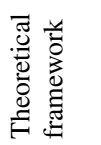 & 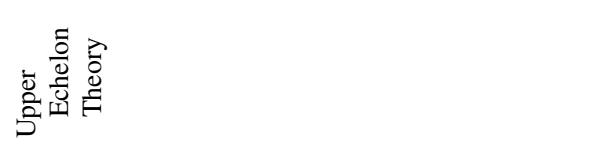 & 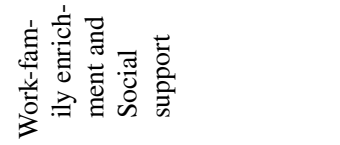 \\
\hline 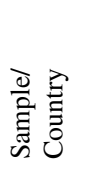 & 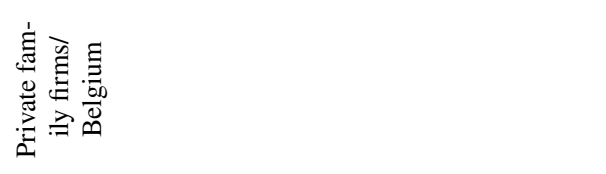 & 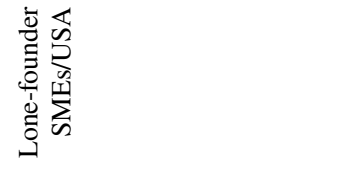 \\
\hline 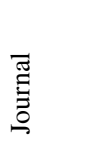 & 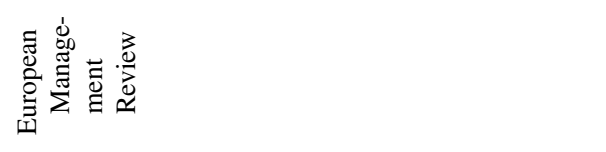 & 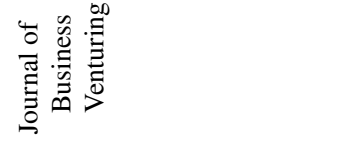 \\
\hline 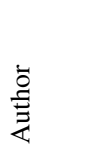 & 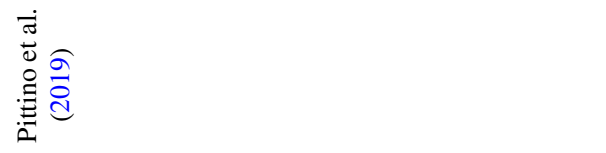 & 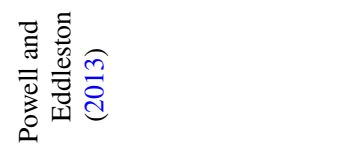 \\
\hline
\end{tabular}




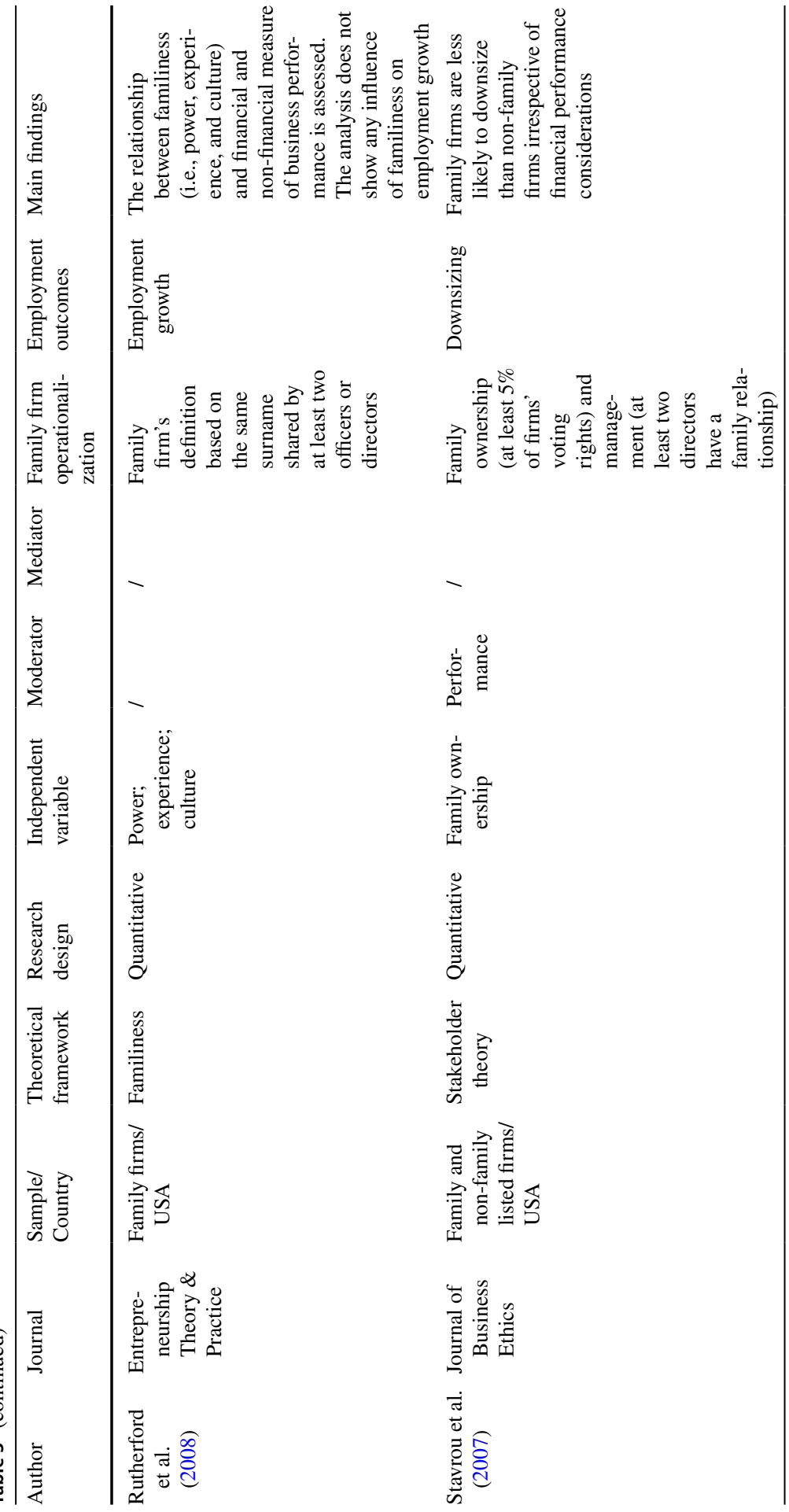




\begin{tabular}{|c|c|c|}
\hline 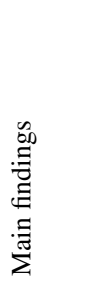 & 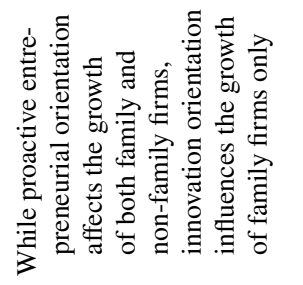 & 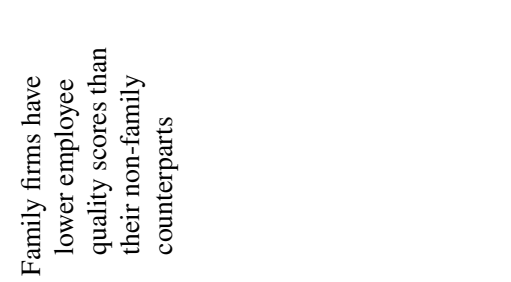 \\
\hline 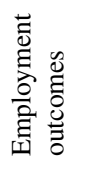 & 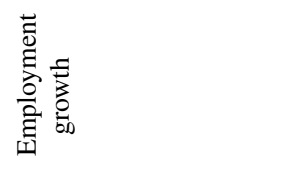 & 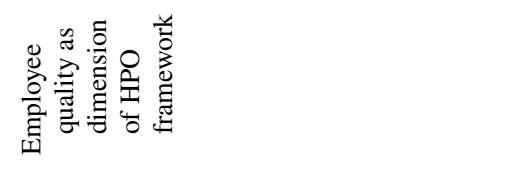 \\
\hline 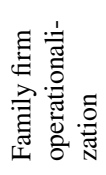 & 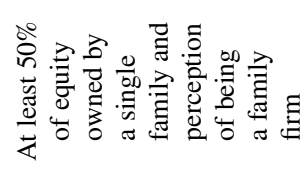 & 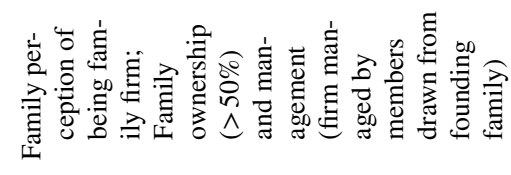 \\
\hline 莺 & 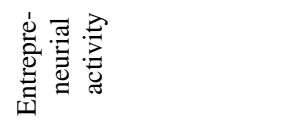 & 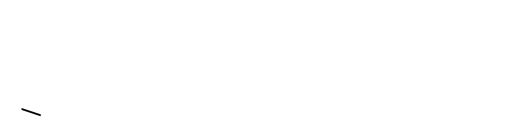 \\
\hline 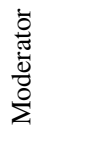 & - & - \\
\hline 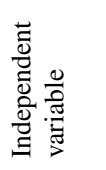 & 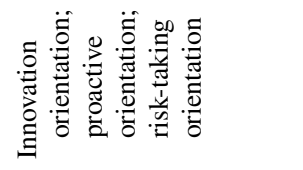 & - \\
\hline 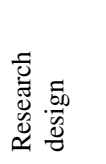 & 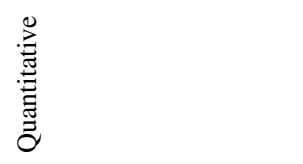 & 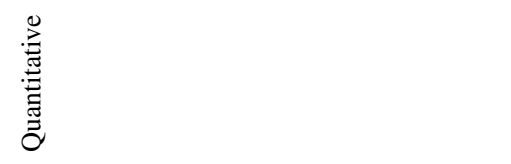 \\
\hline 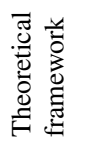 & 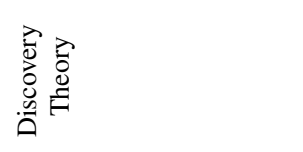 & 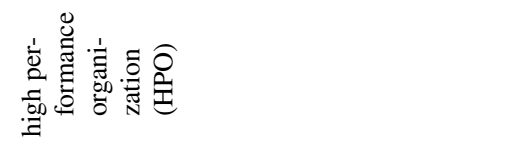 \\
\hline 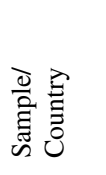 & 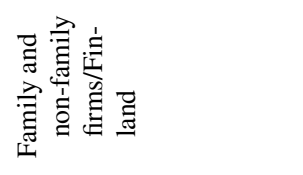 & 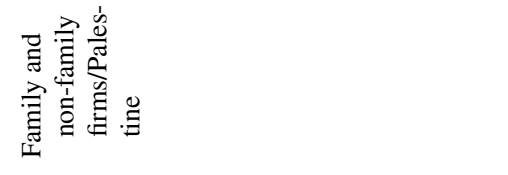 \\
\hline $\begin{array}{l}\text { 范 } \\
\text { 总 }\end{array}$ & 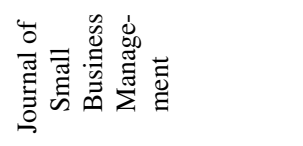 & 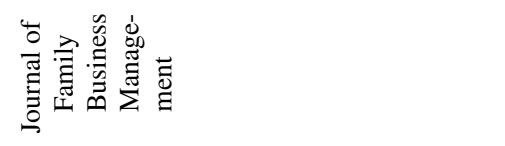 \\
\hline 泀 & 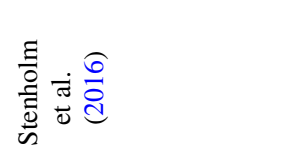 & 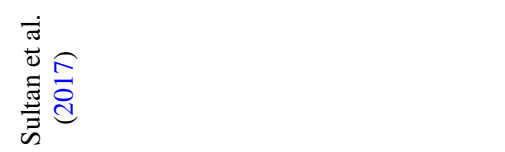 \\
\hline
\end{tabular}




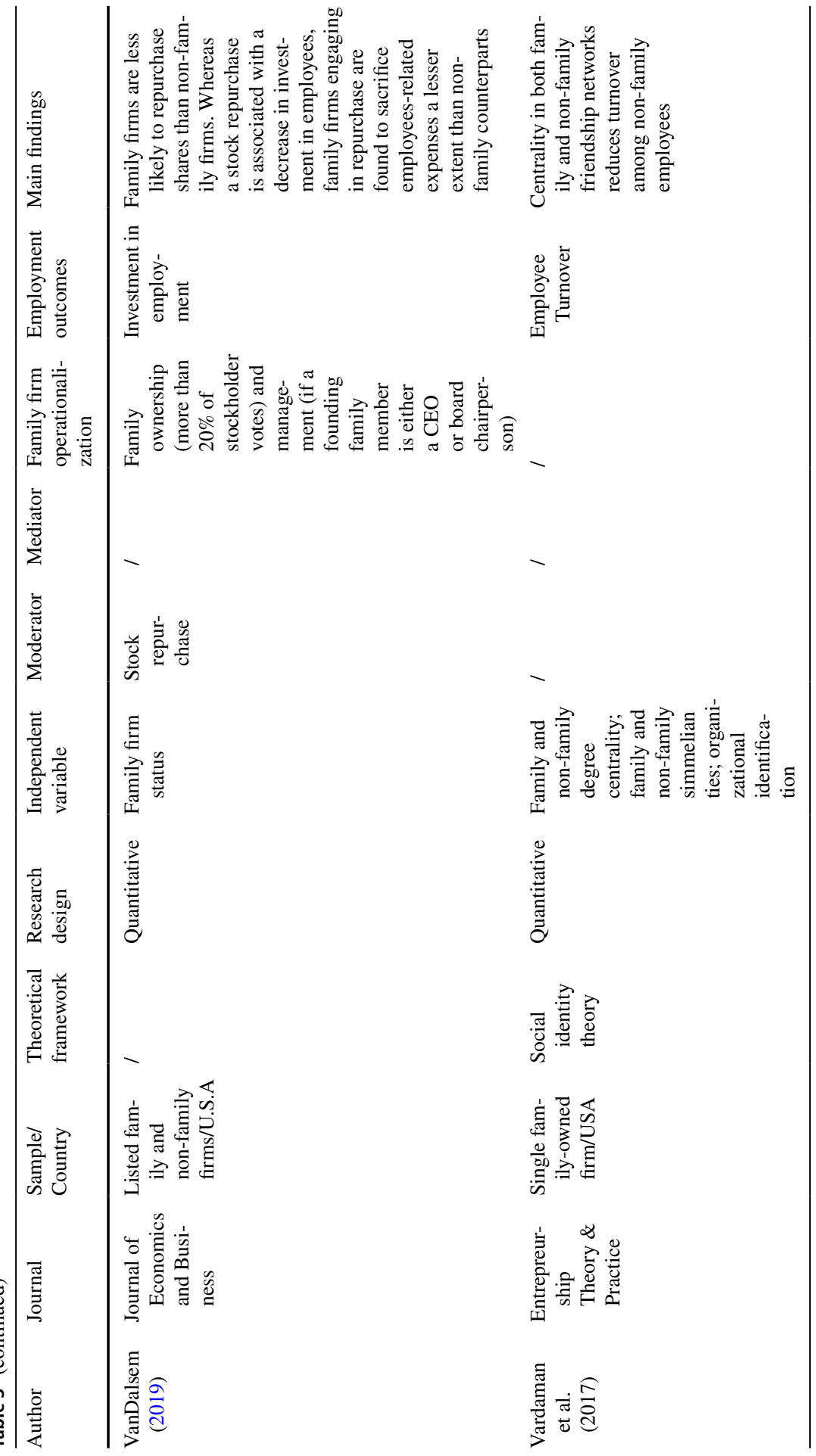


Regarding the theoretical background, while there are several articles that rely on a data-driven approach to explore and explain employment outcomes in family and non-family firms (e.g., Bassanini et al. 2013; Bennedsen et al. 2019), the rest of the articles focus on two important specificities of family firms that may affect employment outcomes. First, the internal familiness emerging from the interrelationship between the family and the firm (e.g., Rutherford et al. 2008) make family firms unique in their behaviour toward their employees because of the family's long-term perspective (e.g., Blanco-Mazagatos et al. 2018), the close involvement of the family in the firm (e.g., Powell and Eddleston 2013), and the family's commitment (e.g., McLarty et al. 2018). Most of these studies are related to well-stablished theories applied to family businesses, such as upper echelon theory (Pittino et al. 2019), stewardship theory (Neckebrouck et al. 2018), and behavioural agency theory (Gomez-Mejia et al. 2018). Second, the external relationship between the family firm and its surroundings is based on identity theory and related concepts, such as social identity (e.g., Barnett et al. 2009) and social embeddedness (e.g., Khanin et al. 2012), among others. The latter are related to family owners' image, sense of pride, and community ties, all of which enable family firms to achieve different employment outcomes from that of non-family firms. Even though family business scholars have highlighted the importance of familiness in its effect on employment outcomes, this external relationship is gaining in importance, so future research should combine both theoretical streams to achieve a holistic perspective of the phenomenon.

Next, we analyse the contributions of the retrieved articles by considering three main clusters of employment outcomes: employment growth, downsizing, and employment quality. First, most of the articles rely extensively on employment growth as the general measure of firm performance (Eddleston et al. 2013) and corporate social responsibility (e.g., Block 2010). The empirical evidence shows conflicting results for the relationship between family involvement dimensions (e.g., ownership, management, governance and succession) and firm employment growth. The family ownership dimension is one of the main determinants affecting employment growth for listed family firms (Amore et al. 2017), family-owned small and medium-sized enterprises (Becchetti and Trovato 2002), and venture capital-backed family firms (Martí et al. 2013) in the United States, Italy, and Spain, respectively. However, the aforementioned relationship is negative for the case of family entrepreneurial start-ups in the context of Denmark (Coad and Timmermans 2014). In disentangling the family effect by considering family ownership, family management, and family generation (Astrachan et al. 2002), whereas Rutherford et al. (2008) did not find evidence that family involvement affects employment growth in the US context, in a sample of Belgian family firms, Pittino et al. (2019) find that increased generational involvement in ownership positions affects firms' employment growth.

To address the contradictory results emerging from studies exploring the direct effect of family involvement on employment growth, an alternative research path focuses on conditional effects (moderation and mediation as a contingency approach). For instance, the impact of family ownership on firm growth may be 
more complex depending on firm-specific characteristics. From this perspective, Bjuggren et al. (2013) reveal that family ownership negatively influences the probability that a firm will be have high-growth, but this negative effect disappears when a longer time period is considered. Additionally, succession is another determinant of employment growth. Based on a sample of small and medium Austrian family firms, Diwisch et al. (2009) find that firms that plan their succession have higher employment growth than firms that lack a formal succession plan. However, the effectiveness of succession planning may depend on the generation involved. For instance, Eddleston et al. (2013) reveal that succession is more conducive to growth for the first, third, and later generations. Unlike previous studies, mediating variables explain the different propensity of family and non-family firms to grow in terms of employment. For instance, Ensley et al. (2007) show that, compared to their nonfamily counterparts, pay dispersion in top management teams produces stronger negative behavioural dynamics that adversely affect employment growth. An additional example of mediation is presented by Stenholm et al. (2016), based on a sample of Finnish firms, who find that the relationship between innovation and employment growth is mediated by entrepreneurial activity only in family firms.

Beyond the different academic perspectives (e.g., management, family business, business economics) used to investigate the phenomenon, several theories have been applied to interpret the relationship between family involvement and employment outcomes. There are two main theoretical justifications. First, there is an external link between the firm and its surroundings created by family involvement. The presence of this connection is supported by complementary approaches, such as social identity theory and social capital and stakeholder perspectives. According to these approaches, family firms are deeply embedded in their local surroundings because of their connections with the community over time, resulting in social pressure to contribute to the future wellbeing of the community itself (Bassanini et al. 2013; D'Aurizio and Romano 2013). Second, there is an internal link between family and firm created by the interaction between family and business systems. The presence of this link is supported by the resource-based view, stewardship theory, and the socio-emotional wealth approach. From this perspective, the renewal of family bonds through dynastic succession leads family firms to proactively engage employees as internal stakeholders (Cennamo et al. 2012).

An alternative group of dependent variables in the articles retrieved is downsizing. Most empirical evidence on this topic shows that that there is a negative association between family involvement and the likelihood of downsizing, at least in the United States (Block 2010; Stavrou et al. 2007), France (Bassanini et al. 2013), Germany (Kappes and Schmid 2013) and Denmark (Bennedsen et al. 2019). The main theoretical rationale for explaining this finding comes from social identity theory (Block 2010), stakeholder theory (Stavrou et al. 2007), and the socio-emotional wealth approach (Colombo et al. 2014). Unlike non-family firms, family owners are more likely to care about their social identity and reputation in the community they are embedded in and thus tend to avoid reputation-damaging behaviour, such as layoffs. In other words, the relationship between family firms and their employees seems to be driven by normative commitment and moral principles rather than merely financial considerations (Stavrou et al. 2007). A number of contributions 
show that the relationship between family firms and employee turnover is mediated by different factors. For instance, Hu and Schaufeli (2011) reveal that job insecurity (i.e., past downsizing and current remuneration) affect turnover intentions via employee wellbeing (i.e., burnout and work engagement). Further, based on a sample of family-owned businesses, Khanin et al. (2012) find that family-business embeddedness and work centrality reduce family employees' turnover intentions by magnifying their job satisfaction. More recently, Vardaman et al. (2019) show that friendship ties between family and non-family members negatively influence nonfamily employee turnover indirectly through organizational identification. However, the negative association between family firm status and turnover is contingent on firms' size, with only small family firms showing distinctive behaviour toward employees (Kölling 2020).

Finally, further evidence suggests that, despite having less incentive to downsize, family firms are associated with low-quality employment resulting in lower salaries than non-family firms in France (Bassanini et al. 2013) and higher voluntary turnover in Belgium (Neckebrouck et al. 2018). Indeed, there is also evidence showing that job insecurity (Hu and Schaufeli 2011) in China, disaffection (Khanin 2013) in the United States, a low employee relationship orientation in firms (Cameron et al. 2009) in Australia, and superior employment prospects elsewhere (Mahto et al. 2020) affect employees' turnover intentions in family firms. However, the empirical evidence of employment quality in family firms is contradictory. It was found that some employment practices such as reciprocity is particularly strong in family firms whereby family ties can cross the family domain to encompass non-family employees (Vardaman et al. 2018). For instance, evidence shows that embedding familiness into human resources practices is an effective way to improve employee retention in the Chinese (Deng 2018), Austrian and Hungarian (Pittino et al. 2016), and North American contexts (Khanin et al. 2012). However, the perceived inequity stemming from the asymmetric treatment of family and non-family members may reduce the benefits of human resource practices on firms' performance (Madison et al. 2018).

We can conclude that aside from differences stemming from the definition of family firm used (i.e., the way the family firm concept is activated/defined to distinguish family firms from non-family firms), current research has focused on determining whether family involvement (captured using demographic or essence dimensions) in the firm affects employment outcomes (i.e., growth, reduction or quality of employment). Current evidence shows that while family firms generally seem to downsize less than their non-family firm counterparts, their effect on employment growth and employment quality is less evident. This evidence could be explained by the lack of theoretical predictability across contexts. That is, even though these findings make important contributions, the limitation lies in the fact that these results are contextless, implying a lack of generalizability. In our analysis of the next two quadrants at the firm level, we explain and interpret the extent to which family business scholars have overcome this context-less limitation. 


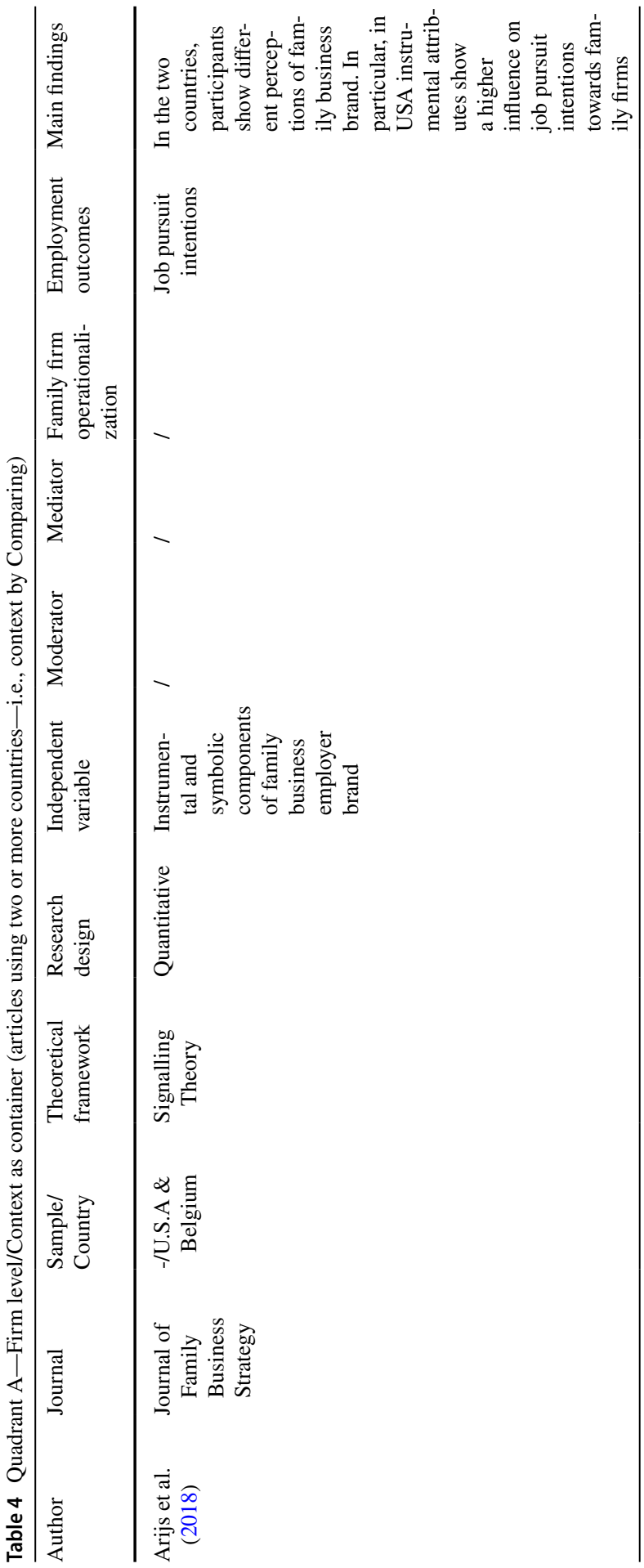




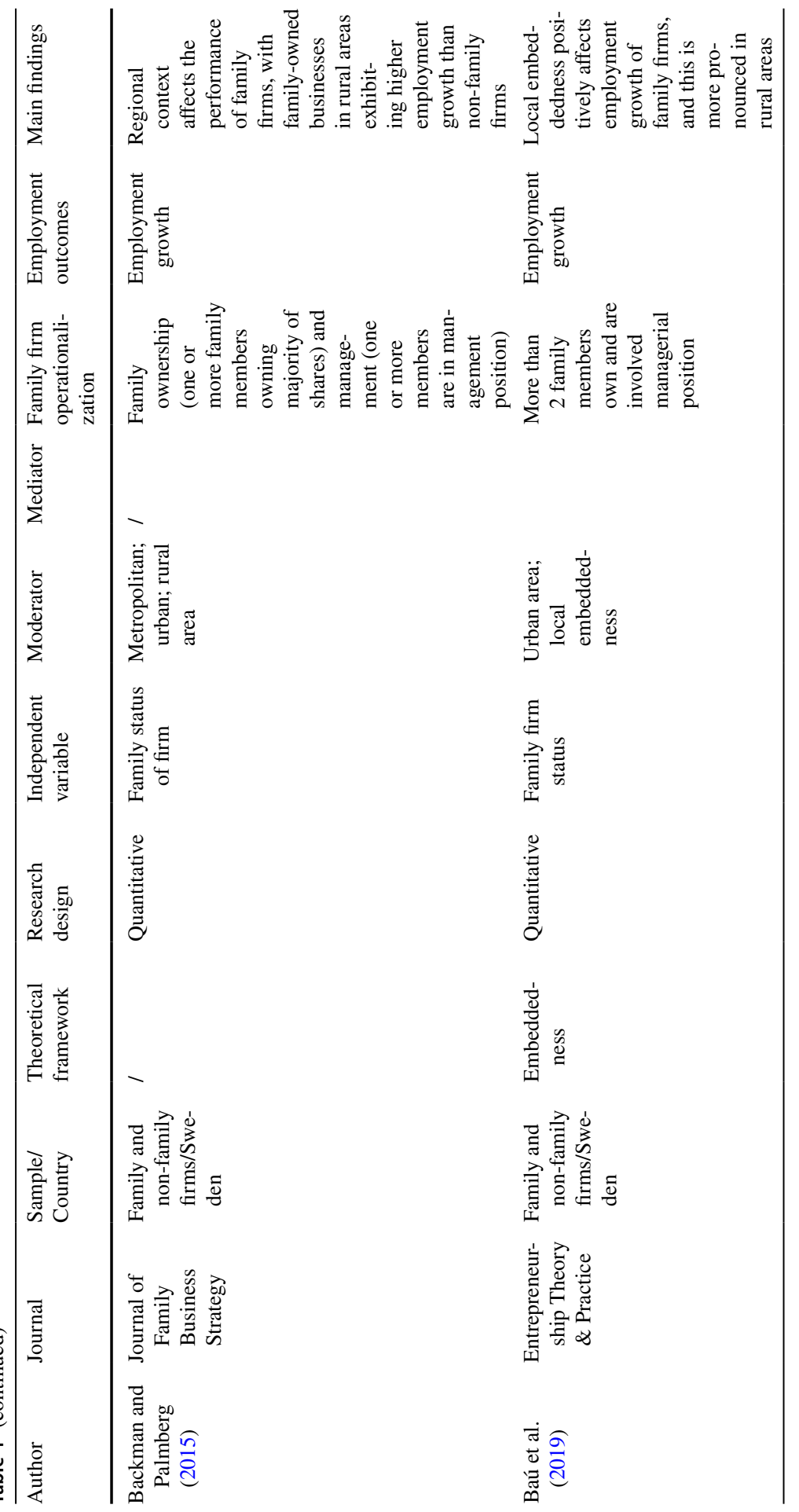




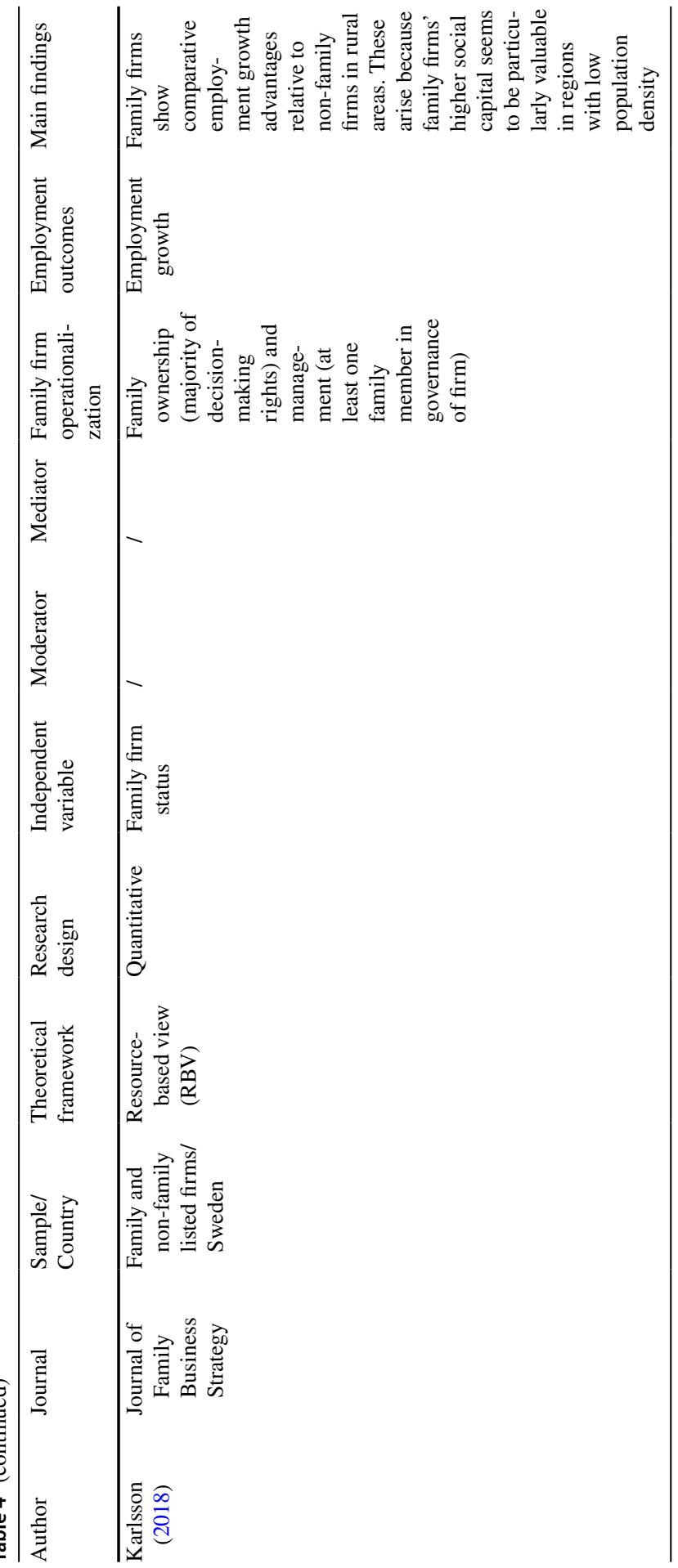




\subsubsection{Context by comparing一firm level}

Only four articles (equal to $6 \%$ of the retrieved articles-see Table 4) contextualize the relationship between family firms and firm employment by comparing family and non-family firms operating in different geographical areas. The articles in this quadrant mostly stress the role of the location of the family firm in exploiting the competitive advantages derived from family involvement in the firm. Specifically, these studies address the question of whether the surrounding socio-economic environment influences family and non-family firm employment outcomes differently. The contributions in this quadrant focus on the urban/rural location of family firms in Sweden, and their conclusions are consistent: family firms exhibit better employment growth than non-family firms in rural areas (Backman and Palmberg 2015; Baú et al. 2019; Karlsson 2018). This research line follows the theoretical rationale of social capital approach (Arregle et al. 2007; Pearson et al. 2008), the resourcebased view of the firm (Barney 1991), and the local embeddedness/regional familiness perspective (Basco 2015; Stough et al. 2015), suggesting that family firms located in rural areas are better positioned to acquire, allocate, and manage valuable tangible (e.g., financial capital) and intangible resources (e.g., human capital) that positively affect employment growth.

Despite the importance of context for firm behaviour and employment, only the aforementioned studies attempt to compare employment outcomes, specifically employment growth, based on location. Even though these results regarding the urban-rural location of family firms align, all of the firms studied are located in the same country. Indeed, these findings set a precedent for Swedish policymakers (Basco and Bartkevičiūte 2016), but that does not mean that these results can be generalized. Another limitation of these studies is related to how they measure location by focusing simply on different categorizations of urban-rural areas, which is a rough measure of socio-spatial context. There are so many assumptions (e.g., the type of embeddedness in local municipalities) when categorizations of urban-rural areas are used to explain the mechanisms behind these contexts and the advantages or disadvantages between family and non-family firms. The econometric exercises in these studies oversimplify reality by failing to measure the socio-economic dynamics occurring in these settings, so most of the conclusions are taken for granted. In the next quadrant at the firm level, we explore how current research overcomes some of the aforementioned limitations by measuring context.

\subsubsection{Context as a covariate}

There are 19 articles (29\% of the retrieved articles-see Table 5) measuring context and its impact on the relationship between family firms and employment outcomes (Quadrant B in Table 1). Most of these studies adopt a cross-country approach in investigating the impact of context in the relationship between family firms and employment outcomes. The most common strategy in these articles consists of using contextual dimensions as moderator variables in the main relationship between family involvement (demographic or essence variables) and employment outcomes. The interpretation of context in this quadrant applies the multi-embeddedness framework 


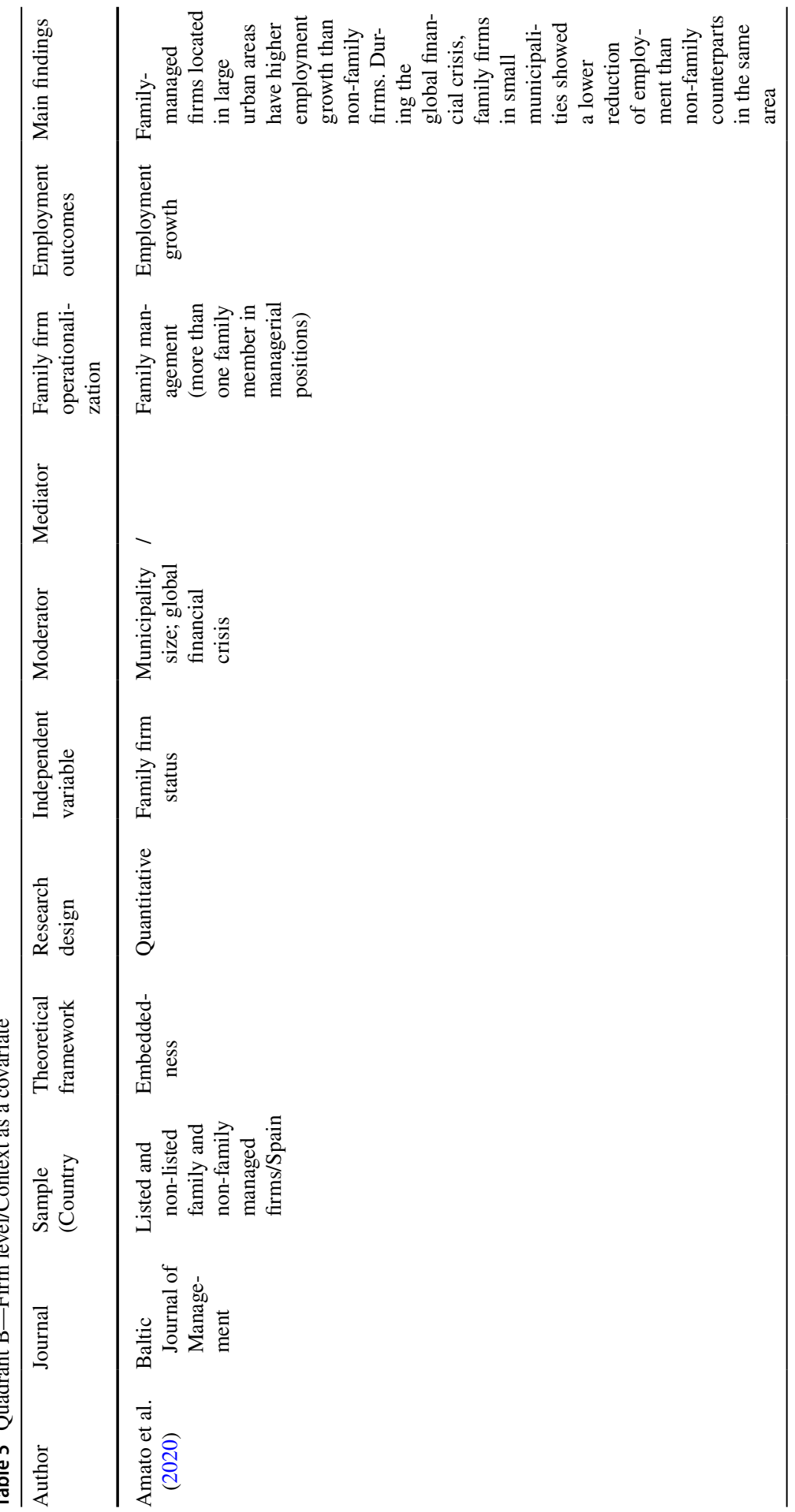




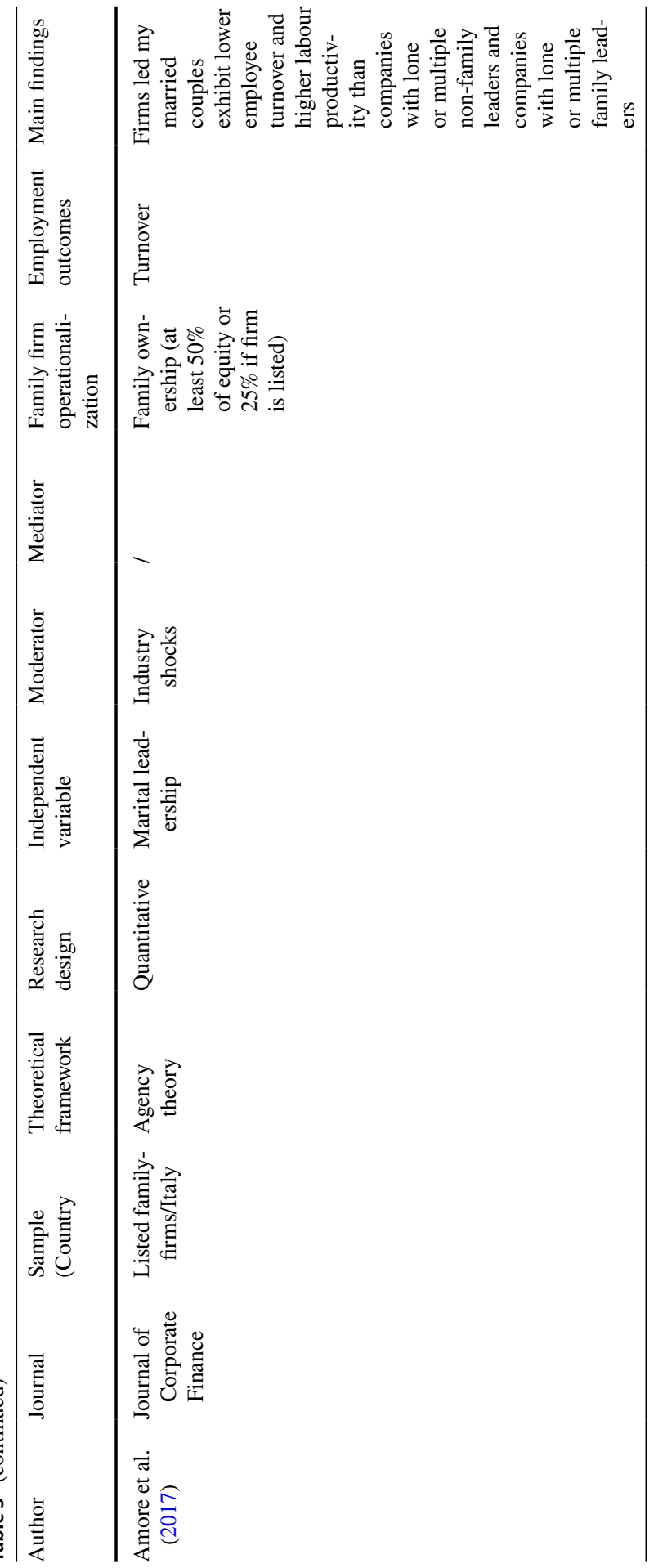




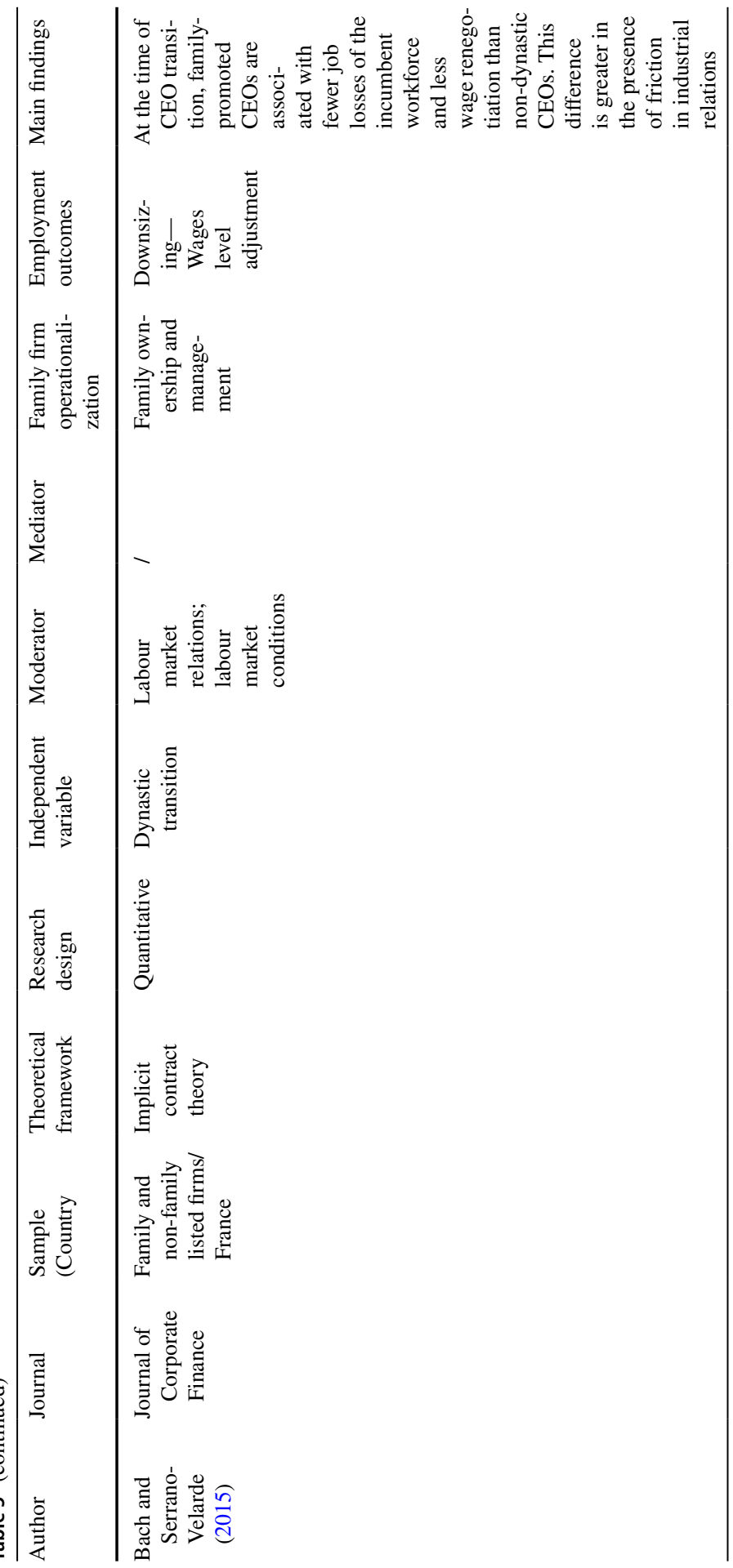




\begin{tabular}{|c|c|}
\hline 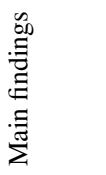 & 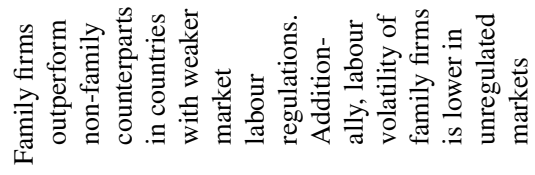 \\
\hline 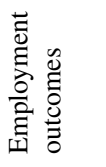 & 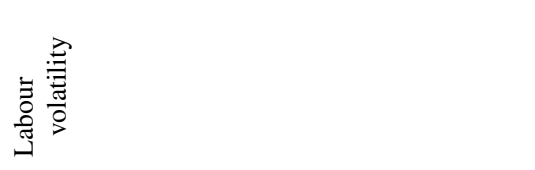 \\
\hline 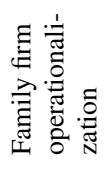 & 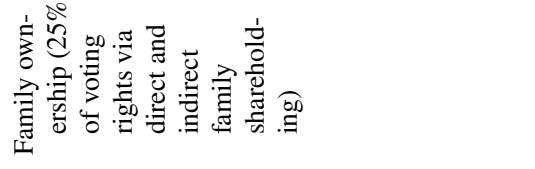 \\
\hline 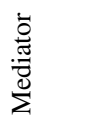 & - \\
\hline 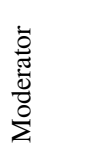 & 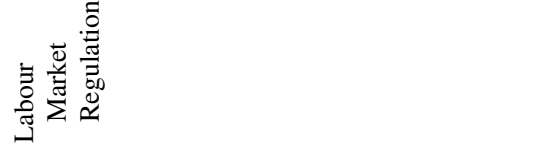 \\
\hline 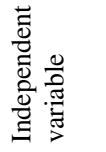 & 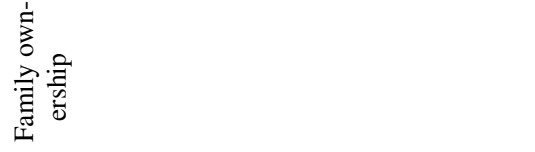 \\
\hline 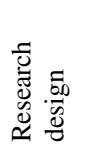 & 䔍 \\
\hline 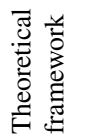 & - \\
\hline 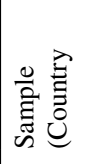 & 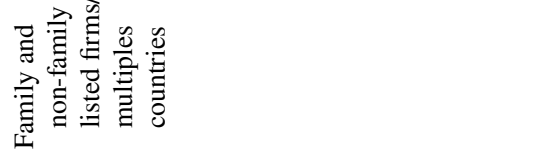 \\
\hline 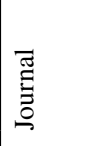 & 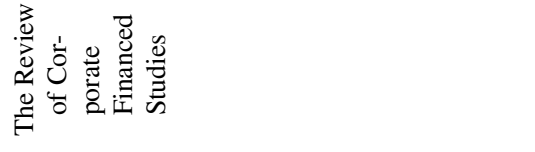 \\
\hline 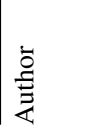 & 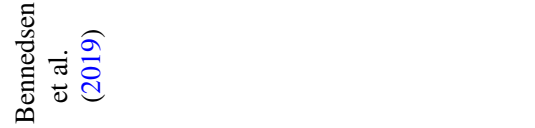 \\
\hline
\end{tabular}




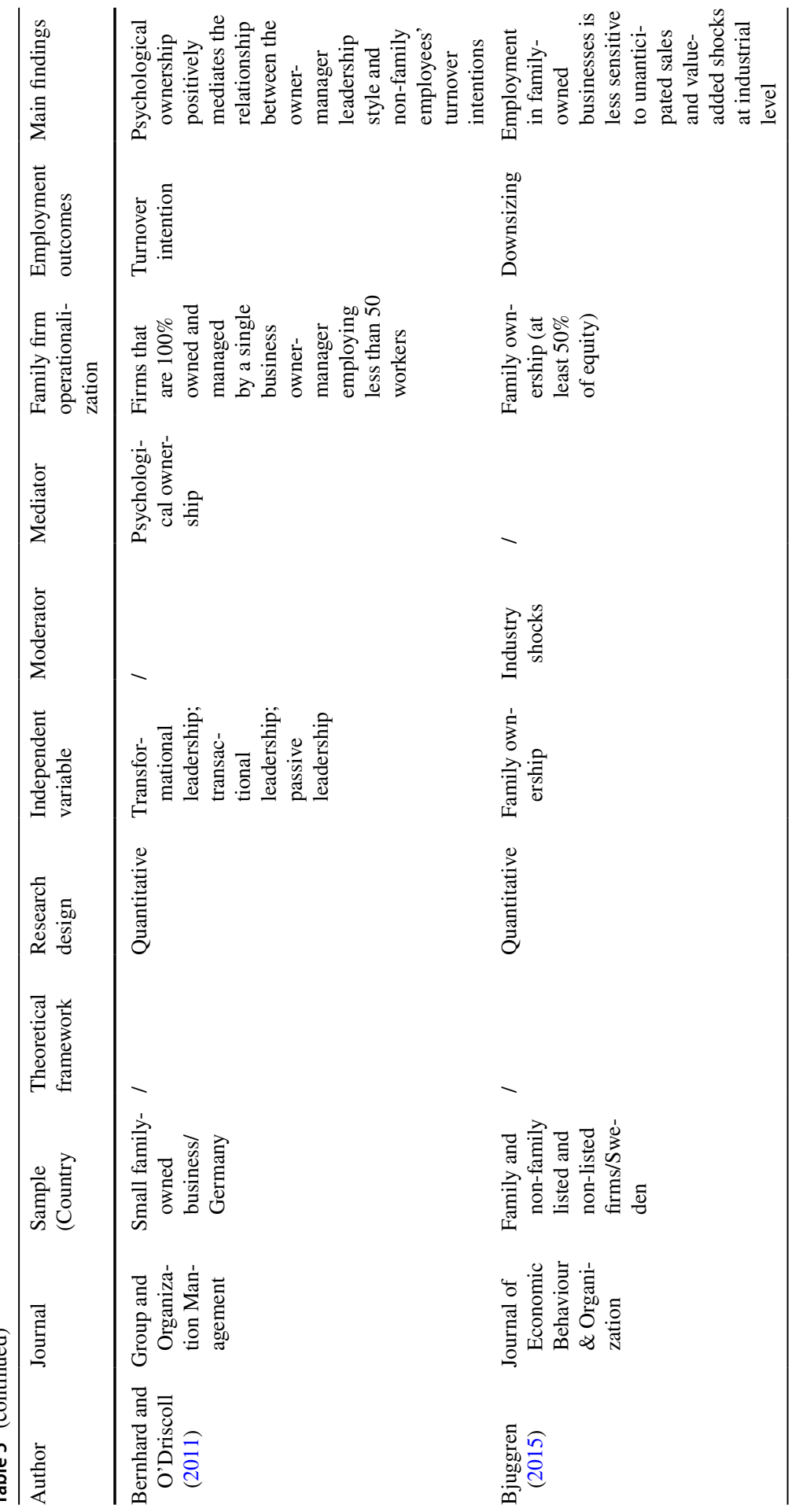




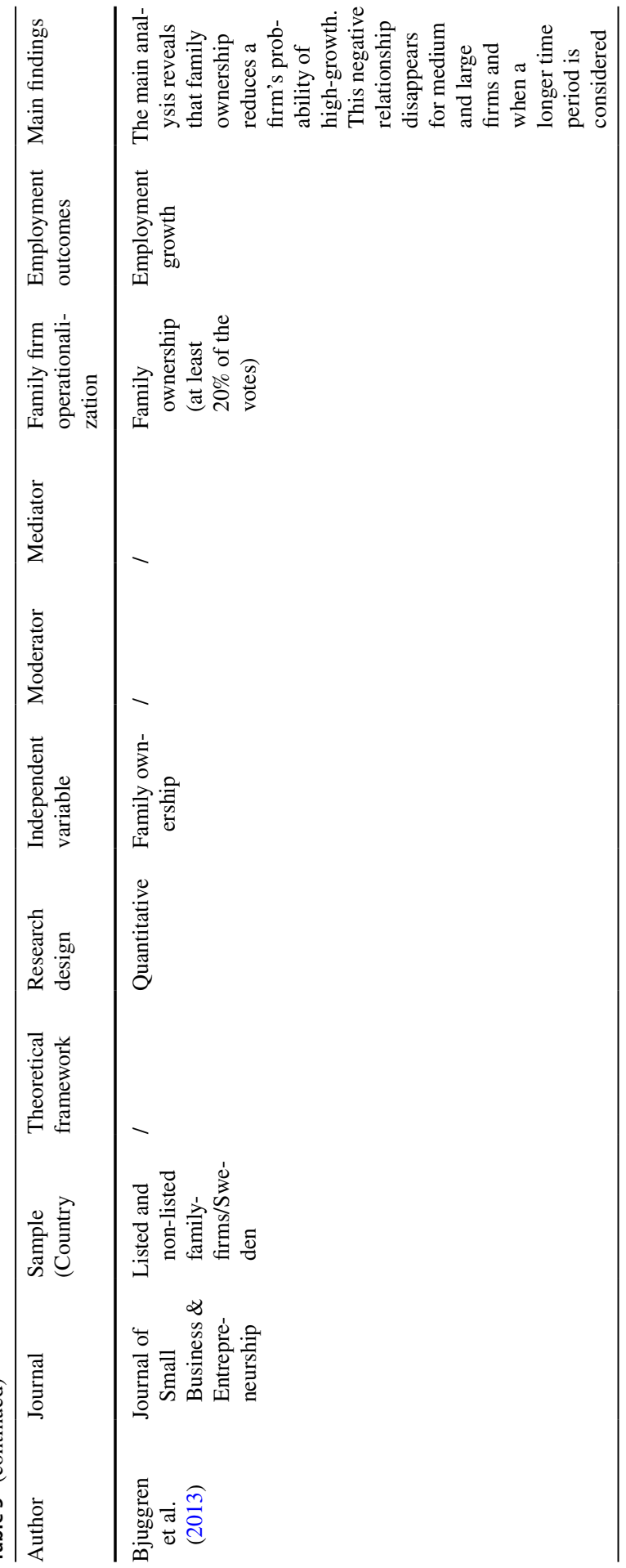




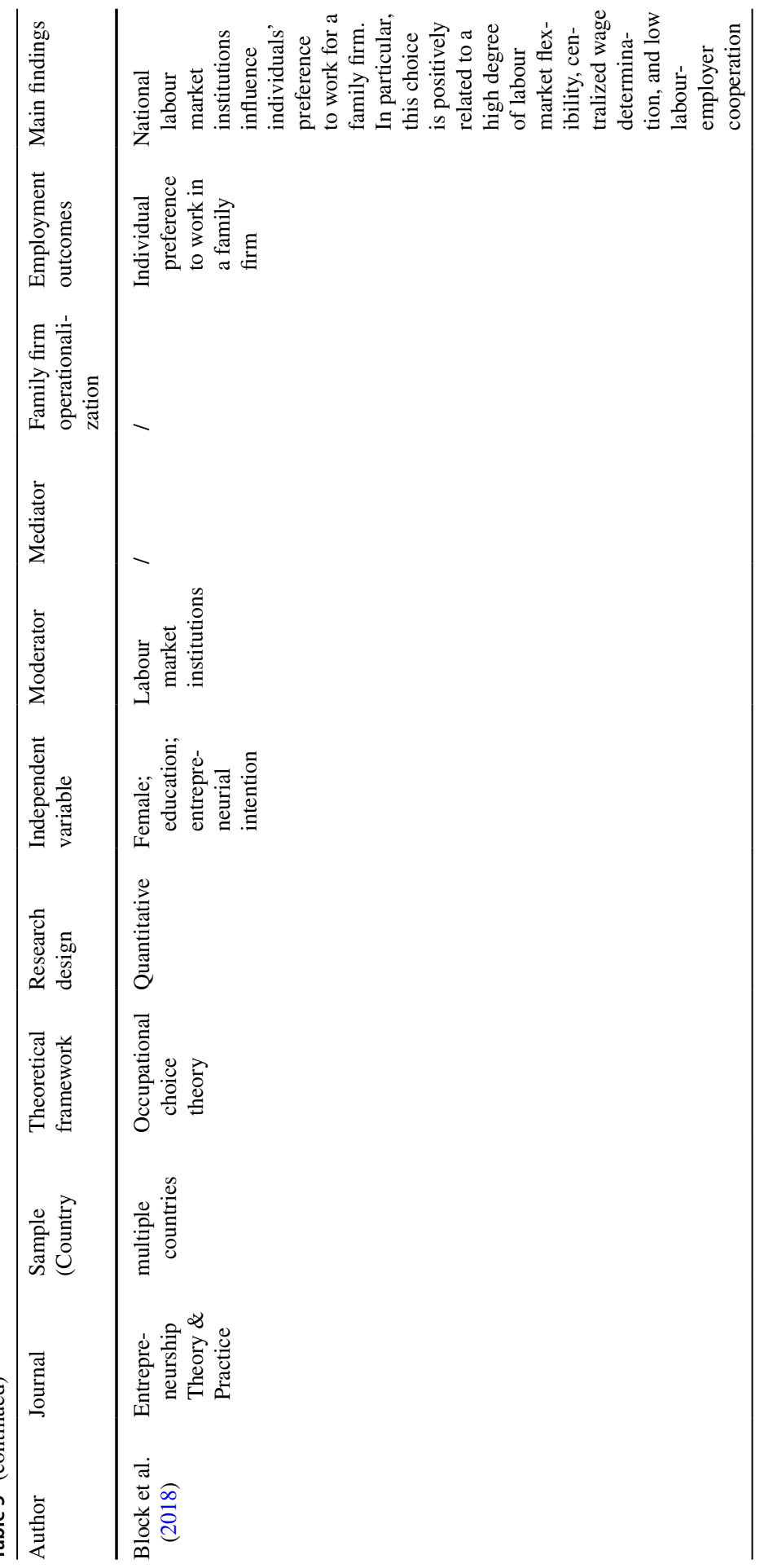




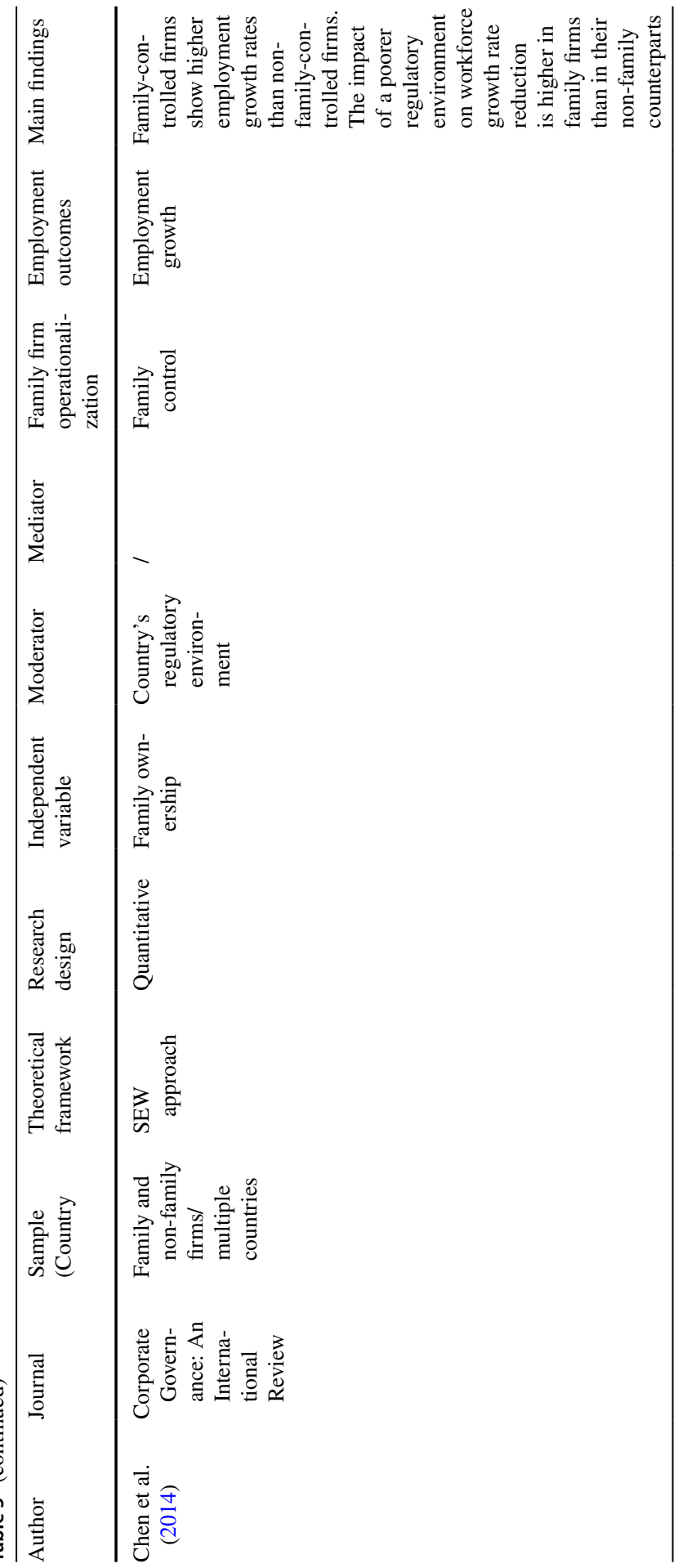




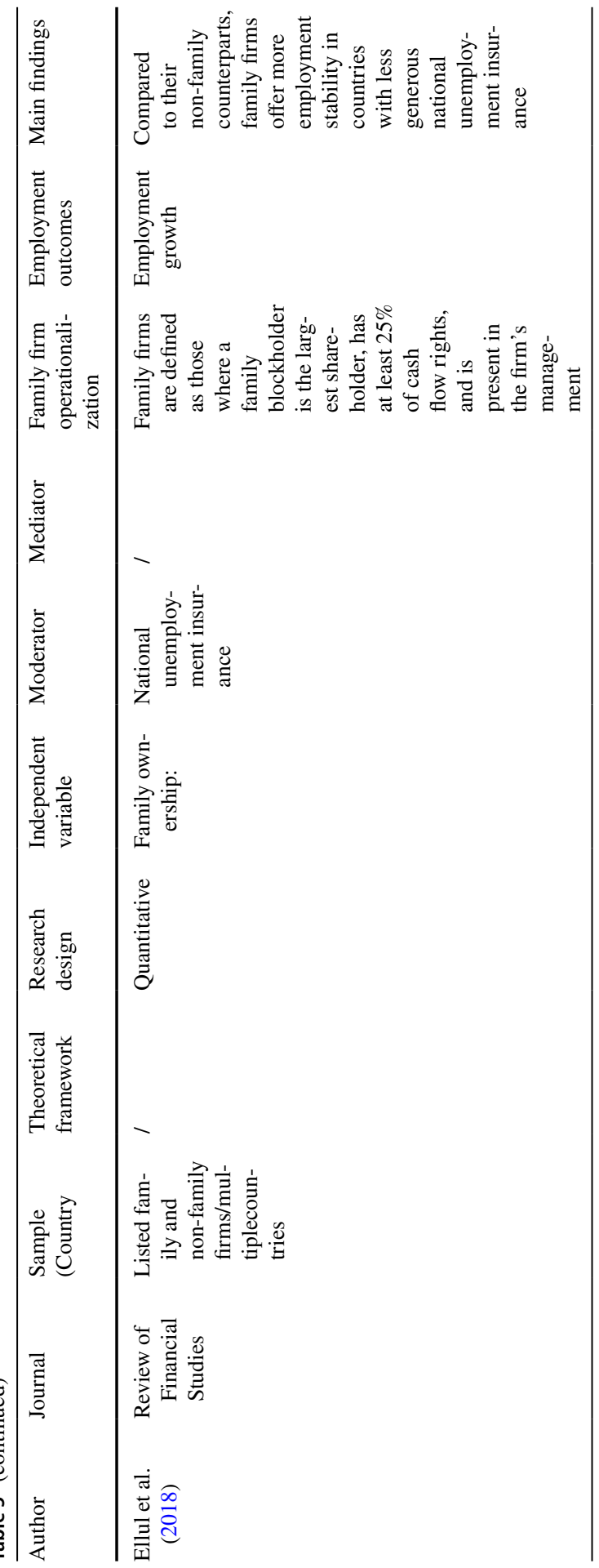




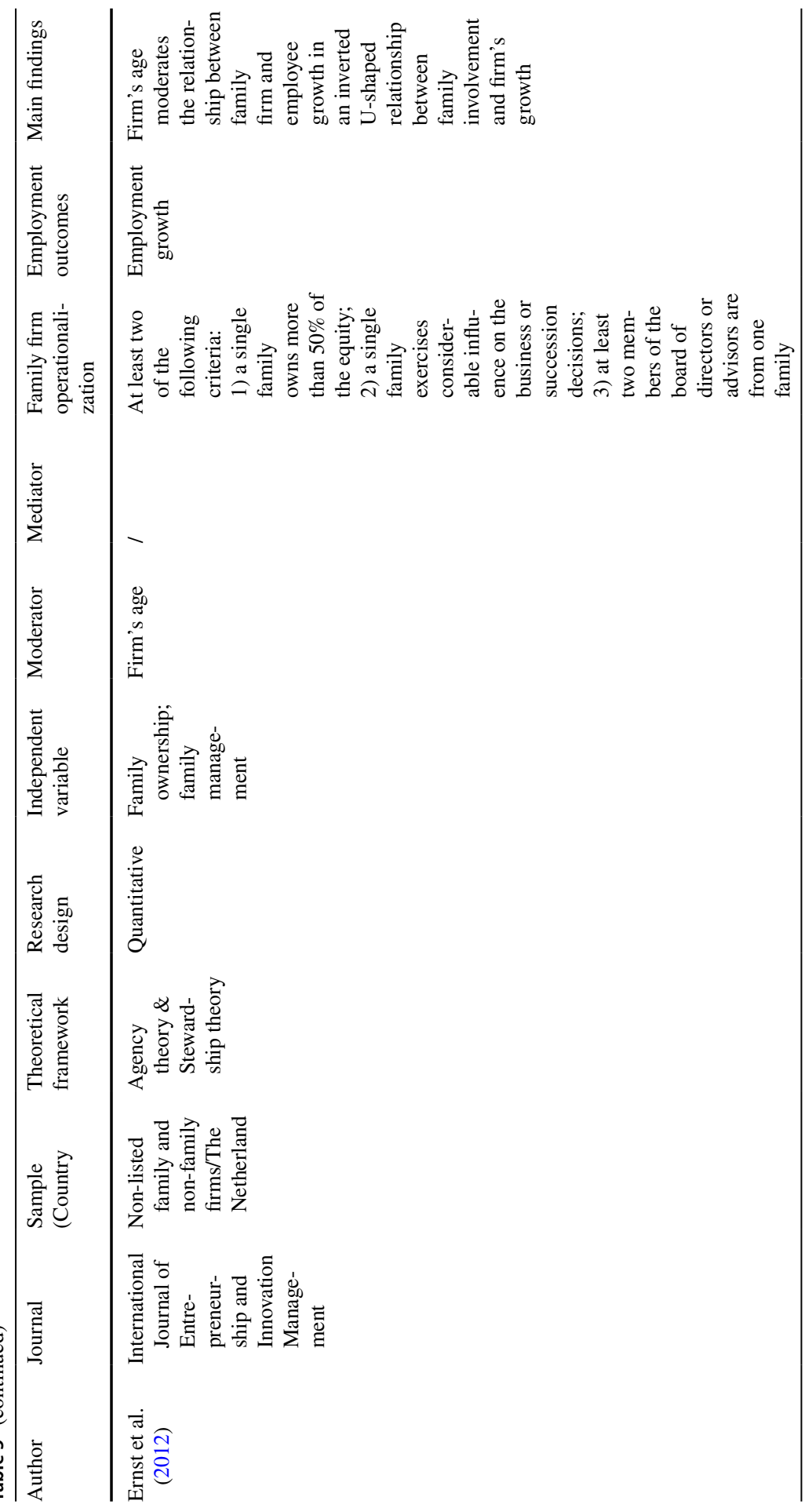




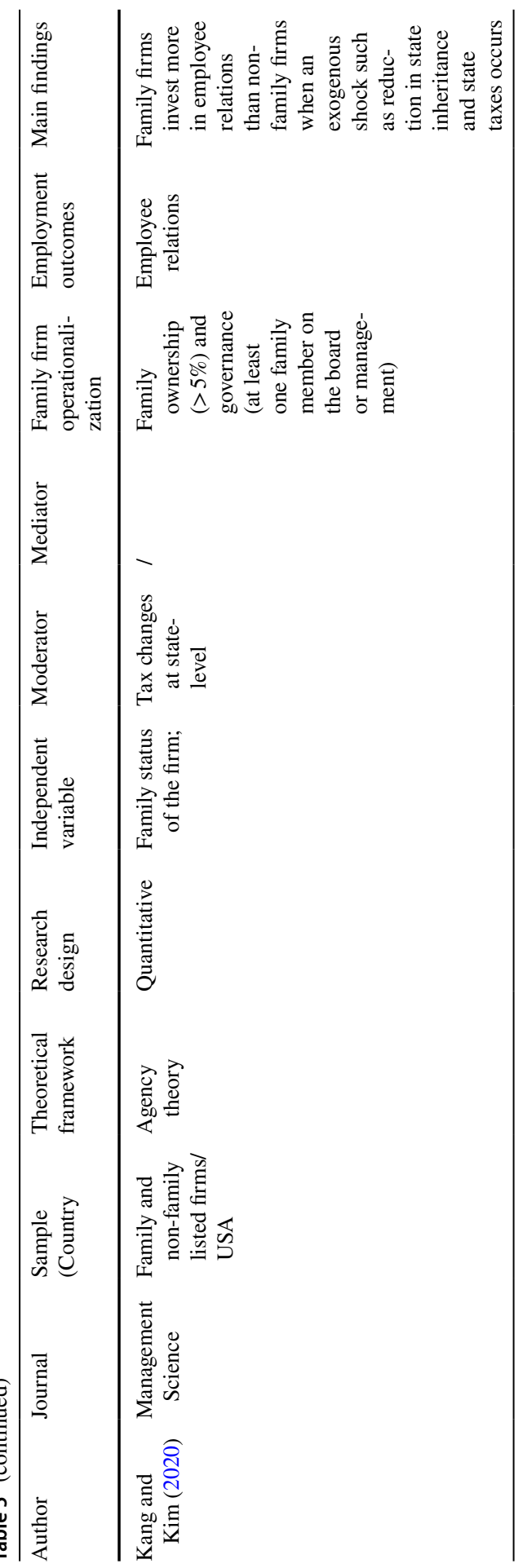




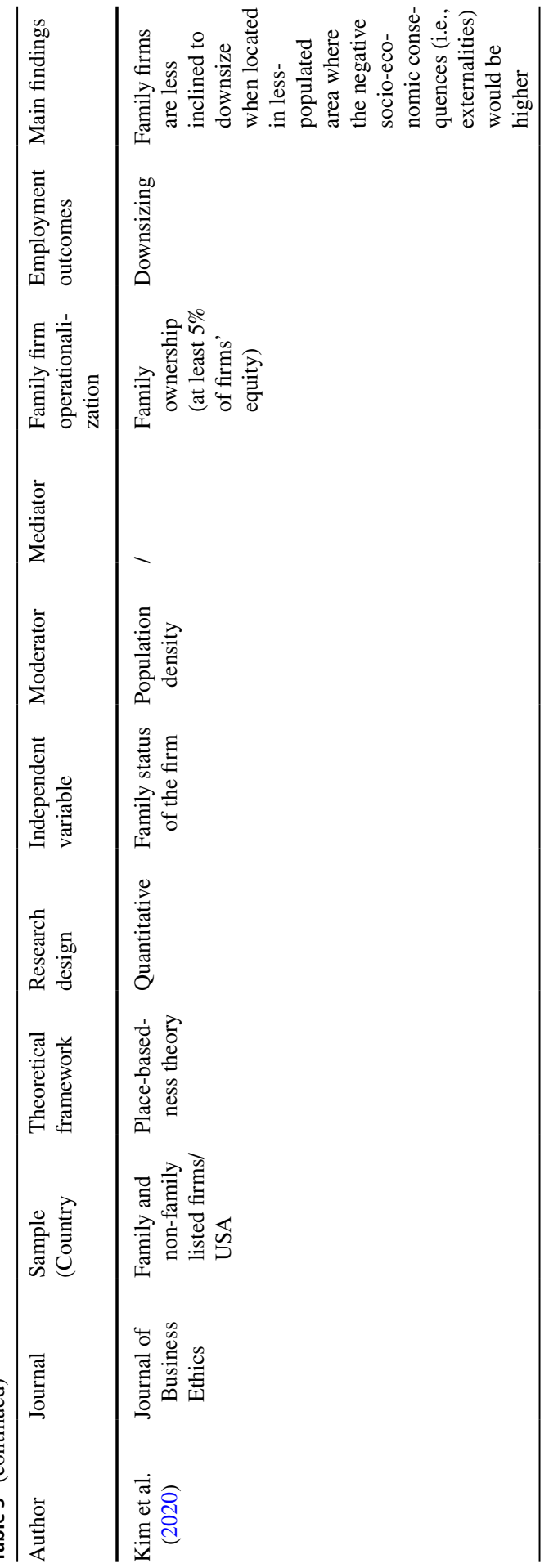




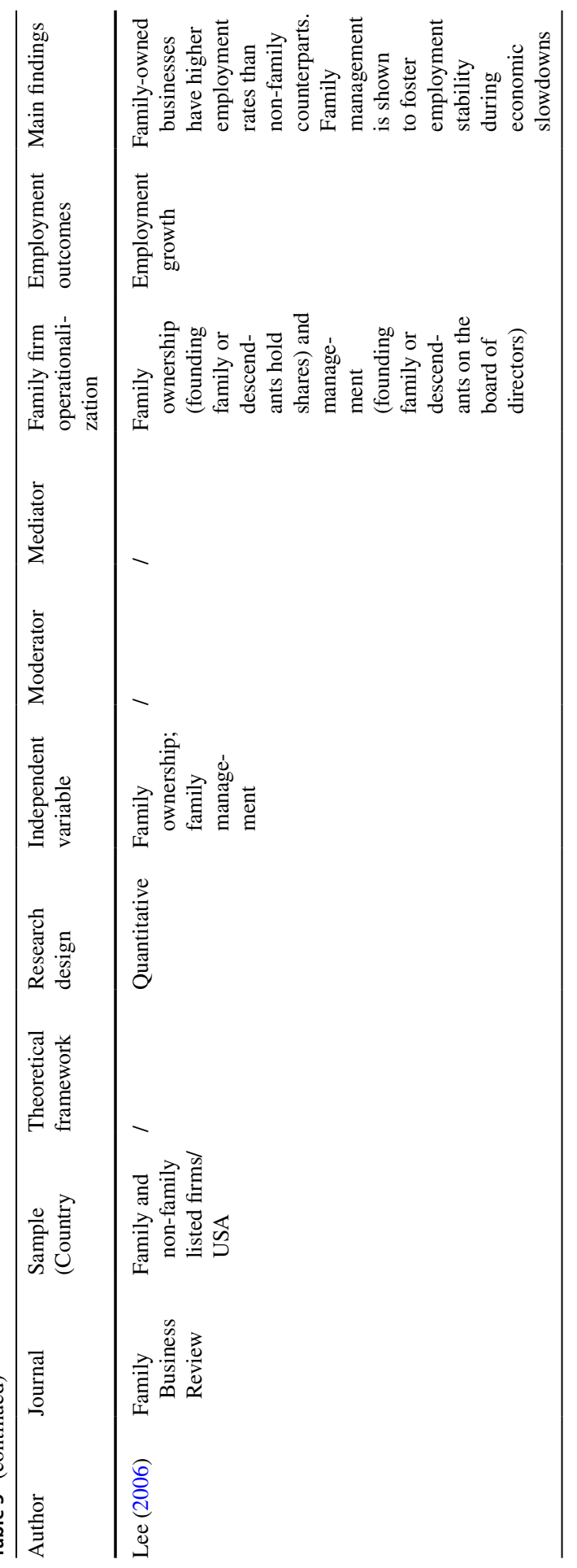




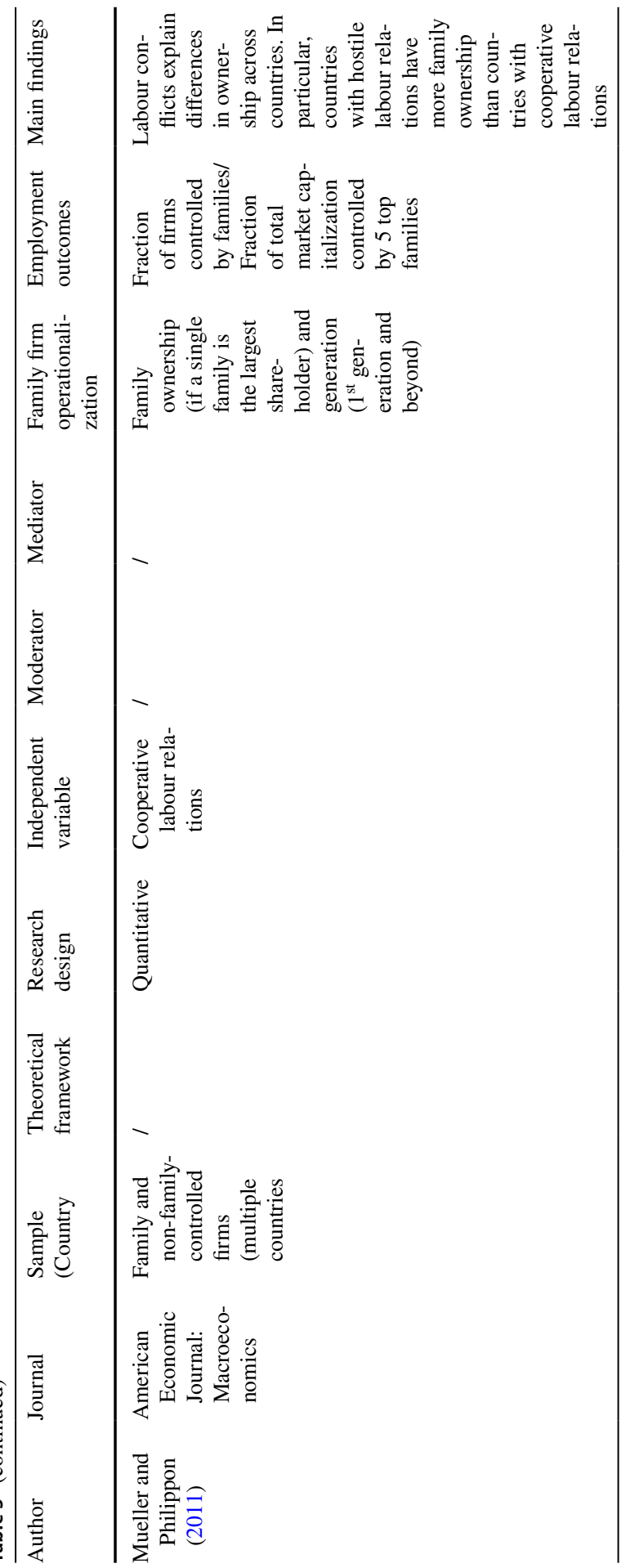




\begin{tabular}{|c|c|}
\hline 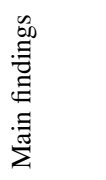 & 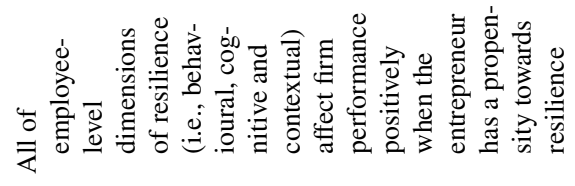 \\
\hline 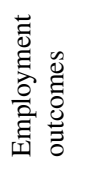 & 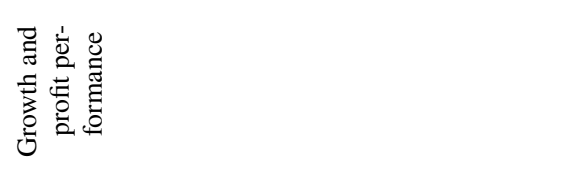 \\
\hline 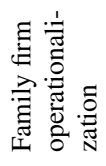 & 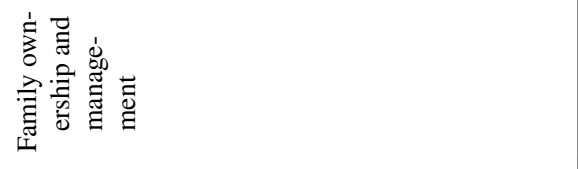 \\
\hline 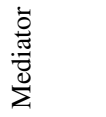 & - \\
\hline 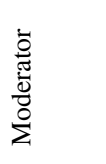 & 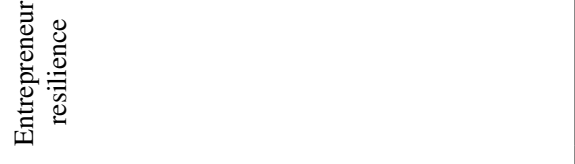 \\
\hline 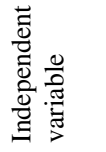 & 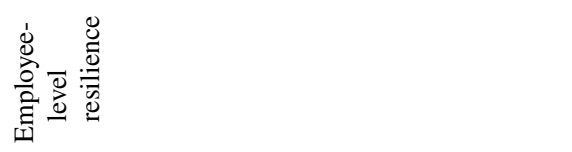 \\
\hline 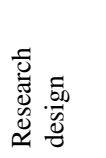 & 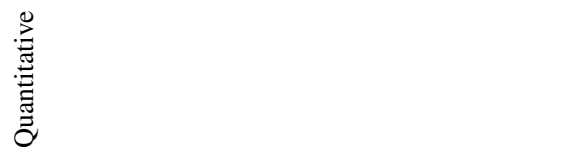 \\
\hline 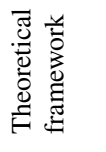 & 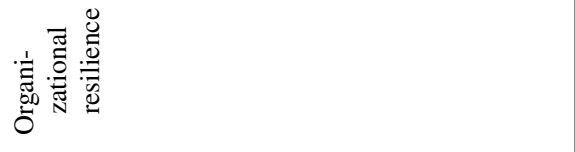 \\
\hline 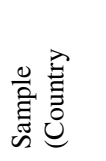 & 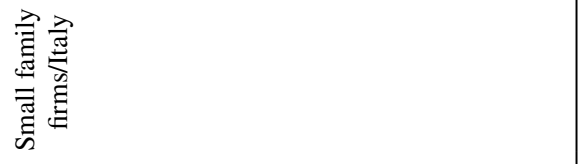 \\
\hline $\begin{array}{l}\text { 胥 } \\
\text { 咅 }\end{array}$ & 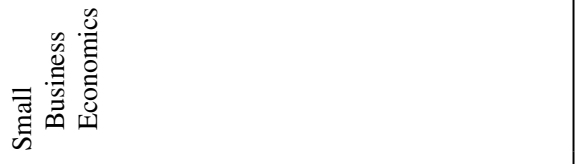 \\
\hline 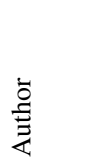 & 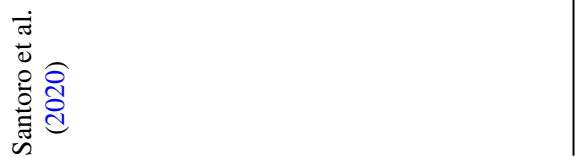 \\
\hline
\end{tabular}




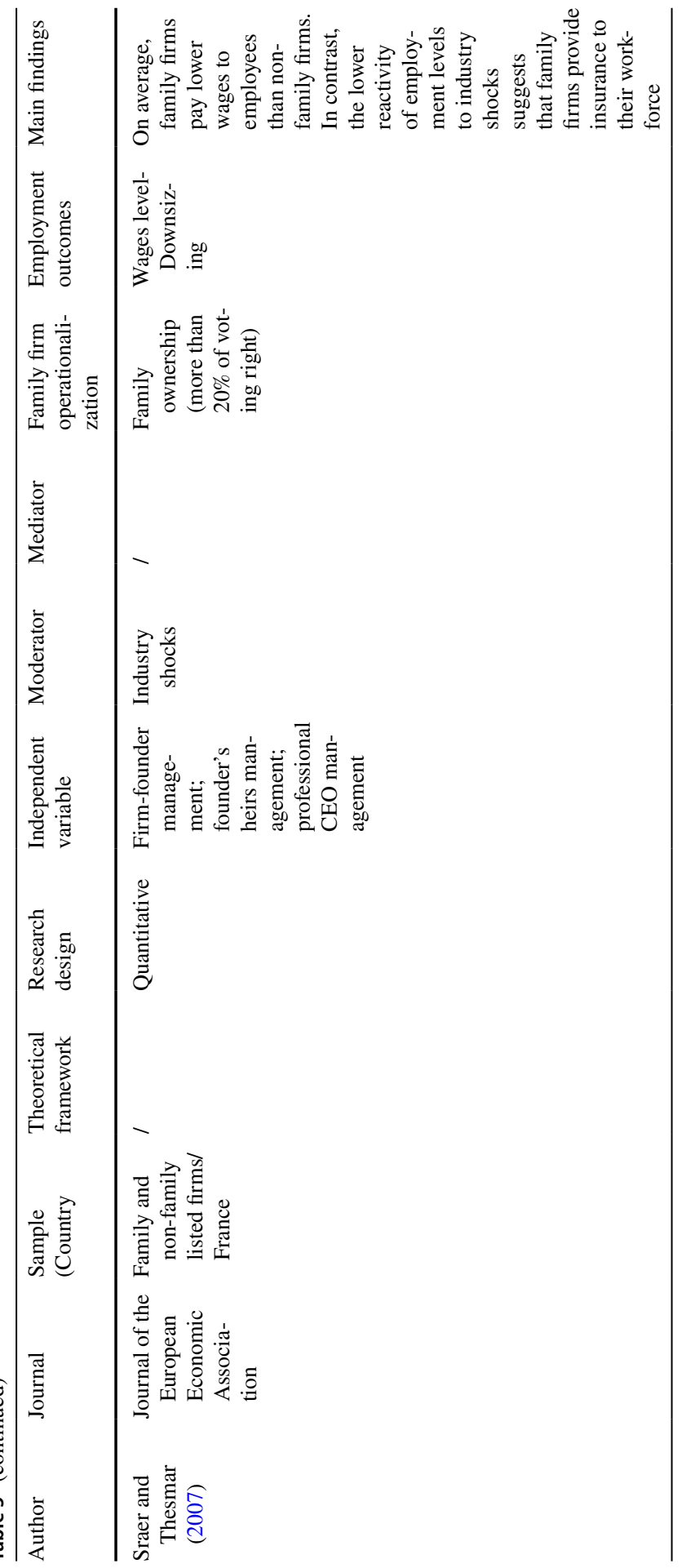




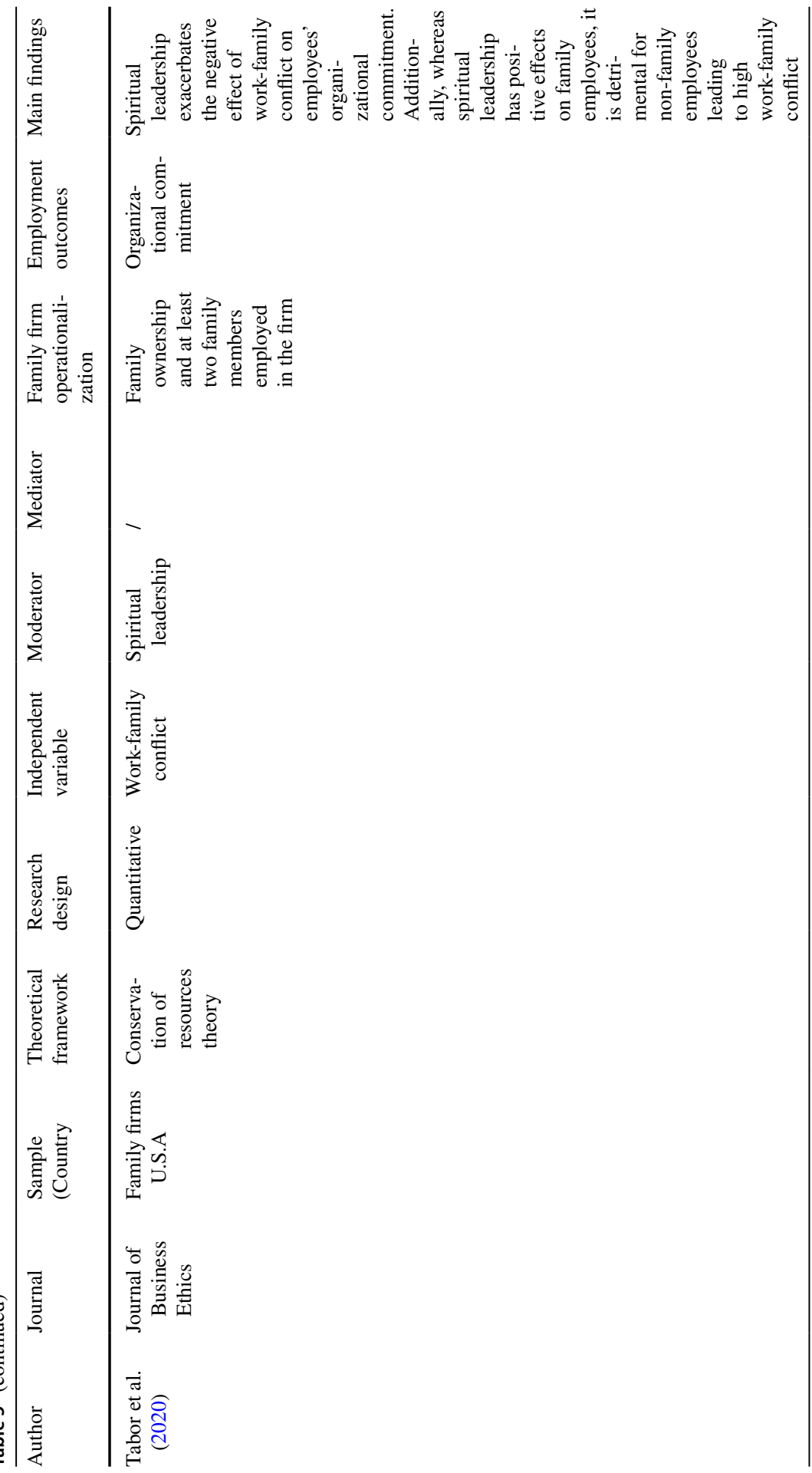




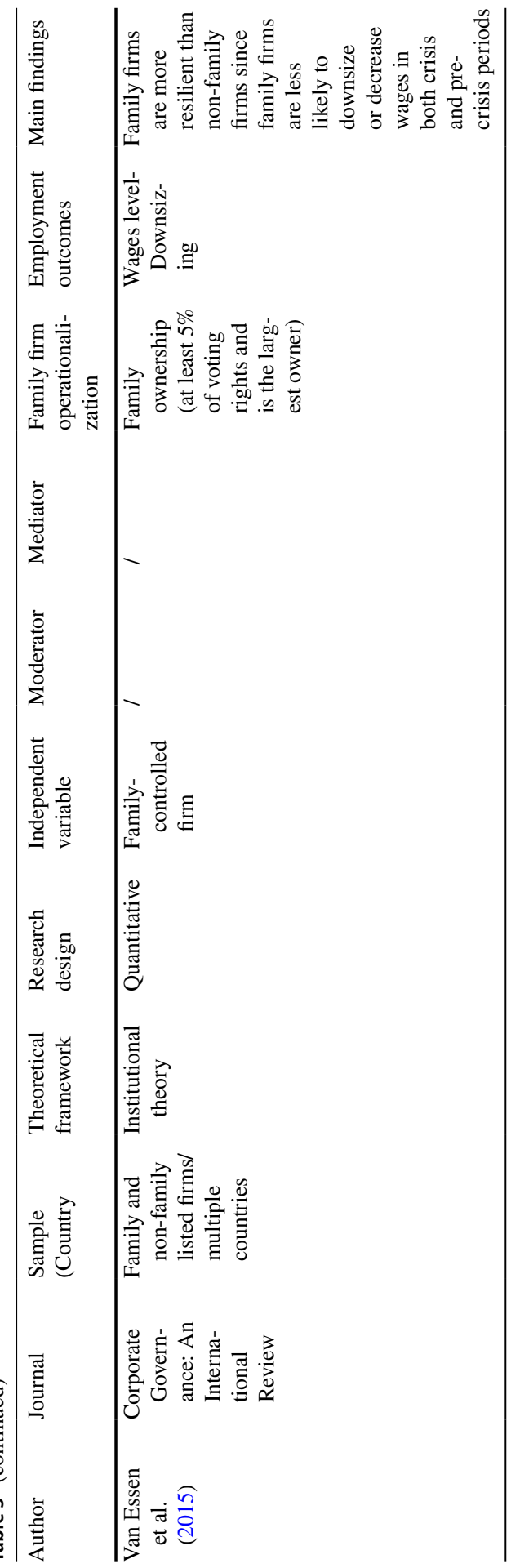


for family firms (James et al. 2020) by discriminating between different contexts, such as the family (e.g., Amore et al. 2017), the meso-context (e.g., industry, labour market, or region) (e.g., Bach and Serrano-Velarde 2015), and the country (Chen et al. 2014). Each of these contexts combines existing family business approaches (e.g., socioemotional wealth) with mainstream theories, such as institutional theory (van Essen et al. 2015) and occupational choice theory (Block et al. 2018). Following the structure presented for Quadrant A, we next analyse the contributions of the retrieved articles by considering three main clusters: employment growth, downsizing, and employment quality.

First, as in Quadrant A, most of the articles focus on employment growth and their contributions lie in revealing the contingent effect of context on the relationship between family involvement and employment growth. Regarding the microcontext, while Bjuggren et al. (2013) find that the negative relationship between family involvement and employment growth disappears for medium and large firms in Sweden, particularly when a longer time period is considered, Ernst et al. (2012) find that firm age seems to play a role in employment growth in the Netherlands. In particular, they show that a non-linear relationship exists between family involvement and employment growth across firm age. We did not find any articles measuring the meso-context, such as industry, to contextualize family involvement and employment outcomes, which indicates an opportunity for future research. Finally, regarding the macro-context, the research mainly focuses on formal institutional contexts and economic crises. For instance, in the United States, Lee (2006) find that family management fosters employment stability during economic slowdowns. More recently, based on a sample of Spanish firms, Amato et al. (2020) found that during crises, family firms located in small municipalities have higher employment growth than their non-family counterparts located in the same socio-spatial settings. In a cross-country study, Chen et al. (2014) find that the quality of the regulatory environment negatively moderates the relationship between family ownership and firm employment growth. In another cross-country analysis, Ellul et al. (2018) find evidence of the "substitutability hypothesis" between unemployment insurance offered by the government and that offered by firms. In particular family firms have been found offer more employment protection than non-family firms but only in countries with less generous national insurance policies. Finally, Bennedsen et al. (2019) found that family firms show less labour volatility, particularly in countries with fewer labour market regulations, wherein implicit insurance is most valuable.

The second most important group of articles explores downsizing. Regarding the micro-context, in a study of French family firms, Bach and Serrano-Velarde (2015) find that CEO transition in dynastic firms is associated with less workforce reduction than in non-dynastic firms. Regarding the meso-context, employment in less sensitive to unanticipated sales and value-added shocks from industry in the Swedish (Bjuggren 2015) and French contexts (Sraer and Thesmar 2007). With regard to the macro-context, Kim et al. (2020) study in the United States reveals that family firms are less likely to downsize, particularly when located in less populated areas, where the negative externalities resulting from massive layoffs would be higher. Finally, in a multi-country study, van Essen et al. (2015) find that family firms are 
more resilient (i.e., less likely to downsize) than non-family firms both before and during crisis periods.

The final group of articles covers employment quality related to wages and turnover. Regarding the micro-context, maritally-led firms have lower employment turnover than family and non-family firms in Italy (Amore et al. 2017). Moreover, leadership style, mediated by psychological ownership, is found to play an important role in explaining turnover intesntions among employees in German family firms (Bernhard and O'Driscoll 2011). In terms of the meso-context, Bach and Serrano-Velarde (2015) show that low wages are more common among dynastic family firms and are even more common in presence of the fictional labour market and conflictual labouremployer relations of the French context.

To sum up, our knowledge in this quadrant goes a step further than in the previous quadrants by attempting to measure context at micro-level (e.g., context in which couples work), meso-level (e.g., sales shock at the industry level), and macrolevel (e.g., economic crises) to determine their impact on the relationship under study. This quadrant provides more information about when the direct general relationship between family involvement and employment growth (reported in Quadrant A) is positive and negative. In other words, context is interpreted as a moderator dimension that affects the strength and/or the direction of direct relationship and overcomes the conflicting empirical evidence emerging between family involvement and employment outcome (Quadrant A). In other words, context can better explain the nuances of the relationship and thus to make generalization from the results more accurate. The importance of context is also valid for downsizing and measures of employment quality. For instance, even though the research on contextualizing confirms the conclusion made in Quadrant A that family firms downsize less than non-family firms, this conclusion is even more apparent during economic crises. At the same time, family firms are less likely to reduce salaries, which seem to be lower than in non-family firms. Theoretically, the most important contribution of this quadrant is to show how theoretical predictions and the behaviour of the phenomenon itself (e.g., family firm) react to external dimensions at the micro-, meso-, macro-levels. Nevertheless, even with the steps to integrate context in the current research, the methodological approaches have hardly advanced. For instance, with the exception of Block et al. 's study (2018), there is no research using multi-level modelling to consider the nested nature of the data.

\subsection{Aggregate level}

\subsubsection{Context as a container-aggregate level}

There are four studies (6\% of the retrieved articles-see Table 6) at the aggregate level of analysis (Quadrant $\mathrm{C}$ in Table 1), which are exploratory in nature and use a datadriven approach. The first three, Astrachan and Shanker (2003); Bjuggren et al. (2011); and Andersson et al. (2018), estimate the economic impact of family firms in terms of workforce employed and GDP generated in the US and Swedish economies, respectively. In both studies, the whole estimation process is constrained by the definition of 


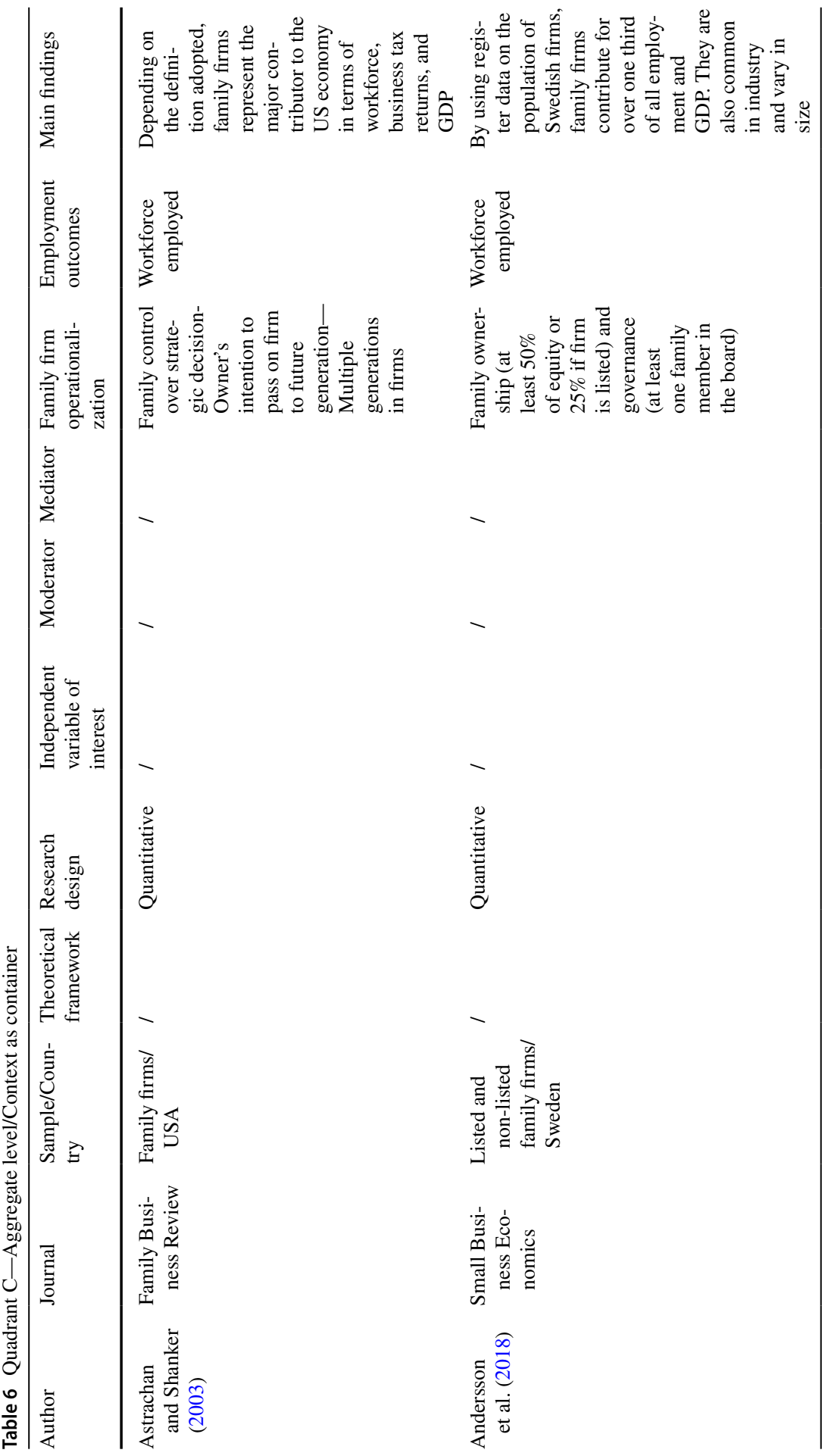




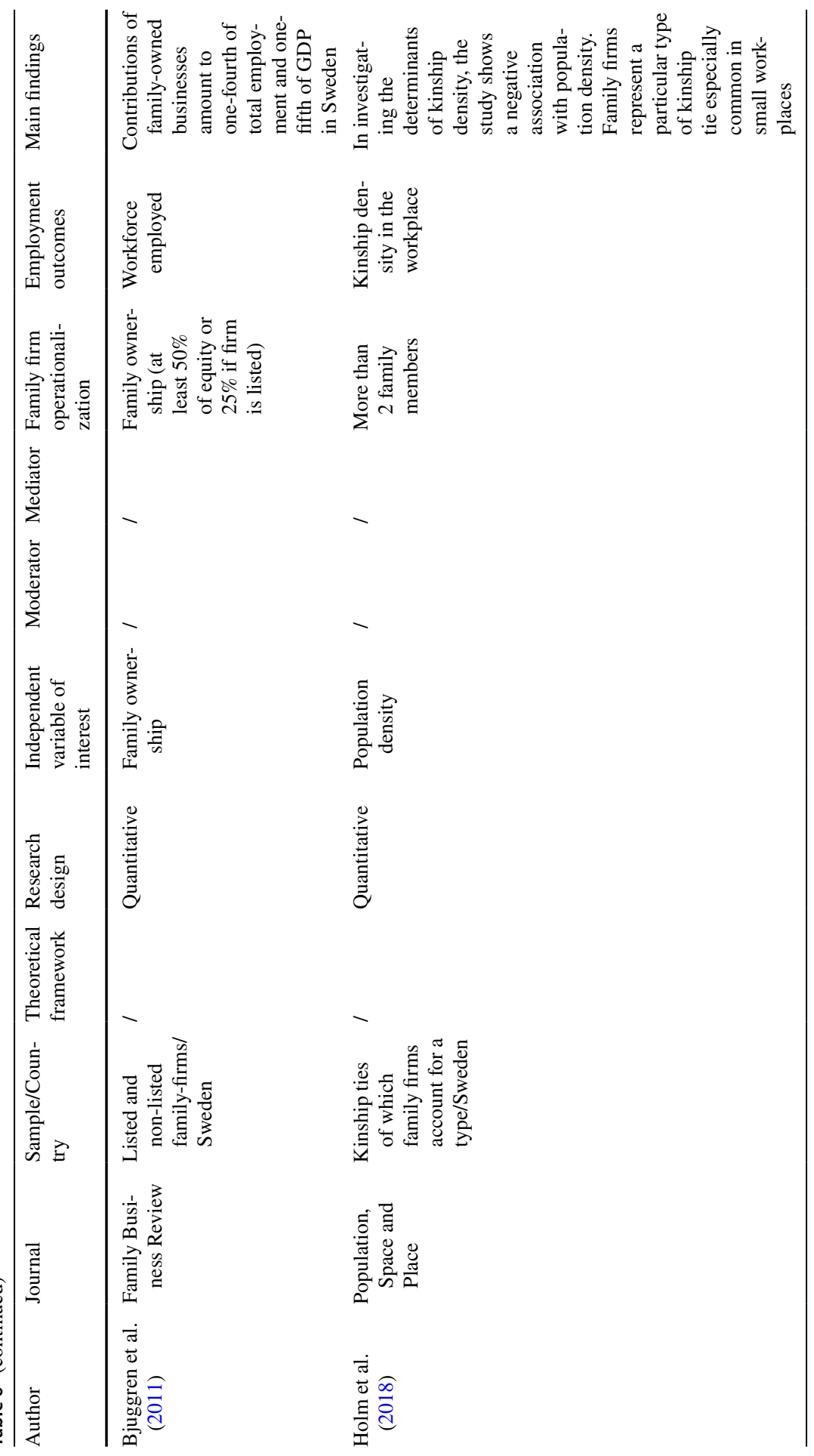


family firm. In the US economy, family businesses account for nearly one-third of the workforce employed if a broad definition of family firm is adopted. Similarly, in the Swedish economy, family firms contribute about one-fourth or one-fifth of the workforce based on the ownership criterion adopted (20\% or $50 \%$ of family ownership). More recently, by drawing on official data covering the population of workplaces, workers, and their relatives in Sweden, Holm et al. (2018) assess the magnitude and composition of in-house kinship ties. The scholars find a negative association between kinship ties in workplaces and population density. Family firms, which represent a particular type of kinship tie, are particularly common in small marketplaces. However, all these findings come from one single country-Sweden - and they cannot be extrapolated to other developed and developing countries.

Even though this line of research is important for describing the employment role of family firms at country level, any conclusions may be premature because of the lack of comparable measures to identify the phenomenon of study across contexts (e.g., local, regional, and national) and the lack of reliable performance measures to understand the impact of family firms at aggregate level (e.g., aggregate measures of productivity, innovation, or exportation). Additionally, there is no research analysing and comparing the effect of family firms on aggregate employment in two or more municipalities, regions, or countries. Therefore, the most promising future research line for the family business field and subsequent contributions to policymaking is likely to come from this quadrant. Following Basco (2015), the unresolved question that emerges is whether the mere presence of family businesses is good or bad for growth and development at local, regional, and national level.

\subsubsection{Context as a covariate-aggregate level}

There is only one article exploring the extent to which family firm aggregate employment creation is affected by contextual dimensions (Quadrant D in Table 1). Mueller and Philippon (2011) found that the prevalence of family ownership is higher in countries in which labour relationships are hostile. This result is in line with the theoretical conception that the quality of the formal institutional environment (i.e., the effective laws, rights, and regulations) enhances ownership concentration and also the ownership held by families as mechanisms to guarantee large investors' rights (Table 7).

The single article in Quadrant D shows the scarce cross-fertilization of family business studies with more mature disciplines conducting research at meso- and macrolevel such as international business and regional studies among others. More research in this quadrant could enhance our understanding of the role that family firms play in different contexts and how the context boosts or hinders their contribution to employment creation. The lack of research on contextualizing aggregate outcomes suggests several possibilities for future lines of research, which we shall discuss in more detail in Sect. 5.

As a visual summary, Fig. 1 provides an integrative model of the relationship of family firm dimensions, contextual dimensions, level of analysis, and employment outcomes. 


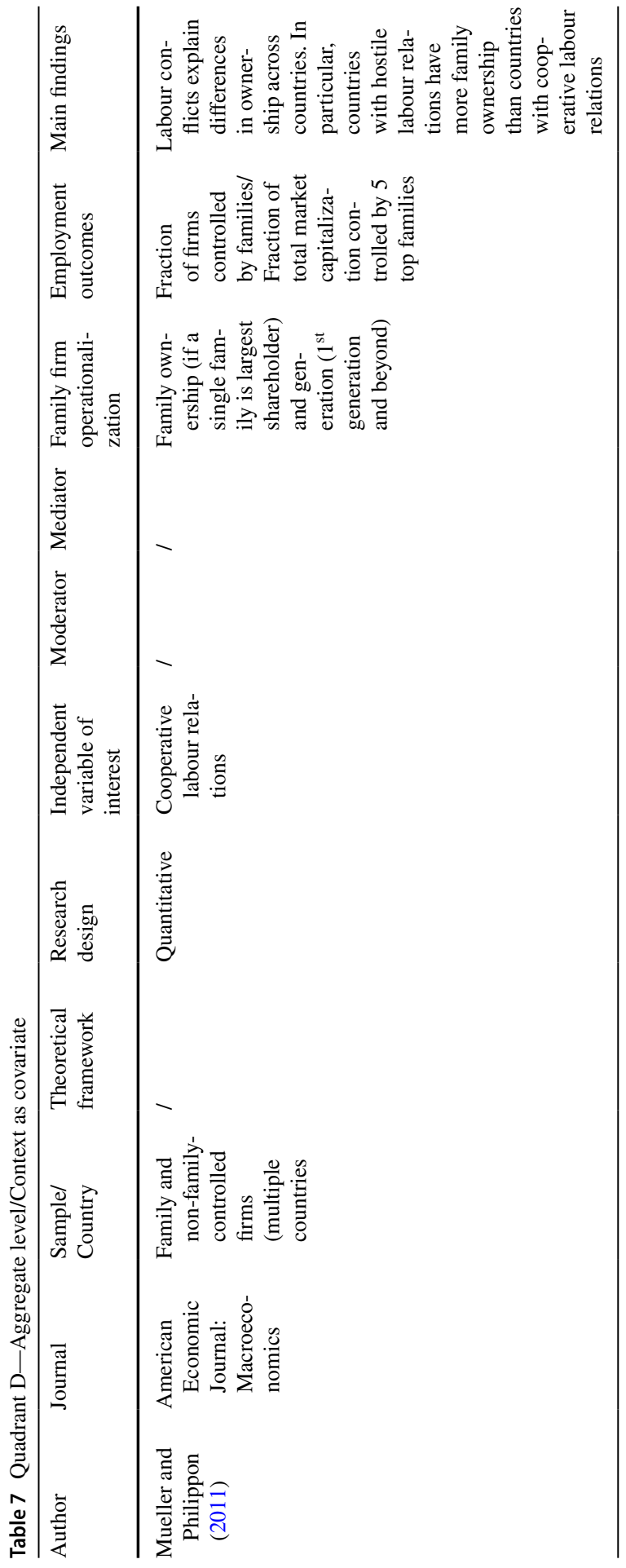




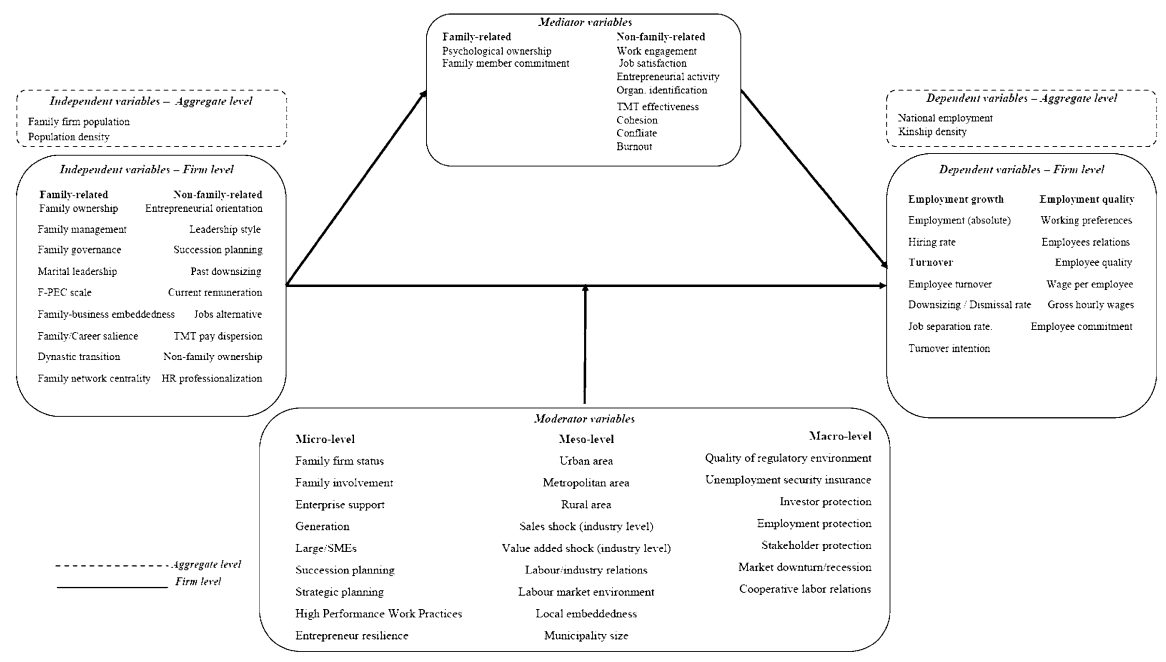

Fig. 1 Integrative model of family firm dimensions, contextual factors, and employment outcomes

\section{Future research: Where can we go from here?}

Our literature review considers how context and level of analysis have been used to understand the relationship between family firms and employment outcomes. We use our micro-macro framework in family business research to present the future research avenues summarized in Table 8.

\subsection{Firm level}

\subsubsection{Context as container}

5.1.1.1 Context by sampling Even though the evolution and consolidation of the family business field in recent decades have affirmed its legitimacy (Pérez Rodríguez and Basco 2011), such research still struggles to operationalize the concept of family firm and to understand the importance of heterogeneity. In this sense, the operationalization of the family firm should not only discriminate between listed and non-listed firms but should also consider differences between lone-owner, family-owner, and family-managed firms. Research into the heterogeneity of family firms could reveal new insights into firm employment outcomes by questioning whether different types of firms have different effects on job creation, downsizing, and employment quality. Indeed, future studies should explain how and why these differences occur.

Second, beyond the operationalization itself, most of the research presented in Quadrant A is built on several assumptions (internal or external link, as discussed in the previous section) to explain a positive or negative effect of family involvement dimensions on employment outcomes. These assumptions, such as family identity and social embeddedness at local level (identity theory, social identity theory, and the socioemotional wealth approach, among others), have hardly been tested, and 


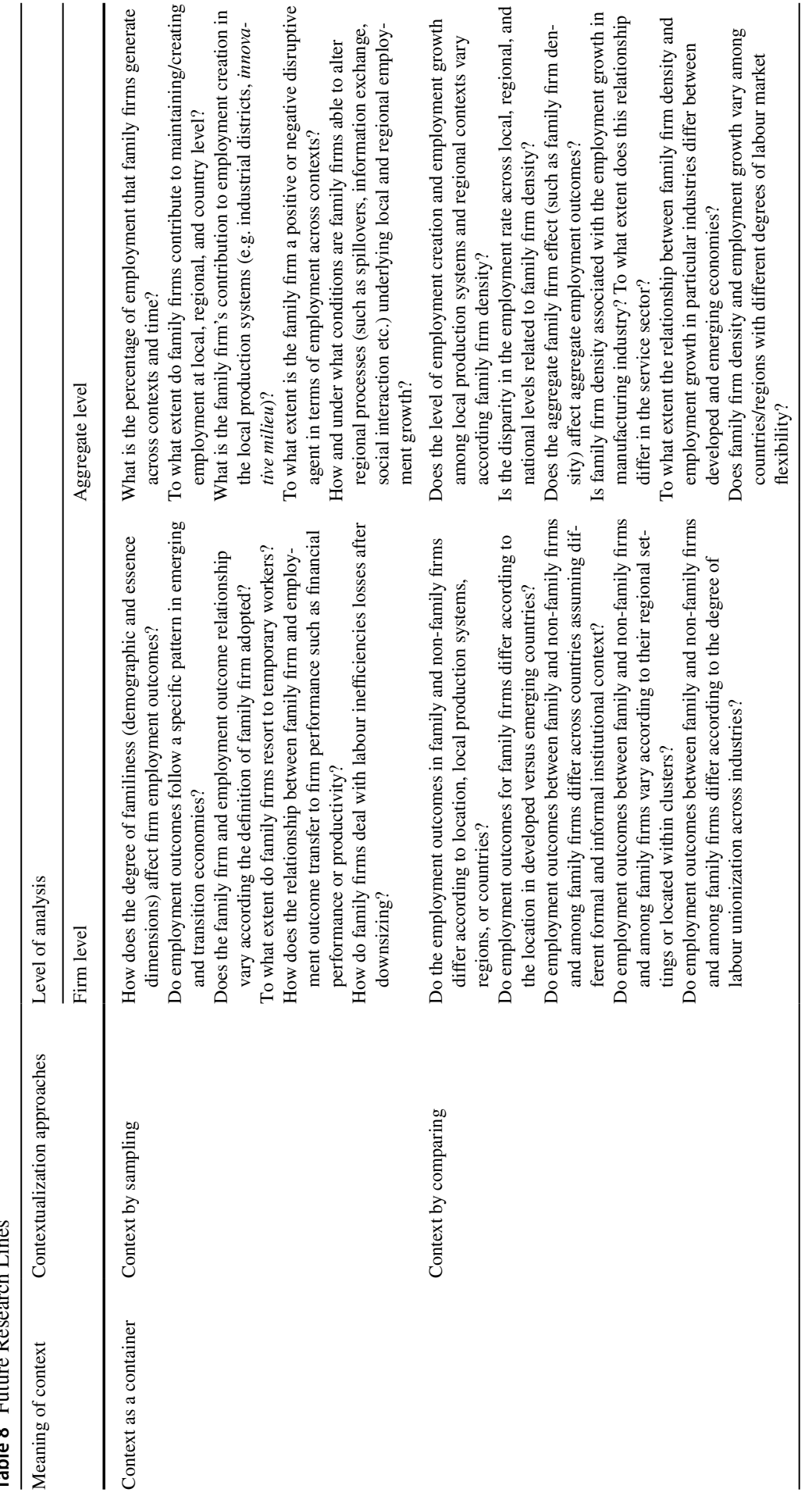




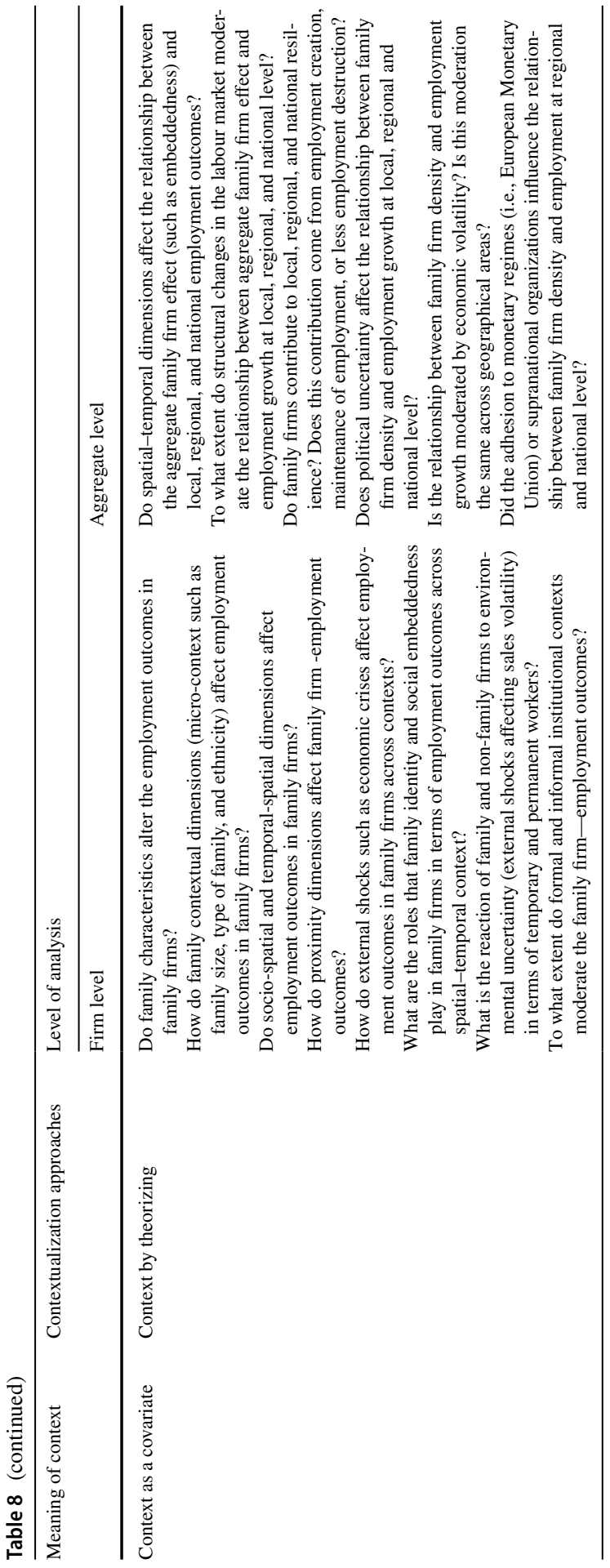


these assumptions remain underexplored. Future research should distinguish demographic dimensions related to family involvement in the firm, which are important for differentiating family firms from non-family firms and types of family firms, from essence dimensions, which account for the intrinsic behavioural consequences of family embeddedness in the firm and their link with society. In other words, the mere condition of being a family firm does not necessarily guarantee a connection and identification with the territory in which both the family and the firm are located. The importance of both dimensions of family involvement could unpack assumptions about what really drives family firms to have better or worse effects on employment outcomes.

Third, the employment outcome measures used in current research are limited in quantity (new measures are needed beyond classical employment growth or downsizing) and quality (to capture working environments, flexibility, and working culture, for instance). In this sense, future studies should expand outcome measures by using alternative measures to capture different aspects of the phenomenon, such as the extent to which family firms resort to temporary employees or temping agencies. On the other hand, beyond the effect of family involvement on employment per se, it is important to relate these measures to alternative performance measures, such as productivity (e.g., Barbera and Moores 2013). Therefore, future research should address the question of how employment outcomes in family firms are transferred to firm performance measures. For instance, possible areas of investigation might be how downsizing affects labour productivity and how family firms deal with losses due to labour inefficiencies. Along the same line, the lens used to theorize the relationship under study could define why and how family involvement in the firm is linked to different employment outcomes. We can expect that not all employment outcomes measured will be affected with the same intensity or in the same direction.

Fourth, as discussed in the previous section, the studies on family firms and firm employment have mainly been conducted in developed countries. Hence, future research could explore the relationship in emerging, developing, and transitional countries and in different cultural/regional settings. Therefore, extending the current research agenda beyond developed countries could be a first step towards a better understanding of the nuances of the effect of family involvement on employment outcomes as it is difficult to imagine that family involvement in economic activities follows the same patterns in developed and emerging economies (Basco 2018). This research effort could help test and validate theoretical predictions across contexts and at different periods of time to challenge mainstream theoretical approaches. Consequently, the aim is not only to test to what extent theoretical predictions work across contexts, but also to explain why they don't work out and how context and time either boost or constrain theoretical assumptions and relationships.

5.1.1.2 Context by comparing This approach represents an opportunity to introduce context into family business research by comparing what happens with the phenomenon in different municipalities, production systems (e.g., industrial districts, clusters, innovative milieu), regions, or countries. While the simplest methodological approach is to have samples covering different countries (macro-level), regions, or local productive systems (meso-level) to compare the effect of fam- 
ily involvement on firm employment across contexts, since the unit of analysis (i.e., family firm) is nested within different higher-order contextual dimensions (e.g., regions or countries), a multi-level approach (hardly used in family business research) would prove extremely useful in investigating the importance of context in the relationship under study.

Comparative exercises should be linked to theoretical lenses to justify the need for the comparisons, to hypothesize about the differences, and explain the differences and similarities of family firms across contexts. Choice of the appropriate theoretical approach should be based on the contextual level at which family firms are compared. For example, while comparisons of family firms across countries could use institutional theory (either from the economic perspective (North 1990) or from the sociological perspective (DiMaggio and Powell 1983) to justify that formal and informal institutional contexts frame individual, family, and firm behaviour, interregional comparisons of family firms may rely on approaches coming from regional studies, such as the territorial embeddedness (Hess 2004) and corruption-trust theory (Rothstein 2013), among others, that have emerged in the cross-fertilization between family firm and regional research.

Country-level comparison represents the first alternative for future research in this quadrant. Such research could use employment outcomes (e.g., downsizing) and compare family firms operating in different culturally distant contexts because informal institutional context, particularly the prevalence of different cultural values (e.g., collectivistic versus individualistic), could affect the relationship between family firms and their employees. Besides cultural aspects, formal institutional contexts differ in the degree of unionization in labour markets. Therefore, a possible research line could compare the employment decisions of family and non-family firms in countries with different union structures. Consequently, this line of research could challenge the current status quo of institutional theory to refine the theory by providing evidence of the relationship between different institutional settings and specific family firm behaviours because the latter are heterogeneous across contexts.

Beyond the country level, future comparative studies should consider alternative contextual levels, such as regional or industrial levels. Future research should consider regions as potential demarcations of family firm behaviour in terms of employment outcomes. Since economic activities and productive resources are unevenly distributed across space, different geographical areas are likely to have different degrees of well-being (Capello 2011) and competitiveness (Camagni and Capello 2013). Hence, comparing family firms located in different regional contexts would shed new light on how family firms' employment behaviour and outcomes are affected when regional resource endowments are considered. On the other hand, the industry in which a firm operates could serve as a demarcation of family firms and employment outcomes. As a result of continuous structural change and new technological paradigms, sectors of the economy undergo profound transformations in the composition of the workforce, labour relations and hiring and firing policies (Pilat et al. 2006). From this perspective, future research should investigate how family firms operating in different sectors cope with sectorial transformations (e.g., Industry 4.0 paradigm) and the resulting employment implications. 
The main limitation of this quadrant is that such comparisons may lead to assumptions regarding context. For this reason, the most important movement for family business research is to measure context by applying a context theorizing approach.

\subsubsection{Context as covariate}

5.1.2.1 Context by theorizing The most important step for future research is to go beyond contextualizing the phenomenon and attempt to measure context, which may help connect family variables and contextual variables at different levels to explain firm employment outcomes. In this sense, the contingency approach could be used to provide theoretical justification for the importance of context as a conditional dimension (Bamberger 2008; Johns 2006) that either moderates or mediates the relationship between family firms and employment growth. Future research will need to measure institutional, socio-spatial and temporal context to capture contextual nuances (Camagni and Capello 2013) that can constrain or ease the relationships under study by considering the micro-, meso-, and macro-levels.

Regarding the micro-context, it is time for family business research to capture family measures (e.g., type of family, size of the family, and ethnicity) to contextualize family involvement and firm employment outcomes at the micro-level. The limitation of today's research in family business is the assumption that families are homogenous. However, the actual context in which family firms are embedded is the family, and not all families are the same (Stangej and Basco 2017). This homogeneity assumption has to be broken down because family business research risks losing its connection with its roots - the family itself - which gives meaning to the field. Therefore, future studies should explore how family, as a context, affect firm behaviour, specifically employment outcomes. This line of research opens the possibility to explore family theories beyond traditional family system theory, such as family developmental theory, social exchange theory, ecological theory, and feminist family theory.

Regarding the meso-context, the future of family business research lies in exploring the impact of the local social and economic environments in which firms operate. This line of research brings proximity dimensions -namely spatial, social, cognitive, and institutional proximity- into the analysis that could better explain how family firms operate in their close environment and what role family firms play at the local and regional levels -i.e., the regional familiness approach (Basco 2015). For instance, it might be worth investigating the effect of social proximity on family firms' employment decisions. Indeed, it is in local communities characterized by close, reciprocal, and trust-based relationships that family firms are particularly likely to behave differently from their non-family counterparts. Family firms' strong territorial identity and deep emotional connection with their home locality (Kim et al. 2020) may unveil further aspects in terms of employment practices. Additionally, future research could analyse social-spatial context alongside the temporal one. So far, investigations of family firms' employment choices during adversity (e.g., economic downturns, pandemics, and natural disasters) with respect to the communities they are located in have been fairly limited (Amato et al. 2020). Hence, it 
would be instructive to shed new light on whether and to what extent family firms respond to downsizing during tough times in different ways depending on their localization. From this perspective, the lens of spatial embeddedness could prove extremely useful (Hess 2004). In addition to exogenous shocks that force firms to reduce their workforce, demand volatility is another external pressure that may lead firms to prefer more flexible working options, such as temporary staff. Hence, future research should investigate whether external volatility affects family firms' reliance on temporary employees.

Finally, at the macro-level, an additional future line of research could be to explore the effect of institutional context (formal and informal) on firm employment. More specifically, this line of research, which traditionally relies on institutional theory to justify potential differences of firms across contexts, lacks both theoretical and empirical clarity regarding what and how contextual dimensions affect the phenomenon under investigation. Exploring the formal institutional context in more detail could help researchers generate a communication channel with policymakers by dismantling the assumption that one policy will affect all economic actors in the same way. For instance, research could measure how family and non-family firms react to changes in labour market flexibility and the effect on employment restructuring, such as layoffs. On the other hand, the cultural context may affect how family firms behave and react to their environment because the family is an agent of cultural change and generation in society. From this perspective, the moderating effect of national cultural dimensions in the relationship between family involvement and employment outcomes could prove highly beneficial.

\subsection{Aggregate level}

\subsubsection{Context as a container}

5.2.1.1 Context by sampling The aggregate level of analysis has received less attention than the firm level, and only a few articles have attempted to measure the impact of family firms on aggregate local, regional, and national employment outcomes. Hence, future research should explore how family firms contribute to aggregate employment (e.g., regional employment growth) and should analyse the conditions under which family firms are able to maintain, boost, or reduce employment at local, regional, or national level. Even more, this type of study should use longitudinal data to capture the creation and demise of family firms and changes in employment variables.

Dismantling the aggregate effect of family firms could be a step forward in understanding the role family firms play in local, regional, and national employment. Following the call made by Basco (2015) and Stough et al. (2015), there is room to investigate how and to what extent family firms are able to alter the regional processes-namely, spillovers, information exchange, learning, social interactions, competition, and institutional dynamics-underlying regional employment outcomes. Qualitative studies could help in describing and explaining the regional mechanisms that family firms alter, create, or transform to produce effects on 
aggregate employment outcomes. Additionally, following previous research focusing on country level (Astrachan and Shanker 2003), more empirical descriptive studies are needed at the local, regional, and national levels to capture the presence of family firms and employment generation across contextual settings and time. Both qualitative and quantitative studies are needed to understand the prevalence and importance of family firms in different contexts.

5.2.1.2 Context by comparing Comparative studies are an extension of the previous quadrant but analyse the density of family firms and aggregate employment outcomes in two or more contexts. This is a natural step towards determining similarities and differences in the phenomenon under study that may be linked to context.

While previous studies have shown that heterogeneous industrial structures and differences in human capital are the main factors contributing to regional disparities in employment growth (Saito and Wu 2016; Simon 1998), it would be worth exploring the condition of the firm (i.e., family or non-family) in explaining these differences. Future steps in this direction should consider two important inter-related paths. First, it is necessary to theorize and test the link between family firms and context to understand their effect on local, regional, and national aggregate patterns of employment. Current theorizing is focused on the family's embeddedness within geographical space, which assumes a particular socio and emotional connection between the family and the economic/social environment (Backman and Palmberg 2015; Basco 2015; Stough et al. 2015) based on the concept of proximity (e.g., spatial, social, organizational, and cognitive), but this assumption has not been empirically tested. Second, we need more explorative empirical studies to understand the phenomenon, which may ultimately lead to improvements in theory. The main reason for moving the aggregate level forward lies in the possibility of creating databases with micro-level information that is also representative at regional level.

\subsubsection{Context as a covariate}

5.2.2.1 Context by theorizing In terms of contextualizing at the aggregate level, future studies should explore how and to what extent family firms contribute to aggregate employment outcomes by considering the context in which this relationship is a moderator dimension. Based on our contingent interpretation of context, we expect that institutional, spatial, and temporal contexts explain when family firms have an effect on aggregate employment outcomes. Research in this quadrant represents the ultimate level of context theorizing, which attempts to measure which facets of context really moderate the aggregate relationship between family firms and employment. The fields of regional studies and international business have developed scales to measures institutional, spatial, and temporal contexts that can be used in family business research. In this sense, local, regional, and national contextual measures do not seem to be a problem; instead, it is difficult to find longitudinal micro-data that is locally and regionally representative across countries. Hence, future research should focus on collaborating with regional, national, or supra-national organizations (e.g., the European Union) to produce more reliable data on the family business phenomenon across regions and countries. 
An important topic in this quadrant is related to local and regional resilience. In regional studies, the concept of resilience, which has attracted growing interest since the international financial crisis, refers to a region's ability to absorb economic disturbances, generally reflected as downward changes in the region's employment level during a shock (i.e., resistance) or some years after it (i.e., recovery) (Boschma2015; Eriksson and Hane-Weijman 2017). Extant research has shown that several factors could explain why a shock is unevenly distributed both within and across regions, such as higher diversification of industry (Eriksson and Hane-Weijman 2017), higher stock of human capital (Mazzola et al. 2018), and higher physical accessibility and connectivity (Giannakis and Bruggeman 2017), among others. In regional studies, however, family firms seem to be a missing factor of regional resilience. As a result of their unique characteristics, such as their long-term orientation in decision making (Huybrechts et al. 2011), non-economic goals (Basco 2017), and embeddedness in the community (Dekker and Hasso 2016), family firms may represent an additional, a hitherto hidden, source of regional resilience.

\section{Conclusion}

Most of the existing research on family firms has focused on the family's effect on firm behaviour and performance (Yu et al. 2012), and the results have been contradictory in terms of employment outcomes at the firm and aggregate levels. We conjectured that these contradictory results stem from of the context-less research in the family business field at different levels of analysis. To address this limitation, we carried out a systematic literature review of 67 published papers in peer-reviewed journal from 1980 to 2020, and developed a framework to classify, analyse, and interpret current knowledge by incorporating three different approaches to contextualize the family firm phenomenon combining two different levels of analysis (i.e., the firm and aggregate levels). Our approach enabled us to map what we know about family business and context in terms of employment outcomes, and what future research areas could be explored further. We summarize our main findings in four takeaway findings.

First, most of the existing family business research on employment has focused on the firm level in one specific context-that is, in one particular regional or national setting. In these studies, the micro-context-namely, family dimensions-is more relevant than the meso- and macro-contexts implicitly defined by the origin of the sample. Additionally, there is a lack of studies comparing family firms in different contexts. This indicates the need for comparative studies to better understand differences and similarities between family and non-family firms across spatial context. We conclude that family business research is context-less because most of the research in this area has used context in post hoc interpretations to contextualize results, and these interpretations are based on speculative assumptions or represent the boundaries for understanding the phenomenon itself. In this sense, the future of family business studies lies in closing the micro-macro gap by measuring context at different levels to interpret family business behaviour and employment outcomes. This stream of research offers a way to unveil nuances among family firms from 
both a phenomenological perspective and theoretical development one (Reay and Whetten 2011).

Second, in line with the theoretical development, future research has to introduce context in its institutional, socio-spatial, and temporal dimensions to explore the contingent effect-that is, researchers must develop context-contingent theory. This is a necessary step toward integrating theory of the family firm to "explain and predict not only the interaction between family and business systems at the individual and family firm levels but also the interaction between family firms and the environment at the aggregate level" (Basco 2015, p. 260). In pursuing this aim, the context theorizing approach should go beyond simple contextualization (i.e., defining the contextual boundaries that restrict theoretical generalization) by specifying and measuring the nature of the contextual forces and explaining the mechanisms that operate to constrain or enable the occurrence of a particular relationship between family firms and employment outcomes.

Third, there is a real need to better explore, analyse, and theorize on the effect of family firms on employment outcomes at the aggregate level. For this purpose, it is necessary to enlarge the unit of analysis by incorporating the actor (i.e., family firms) with space (i.e., the physical-relational entity with which the actor interacts) and time (Gomez-Mejia et al. 2020; James et al. 2020; Stough et al. 2015). This movement in the family business field requires multi-disciplinary research to embrace alternative theoretical perspectives from the fields of economic geography, regional science, and urban economics. By doing this, the family business field is likely to develop and expand its external legitimacy (Pérez Rodríguez and Basco 2011) to new research fields beyond its current connections with management and strategic research. In so doing, family business research would expand the boundaries of its core knowledge by introducing context as a dimension for future investigations. Research at aggregate levels is important for unpacking the role family firms play in the places where they live, endure, and thrive and therefore their contribution to local, regional and national development.

Funding Open access funding provided by Scuola IMT Alti Studi Lucca within the CRUI-CARE Agreement. The authors declare that they have no known competing financial interests or personal relationships that could have appeared to influence the work reported in this paper.

\section{Declarations}

\section{Conflict of interest None.}

Open Access This article is licensed under a Creative Commons Attribution 4.0 International License, which permits use, sharing, adaptation, distribution and reproduction in any medium or format, as long as you give appropriate credit to the original author(s) and the source, provide a link to the Creative Commons licence, and indicate if changes were made. The images or other third party material in this article are included in the article's Creative Commons licence, unless indicated otherwise in a credit line to the material. If material is not included in the article's Creative Commons licence and your intended use is not permitted by statutory regulation or exceeds the permitted use, you will need to obtain permission directly from the copyright holder. To view a copy of this licence, visit http://creativecommons.org/licen ses/by/4.0/. 


\section{References}

Aguinis H, Boyd BK, Pierce CA, Short JC (2011) Walking new avenues in management research methods and theories: bridging micro and macro domains. J Manag 37:395-403. https://doi.org/10. $1177 / 0149206310382456$

Amato S, Basco R, Gómez-Ansón S, Lattanzi N (2020) Family-managed firms and employment growth during an economic downturn: Does their location matter? Baltic J Manag 15:607-630. https://doi. org/10.1108/BJM-07-2019-0260

Amore MD, Miller D, Le Breton-Miller I, Corbetta G (2017) For love and money: marital leadership in family firms. J Corp Fin 46:461-476. https://doi.org/10.1016/j.jcorpfin.2017.09.004

Andersson FW, Johansson D, Karlsson J, Lodefalk M, Poldahl A (2018) The characteristics of family firms: exploiting information on ownership, kinship, and governance using total population data. Small Bus Econ 51:539-556. https://doi.org/10.1007/s11187-017-9947-6

Aoi M, Asaba S, Kubota K, Takehara H (2015) Family firms, firm characteristics, and corporate social performance: a study of public firms in Japan. J Fam Bus Manag 5:192-217

Arijs D, Botero IC, Michiels A, Molly V (2018) Family business employer brand: understanding applicants' perceptions and their job pursuit intentions with samples from the US and Belgium. J Fam Bus Strat 9:180-191. https://doi.org/10.1016/j.jfbs.2018.08.005

Arregle JL, Hitt MA, Sirmon DG, Very P (2007) The development of organizational social capital: attributes of family firms. J Manag Stud 44:73-95

Astrachan JH, Shanker M (2003) Family businesses' contribution to the U. S. economy: a closer look. Fam Bus Rev 16:211-219

Bach L, Serrano-Velarde N (2015) CEO identity and labor contracts: evidence from CEO transitions. J Corp Fin 33:227-242. https://doi.org/10.1016/j.jcorpfin.2015.01.009

Backman M, Palmberg J (2015) Contextualizing small family firms: How does the urban-rural context affect firm employment growth? J Fam Bus Strategy 6:247-258. https://doi.org/10.1016/j.jfbs. 2015.10.003

Bamberger P (2008) From the editors beyond contextualization: using context theories to narrow the micro-macro gap in management research. Acad Manag J 51:839-846. https://doi.org/10.5465/ amj.2008.34789630

Barbera F, Moores K (2013) Firm ownership and productivity: a study of family and non-family SMEs. Small Bus Econ 40:953-976. https://doi.org/10.1007/s11187-011-9405-9

Barnett T, Eddleston K, Kellermanns FW (2009) The effects of family versus career role salience on the performance of family and nonfamily firms. Fam Bus Rev 22:39-52

Barney J (1991) Firm resources an sustained competitive advantage. J Manag 17:99-120

Basco R (2013) The family's effect on family firm performance: a model testing the demographic and essence approaches. J Fam Bus Strategy 4:42-66. https://doi.org/10.1016/j.jfbs.2012.12.003

Basco R (2015) Family business and regional development-a theoretical model of regional familiness. J Fam Bus Strategy 6:259-271. https://doi.org/10.1016/j.jfbs.2015.04.004

Basco R (2017) "Where do you want to take your family firm?" A theoretical and empirical exploratory study of family business goals. BRQ Bus Res Q 20:28-44. https://doi.org/10.1016/j.brq.2016.07. 001

Basco R (2018) Family business in emerging markets. In: Grosse R and Meyer KE (ed) The oxford handbook of management in emerging markets, Oxford University Press, Oxford, pp 527-546. https:// doi.org/10.1093/oxfordhb/9780190683948.013.23

Basco R, Bartkevičiūtė I (2016) Is there any room for family business into European Union 2020 Strategy? Family business and regional public policy. Loc Econ 31:709-732

Bassanini A, Breda T, Caroli E, Rebérioux A (2013) Working in family firms: Paid less but more secure? evidence from french-matched employer-employee data. ILR Rev 66:433-466

Baú M, Chirico F, Pittino D, Backman M, Klaesson J (2019) Roots to grow: family firms and local embeddedness in rural and urban context. Entrep Theory Pract 43:360-385. https://doi.org/10. $1177 / 1042258718796089$

Becchetti L, Trovato G (2002) The determinants of growth for small and medium sized firms. The role of the availability of external finance. Small Bus Econ 19:291-306. https://doi.org/10.1023/A:10196 78429111

Bennedsen M, Tsoutsoura M, Wolfenzon D (2019) Drivers of effort: evidence from employee absenteeism. J Finan Econ 133:658-684. https://doi.org/10.1016/j.jfineco.2018.12.001 
Bernhard F, O’Driscoll MP (2011) Psychological ownership in small family-owned businesses: leadership style and nonfamily-employees' work attitudes and behaviors. Group Org Manag 36:345-384

Bjuggren CM (2015) Sensitivity to shocks and implicit employment protection in family firms. J Econ Behav Org 119:18-31. https://doi.org/10.1016/j.jebo.2015.07.011

Bjuggren CM, Daunfeldt SO, Johansson D (2013) High-growth firms and family ownership. J Small Bus Ent 26:365-385. https://doi.org/10.1080/08276331.2013.821765

Bjuggren CM, Johansson D, Sjögren H (2011) A note on employment and gross domestic product in swedish family-owned businesses: a descriptive analysis. Fam Bus Rev 24:362-371. https://doi. org/10.1177/0894486511420138

Blanco-Mazagatos V, de Quevedo-Puente E, Delgado-García JB (2018) Human resource practices and organizational human capital in the family firm: the effect of generational stage. J Bus Res 84:337348. https://doi.org/10.1016/j.jbusres.2017.09.017

Block JH (2010) Family management, family ownership, and downsizing: evidence from S\&P 500 firms. Fam Bus Rev 23:109-130. https://doi.org/10.1177/089448651002300202

Block JH, Fisch CO, Lau J, Obschonka M, Presse A (2018) How do labor market institutions influence the preference to work in family firms? A multilevel analysis across 40 countries. Entrep Theory Pract 43:1067-1093. https://doi.org/10.1177/1042258718765163

Boschma RA (2015) Towards an evolutionary perspective on regional resilience. Reg Stud 49:733-751. https://doi.org/10.1080/00343404.2014.959481

Camagni R, Capello R (2013) Regional competitiveness and territorial capital: a conceptual approach and empirical evidence from the European Union. Reg Stud 47:1383-1402. https://doi.org/10.1080/ 00343404.2012 .681640

Cameron L, Miller P, Frew E (2009) Relationship marketing in the recruitment and retention of service industry staff in family-owned businesses. J Hum Res Hosp Manag 9:71-91. https://doi.org/10. $1080 / 15332840902942735$

Capello R (2011) Location, regional growth, and local development theories. AESTIMUN 58:1-25

Cennamo C, Berrone P, Cruz C, Gomez-Mejia LR (2012) Socioemotional wealth and proactive stakeholder engagement: why family-controlled firms care more about their stakeholders. Entrep Theory Pract 36:1153-1173

Coad A, Timmermans B (2014) Two's company: composition, structure and performance of entrepreneurial pairs. Eu Manag Rev 11:117-138. https://doi.org/10.1111/emre.12030

Colombo MG, De Massis A, Piva E, Rossi-Lamastra C, Wright M (2014) Sales and employment changes in entrepreneurial ventures with family ownership: empirical evidence from high-tech industries. J Small Bus Manag 52:226-245

Chang EPC, Chrisman JJ, Chua JH, Kellermanns FW (2008) Regional economy as a determinant of the prevalence of family firms in the United States: a preliminary report. Entrep Theory Pract 32:559-573

Chen Q, Hou W, Li W, Wilson C, Wu Z (2014) Family control, regulatory environment, and the growth of entrepreneurial firms: international evidence. Corp Gov Int Rev 22:132-144. https://doi.org/10. 1111/corg. 12060

D'Aurizio L, Romano L (2013) Family firms and the great recession: Out of sight, out of mind? Temi Di Discussione. https://doi.org/10.1162/JEEA.2008.6.6.1109

Dailey RC, Reuschling TE (1980) Human resource practice in family owned company. J Gen Man 5:49-56

Damiani M, Pompei F, Ricci A (2018) The role of employee incentive pay in the competitiveness of family and non-family firms. Econ Pol 36:805-839. https://doi.org/10.1007/s40888-018-0135-1

De Massis A, Foss NJ (2018) Advancing family business research: the promise of microfoundations. Fam Bus Rev 31:386-396. https://doi.org/10.1177/0894486518803422

Dekker J, Hasso T (2016) Environmental performance focus in private family firms: the role of social embeddedness. J Bus Ethics 136:293-309. https://doi.org/10.1007/s10551-014-2516-X

Deng X (2018) Embedding 'familiness' in HRM practices to retain a new generation of migrant workers in China. Asia Pacific Bus Rev 24:561-577. https://doi.org/10.1080/13602381.2018.1451124

Denyer D, Tranfield D (2009) Producing a systematic review. In: Buchanan DA, Bryman A (eds) The sage handbook of organizational research methods. Sage Publications, Los Angeles, pp 671-689

DiMaggio PJ, Powell WW (1983) The iron cage revisited: institutional isomorphism and collective rationality in organizational fields. Americ Soc Rev 48:147-160. https://doi.org/10.2307/2095101

Diwisch DS, Voithofer P, Weiss CR (2009) Succession and firm growth: results from a non-parametric matching approach. Small Bus Econ 32:45-53. https://doi.org/10.1007/s11187-007-9072-z 
Eddleston KA, Kellermanns FW, Floyd SW, Crittenden VL, Crittenden WF (2013) Planning for growth: life stage differences in family firms. Entrep Theory Pract 37:1177-1202. https://doi.org/10.1111/ etap. 12002

Ellul A, Pagano M, Schivardi F (2018) Employment and wage insurance within firms: worldwide evidence. Rev Finan Studies 31:1298-1340. https://doi.org/10.1093/rfs/hhx104

Ensley MD, Pearson AW, Sardeshmukh SR (2007) The negative consequences of pay dispersion in family and non-family top management teams: an exploratory analysis of new venture, high-growth firms. J Bus Res 60:1039-1047. https://doi.org/10.1016/j.jbusres.2006.12.012

Eriksson RH, Hane-Weijman E (2017) How do regional economies respond to crises? The geography of job creation and destruction in Sweden (1990-2010). European Urban and Regional Studies 24:87-103. https://doi.org/10.1177/0969776415604016

Ernst J, Kraus S, Matser I (2012) The relation between performance and family involvement- an exploration into the non-linear effects during the life-stage of Dutch firms. Int J Entr Inn Man 15:1982014. https://doi.org/10.1504/IJEIM.2012.046600

Giannakis E, Bruggeman A (2017) Determinants of regional resilience to economic crisis: a European perspective. Eur Plann Stud 25:1394-1415. https://doi.org/10.1080/09654313.2017.1319464

Gomez-Mejia LR, Basco R, Müller C, Gonzalez AC (2020) Family business and local development in Iberoamerica. Cross-Cult Man J 21:51-56. https://doi.org/10.1108/CCSM-02-2020-223

Gomez-Mejia LR, Larraza-Kintana M, Moyano-Fuentes J, Firfiray S (2018) Managerial family ties and employee risk bearing in family firms: evidence from Spanish car dealers. Hum Res Man 57:9931007. https://doi.org/10.1002/hrm.21829

Hess M (2004) "Spatial" relationships? Towards a reconceptualization of embeddedness. Prog in Hum Geo 28:165-186

Holm E, Westin K, Haugen K (2018) Place, kinship, and employment. Popul Space Place 24:1-12. https://doi.org/10.1002/psp.2118

Hoon C, Baluch AM (2020) The role of dialectical interrogation in review studies: theorizing from what we see rather than what we have already seen. J Man St 57:1246-1271. https://doi.org/10.1111/ joms. 12543

Hu Q, Schaufeli WB (2011) Job insecurity and remuneration in Chinese family-owned business workers. Career Dev Int 16:6-19. https://doi.org/10.1108/13620431111107784

Huybrechts J, Voordeckers W, Vandemaele S, Lybaert N (2011) The distinctiveness of family-firm intangibles: a review and suggestions for future research. J Man Org 17:268-287. https://doi.org/10. 2139/ssrn. 1780882

James AE, Hadjielias E, Guerrero M, Discua Cruz A, Basco R (2020) Entrepreneurial families in business across generations, context, and cultures. J Fam Bus Man. https://doi.org/10.1108/ JFBM-01-2020-0003

Jeong SH, Kim H, Kim H (2021) Strategic nepotism in family director appointments: evidence from family business groups in South Korea. Acad Man J. https://doi.org/10.5465/amj.2018.1418

Jesson J, Matheson L, Lacey FM (2013) Doing your literature review: traditional and systematic techniques. Sage

Johns G (2006) The essential impact of context on organizational behavior. Acad Man Rev 31:386-408. https://doi.org/10.5465/amr.2006.20208687

Kang JK, Kim J (2020) Do family firms invest more than nonfamily firms in employee-friendly policies? Manag Science 66:1005-1507. https://doi.org/10.1287/mnsc.2018.3231

Karlsson J (2018) Does regional context matter for family firm employment growth? J Fam Bus Strat 9:293-310.https://doi.org/10.1016/j.jfbs.2018.08.004

Khanin D (2013) How to reduce turnover intentions in the family business: managing centripetal and centrifugal forces. Bus Horiz 56:63-73. https://doi.org/10.1016/j.bushor.2012.09.005

Khanin D, Turel O, Mahto RV (2012) How to increase job satisfaction and reduce turnover intentions in the family firm: the family-business embeddedness perspective. Fam Bus Rev 25:391-408. https:// doi.org/10.1177/0894486512441944

Kim K, Haider ZA, Wu Z, Dou J (2020) Corporate social performance of family firms: a placebased perspective in the context of layoffs. J Bus Ethics 167:235-252. https://doi.org/10.1007/ s10551-019-04152-5

Kim A, Lee Y (2018) Family firms and corporate social performance: evidence from Korean firms. Asia Pac Bus Review 24:693-713. https://doi.org/10.1080/13602381.2018.1473323 
Kölling A (2020) Employment in family managed firms: Less but safe? Analysing labour demand of German family managed firms with a treatment model for panel data. Bulletin Econ Res 72:14-32. https://doi.org/10.1111/boer.12203

Krueger N, Bogers M, Labaki R, Basco R (2021) Advancing family business science through context theorizing: the case of the Arab World. J Fam Bus Str 12:100377. https://doi.org/10.1016/j.jfbs. 2020.100377

Lee J (2006) Family firm performance: further evidence. Fam Bus Rev 19:103-114

Levie J, Lerner M (2009) Resource mobilization and performance in family and nonfamily businesses in the United Kingdom. Fam Bus Rev 22:25-38

Madison K, Daspit JJ, Turner K, Kellermanns FW (2018) Family firm human resource practices: investigating the effects of professionalization and bifurcation bias on performance. J Bus Res 84:327336. https://doi.org/10.1016/j.jbusres.2017.06.021

McLarty BD, Holt DT (2019) A bright side to family firms: How socioemotional wealth importance affects dark traits-job performance relationships. Fam Bus Rev 32:378-395

Mahto RV, Vora G, McDowell WC, Khanin D (2020) Family member commitment, the opportunity costs of staying, and turnover intentions. J Bus Res 108:9-19. https://doi.org/10.1016/j.jbusres.2019.10. 013

Martí J, Menéndez-Requejo S, Rottke OM (2013) The impact of venture capital on family businesses: evidence from Spain. J World Bus 48:420-430. https://doi.org/10.1016/j.jwb.2012.07.025

Mazzola F, Lo Cascio I, Epifanio R, Di Giacomo G (2018) Territorial capital and growth over the Great Recession: a local analysis for Italy. Ann Reg Sci 60:411-441. https://doi.org/10.1007/ s00168-017-0853-2

McLarty BD, Vardaman JM, Barnett T (2018) Congruence in exchange: the influence of supervisors on employee performance in family firms. Entrep Theory Pract 43:302-321. https://doi.org/10.1177/ 1042258718796079

Morck RK, Yeung B (2004) Family control and the rent-seeking society. Entrep Theory Pract 28:391-409

Mueller HM, Philippon T (2011) Family firms and labor relations. Am Econ J Macroecon 3:218-245. https://doi.org/10.1257/mac.3.2.218

Neckebrouck J, Schulze W, Zellweger T (2018) Are family firms good employers? Acad Man J 61:553585. https://doi.org/10.5465/amj.2016.0765

North DC (1990) Institutions, institutional change and economic performance. Cambridge University Press

Pearson AW, Carr JC, Shaw JC (2008) Toward a theory of familiness: a social capital perspective. Entrep Theory Pract 32:949-969. https://doi.org/10.1111/j.1540-6520.2011.00475.x

Pérez Rodríguez MJ, Basco R (2011) The cognitive legitimacy of the family business field. Fam Bus Rev 24:322-342

Pilat D, Cimper A, Olsen KB, Webb C (2006) The changing nature of manufacturing in OECD economies. OECD Science, technology and industry working papers 2006/09. OECD publishing, Paris. https://doi.org/10.1787/308452426871

Pittino D, Chirico F, Henssen B, Broekaert W (2019) Does increased generational involvement foster business growth? The moderating roles of family involvement in ownership and management. Eur Man Rev 17:785-801. https://doi.org/10.1111/emre.12366

Pittino D, Visintin F, Lenger T, Sternad D (2016) Are high performance work practices really necessary in family SMEs? An analysis of the impact on employee retention. J Fam Bus Strat 7:7589. https:// doi.org/10.1016/j.jfbs.2016.04.002

Powell GN, Eddleston KA (2013) Linking family-to-business enrichment and support to entrepreneurial success: Do female and male entrepreneurs experience different outcomes? J Bus Vent 28:261-280

Reay T, Whetten DA (2011) What constitutes a theoretical contribution in family business? Fam Bus Rev 24:105-110

Richard PJ, Devinney TM, Yip GS, Johnson G (2009) Measuring organizational performance: towards methodological best practice. J Man 35:718-804

Rothstein B (2013) Corruption and social trust: why the fish rots from the head down. Soc Res 80:1009-1032

Rutherford MW, Kuratko DF, Holt DT (2008) Examining the link between "Familiness" and performance: can the F-PEC untangle the family business theory jungle? Entrep Theory Pract 32:10891109. https://doi.org/10.1515/epoly-2018-0107 
Santoro G, Messeni-Petruzzelli A, Del Giudice M (2020) Searching for resilience: the impact of employee-level and entrepreneur-level resilience on firm performance in small family firms. Small Bus Econ. https://doi.org/10.1007/s11187-020-00319-x

Saito H, Wu J (2016) Agglomeration, congestion, and U.S. regional disparities in employment growth. J Reg Science 56:53-71. https://doi.org/10.1111/jors.12204

Schwartz ND (2020) A family business survived one pandemic. It's determined to Do It Again. The New York Times. Retrieved from https://www.nytimes.com/2020/05/04/business/economy/coronavirusfamily-business.html?referringSource=articleShare\&fbclid=IwAR0uRRXAK4YsjfrXpH4IFiH_ ZTKPW9_zudVEYEfUG110ZQf6eoVJH8PyxUg

Simon CJ (1998) Human capital and metropolitan employment growth. J Urban Econ 43:223-243. https://doi.org/10.1006/juec.1997.2048

Soleimanof S, Rutherford MW, Webb JW (2018) The intersection of family firms and institutional contexts: a review and agenda for future research. Fam Bus Rev 31:32-53

Sraer D, Thesmar, D (2007) Performance and behavior of family firms: evidence from the French stock market. J Eur Eco Assoc 5:709-751. https://doi.org/10.1162/JEEA.2007.5.4.709

Stangej O, Basco R (2017) The entrepreneurial role of families in transitional economies: the case of Lithuania. In: Sauka A, Chepurenko A (eds) Entrepreneurship in transition economies: diversity, trends, and perspectives. Springer International Publishing, pp 345-365

Stavrou E, Kassinis G, Filotheou A (2007) Downsizing and stakeholder orientation among the fortune 500: Does family ownership matter? J Bus Ethics 72:149-162. https://doi.org/10.1007/ s10551-006-9162-x

Stenholm P, Pukkinen T, Heinonen J (2016) Firm growth in family businesses-the role of entrepreneurial orientation and the entrepreneurial activity. J Small Bus Manag 54:697-713. https://doi.org/10. $1111 /$ jsbm. 12166

Sultan S, de Waal A, Goedegebuure R (2017) Analyzing organizational performance of family and nonfamily businesses using the HPO framework. J Fam Bus Manag 7:242-255. https://doi.org/10. 1108/JFBM-07-2017-0021

Stough R, Welter F, Block J, Wennberg K, Basco R (2015) Family business and regional science: "Bridging the gap.” J Fam Bus Strat 6:208-218. https://doi.org/10.1016/j.jfbs.2015.11.002

Tabor W, Madison K, Marler LE, Kellermanns FW (2020) The effects of spiritual leadership in family firms: a conservation of resources perspective. J Bus Ethics 163:729-743. https://doi.org/10.1007/ s10551-019-04379-2

Tranfield D, Denyer D, Smart P (2003) Towards a methodology for developing evidence-informed management knowledge by means of systematic review. British J Manag 14:207-222. https://doi.org/ $10.1111 / 1467-8551.00375$

VanDalsem SA (2019) Sacrificing corporate investment for stock repurchases: Are family firms different? J Econ Bus 104:105837. https://doi.org/10.1016/j.jeconbus.2019.03.001

van Essen M, Strike VM, Carney M, Sapp S (2015) The resilient family firm: stakeholder outcomes and institutional effects. Corp Gov Int Rev 23:167-183. https://doi.org/10.1111/corg.12087

Vardaman JM, Allen DG, Rogers BL (2018) We are friends but are we family? Organizational identification and nonfamily employee turnover. Entrep Theory Pract 42:290-309. https://doi.org/10.1177/ 1042258717749235

Williams RI, Pieper TM, Kellermanns FW, Astrachan JH (2019) Family business goal formation: a literature review and discussion of alternative algorithms. Manag Rev Q 69:329-349. https://doi.org/10. 1007/s11301-019-00155-8

Yu A, Lumpkin GT, Sorenson RL, Brigham KH (2012) The landscape of family business outcomes: a summary and numerical taxonomy of dependent variables. Fam Bus Rev 25:33-57. https://doi.org/ $10.1177 / 0894486511430329$

Publisher's Note Springer Nature remains neutral with regard to jurisdictional claims in published maps and institutional affiliations. 


\section{Authors and Affiliations}

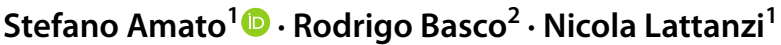

Rodrigo Basco

bascorodrigo@gmail.com

Nicola Lattanzi

nicola.lattanzi@imtlucca.it

1 IMT School for Advanced Studies Lucca, Piazza S. Francesco, 19, 55100 Lucca, Italy

2 The Sheikh Saoud Bin Khalid Bin Khalid Al Qassimi Chair in Family Business, American University of Sharjah, PO BOX 26666 University City, Sharjah, United Arab Emirates 